\title{
Moving forward in nursing home practice
}

\author{
Citation for published version (APA):
}

Kuk, N. O. (2017). Moving forward in nursing home practice: supporting nursing staff in implementing innovations. [Doctoral Thesis, Maastricht University]. Datawyse / Universitaire Pers Maastricht. https://doi.org/10.26481/dis.20170607nk

Document status and date:

Published: 01/01/2017

DOI:

10.26481/dis.20170607nk

Document Version:

Publisher's PDF, also known as Version of record

\section{Please check the document version of this publication:}

- A submitted manuscript is the version of the article upon submission and before peer-review. There can be important differences between the submitted version and the official published version of record.

People interested in the research are advised to contact the author for the final version of the publication, or visit the DOI to the publisher's website.

- The final author version and the galley proof are versions of the publication after peer review.

- The final published version features the final layout of the paper including the volume, issue and page numbers.

Link to publication

\footnotetext{
General rights rights.

- You may freely distribute the URL identifying the publication in the public portal. please follow below link for the End User Agreement:

www.umlib.nl/taverne-license

Take down policy

If you believe that this document breaches copyright please contact us at:

repository@maastrichtuniversity.nl

providing details and we will investigate your claim.
}

Copyright and moral rights for the publications made accessible in the public portal are retained by the authors and/or other copyright owners and it is a condition of accessing publications that users recognise and abide by the legal requirements associated with these

- Users may download and print one copy of any publication from the public portal for the purpose of private study or research.

- You may not further distribute the material or use it for any profit-making activity or commercial gain

If the publication is distributed under the terms of Article $25 \mathrm{fa}$ of the Dutch Copyright Act, indicated by the "Taverne" license above, 


\section{Moving forward in nursing home practice}

Supporting nursing staff in implementing innovations 
(C) Copyright Nienke Kuk, Maastricht 2017

Cover: Freak Flag Graphics

Printing: Datawyse | Universitaire Pers Maastricht

ISBN 9789461596895

The research presented in this dissertation was part of the research line 'Nurses on the Move: towards high quality care in nursing homes,' which was funded by ZonMw, the Netherlands Organization for Health Research and Development (grant 520001003). 


\title{
Moving forward in nursing home practice
}

Supporting nursing staff in implementing innovations

\author{
PROEFSCHRIFT
}

ter verkrijging van de graad van doctor aan de Universiteit Maastricht, op gezag van de Rector Magnificus, Prof. dr. Rianne M. Letschert, volgens het besluit van het College van Decanen,

in het openbaar te verdedigen

op woensdag 7 juni 2017 om 14.00 uur

door

Nienke Okje Kuk 


\section{PROMOTORES}

Prof. dr. G.I.J.M. Kempen

Prof. dr. J.P.H. Hamers

\section{COPROMOTORES}

Dr. G.J.J.W. Bours (Zuyd Hogeschool)

Dr. G.A.R. Zijlstra

\section{BEOORDELINGSCOMMISSIE}

Prof. dr. T. van der Weijden (voorzitter)

Prof. dr. R.T.C.M. Koopmans (Radboud Universitair Medisch Centrum)

Dr. M.D. Spreeuwenberg

Prof. dr. H. Vermeulen (Radboud Universitair Medisch Centrum)

Dr. M.E. de Vugt 


\section{CONTENTS}

$\begin{array}{lll}\text { Chapter } 1 & \text { General introduction } & 7\end{array}$

Chapter 2 Development and usability of the MAINtAIN, an inventory 19 assessing nursing staff behavior to optimize and maintain functional activity among nursing home residents: A mixedmethods approach

BMC Health Services Research, 2016.

Chapter 3 Do nursing staff encourage functional activity among nursing 45 home residents? A cross-sectional study of nursing staff perceived behaviors and associated factors

BMC Geriatrics, 2017.

Chapter 4 The role of nursing staff in the activities of daily living of nursing 65 home residents

Geriatric Nursing, 2016.

Chapter 5 Promoting functional activity among nursing home residents: A 81 cross-sectional study on barriers experienced by nursing staff Journal of Aging and Health, 2017.

Chapter 6 Implementation activities for nursing home staff: Results of a 99 World Café method

Submitted for publication.

Chapter 7 Feasibility of the Translating Innovations into Practice-toolbox (TIPtoolbox): A mixed-methods study for implementing activity innovations in nursing homes

Geriatric Nursing, 2017.

Chapter 8 General discussion

Summary

Samenvatting

Valorization addendum

Dankwoord

About the author

List of publications

Living lab in ageing and long-term care 



\section{CHAPTER 1}

General introduction

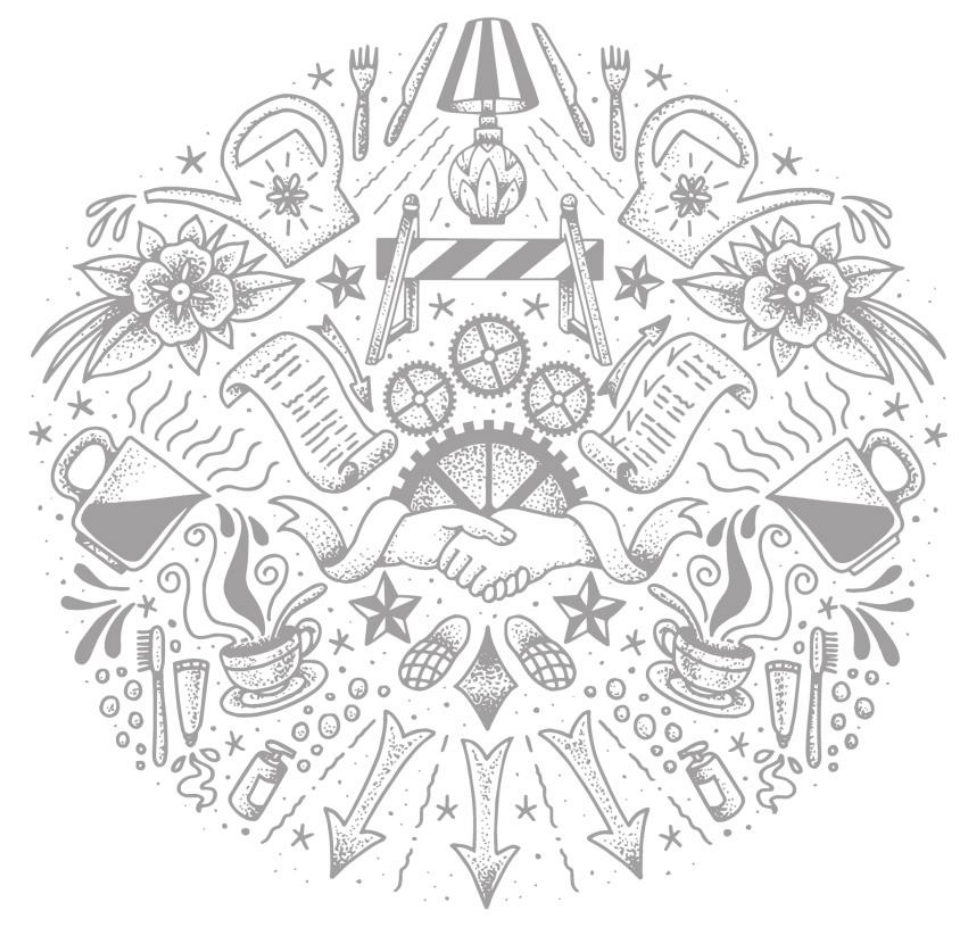



This dissertation focuses on supporting nursing staff in implementing innovations in nursing home care. Numerous studies have shown that a gap exists between the available evidence and nursing practice. ${ }^{1-3}$ Particularly with respect to nursing homes, few studies have been conducted regarding the implementation of evidence-based innovations. ${ }^{4}$ Compared with other healthcare settings, the educational level of the nursing staff is generally low in nursing homes. 5,6 This makes it challenging to implement evidence-based innovations. Research shows that involving nursing staff in the implementation of innovations increases the commitment towards the innovation. ${ }^{7}$ Interpersonal contact between the nurses involved in the implementation and other nursing staff improves the likelihood that nursing practices can be changed. ${ }^{8,9}$ To bridge the gap between research and practice in nursing homes it is therefore important that nursing staff are supported in implementing innovations. Although this gap encompasses multiple areas, ${ }^{1-3}$ this dissertation particularly focuses on nursing staffpromotion of functional activity among nursing home residents.

This first chapter provides insight into models that can be used to change healthcare, including the Implementation of Change model that was used throughout this dissertation. Furthermore, the concepts 'nursing homes' and 'functional activity' are explained. This is followed by an overview of the aims and outline of this dissertation. The chapter concludes with a description of the research line 'Nurses on the Move' and the Living Lab in Ageing and Long-Term Care, of which the research in this dissertation was part of.

\section{Changing healthcare}

Changing healthcare can be challenging. There are many models that can help explain how change can be achieved. In general, a distinction can be made between models that focus more on the passive spread of innovations (i.e., 'diffusion'), and models that focus more on active and planned efforts to ensure the adoption of innovations within a setting (i.e., 'implementation'). ${ }^{10-12}$ Many of these models help researchers understand which factors can influence diffusion or implementation. ${ }^{13}$ For example, Rogers' Theory on the Diffusion of Innovations states that the diffusion of an innovation is influenced by the characteristics of the innovation, the communication channels through which information about the innovation is spread, time, and the social system or context in which the innovation is used. ${ }^{14}$ While Rogers addresses the diffusion of innovations in general, others have specifically concentrated on the diffusion or implementation of innovations in healthcare, which is often complex, usually involves groups of people instead of individuals, ${ }^{15}$ and is generally influenced by factors at different levels. ${ }^{16}$ Greenhalgh's Conceptual Model for the Diffusion of Innovations in Health Service Organizations distinguishes between factors related to the inner organizational context (e.g., size of the organization, leadership) and the outer organizational context (e.g., 
political streams) that can influence the adoption of innovations in healthcare. ${ }^{15}$ The PARIHS framework focuses on the factors that influence the implementation of innovations in healthcare, and states that successful implementation depends upon the nature of the evidence, the quality of the context, and the type of facilitation. ${ }^{17}$ One can furthermore distinguish between models that explain the factors that can influence the diffusion or implementation of innovations (e.g., the previously mentioned models), and models that focus more on guiding the process of implementing innovations into practice. $^{13,18}$ The latter models often use a stepwise approach and highlight the aspects that need to be considered during implementation. ${ }^{13}$ One such model that helps in the planning and managing the implementation process is the Implementation of Change model of Grol and colleagues. ${ }^{19}$ In contrast to many other models, ${ }^{12}$ this model was developed to help not only researchers but also people working in healthcare to implement innovations. ${ }^{19}$ The model is based on evidence and uses a clear analytic approach that is applicable to a variety of healthcare settings. ${ }^{20}$ Therefore, this model will be used throughout this dissertation.

\section{The Implementation of Change model}

The Implementation of Change model is a comprehensive model that can guide the implementation of an innovation in healthcare. It is based on several theories of implementation. It uses a stepwise approach tailored to the setting in which the innovation will be used. ${ }^{19}$ This entails gaining insight into the extent to which the innovation or desired behavior is already put into practice. ${ }^{19}$ This can, for example, be done by using existing data sources, by administering questionnaires, or by conducting observations. ${ }^{21}$ In addition, insight is needed into the barriers to or facilitators of the innovation. These barriers may be related to the innovation itself, to individual health professionals, to the social context, the organizational context, and the economic and political context. ${ }^{16,18}$ Which factors are important when implementing an innovation depends on the specific innovation and the setting in which the innovation will be used. Therefore, implementing innovations requires careful consideration of which factors may play a role in a specific setting. ${ }^{22}$ Based on these insights, strategies for change can be developed or selected. Examples of potentially effective strategies are reminders, education, or audit and feedback. ${ }^{23}$ To ensure that the change in practice is sustainable, it is important that the improvements are integrated into routine care. Lastly, it should be evaluated whether or not implementation was effective. If this is not the case, changing the implementation plan might be needed. Figure 1.1 provides an overview of the seven-stepped Implementation of Change model. It is important to notice that this is not a linear process; it may be necessary to return to a previous step or change the sequence of the steps. During the execution of the seven steps, it is essential to involve the end-users of the innovation. This makes it more likely that the innovation fits with current practices and will be used. ${ }^{10,19,24,25}$ 
The Implementation of Change model can be used for the implementation of change or an innovation in healthcare. In this dissertation, the specific healthcare setting is the nursing home. The innovation itself relates to the promotion of functional activity among nursing home residents by nursing staff.

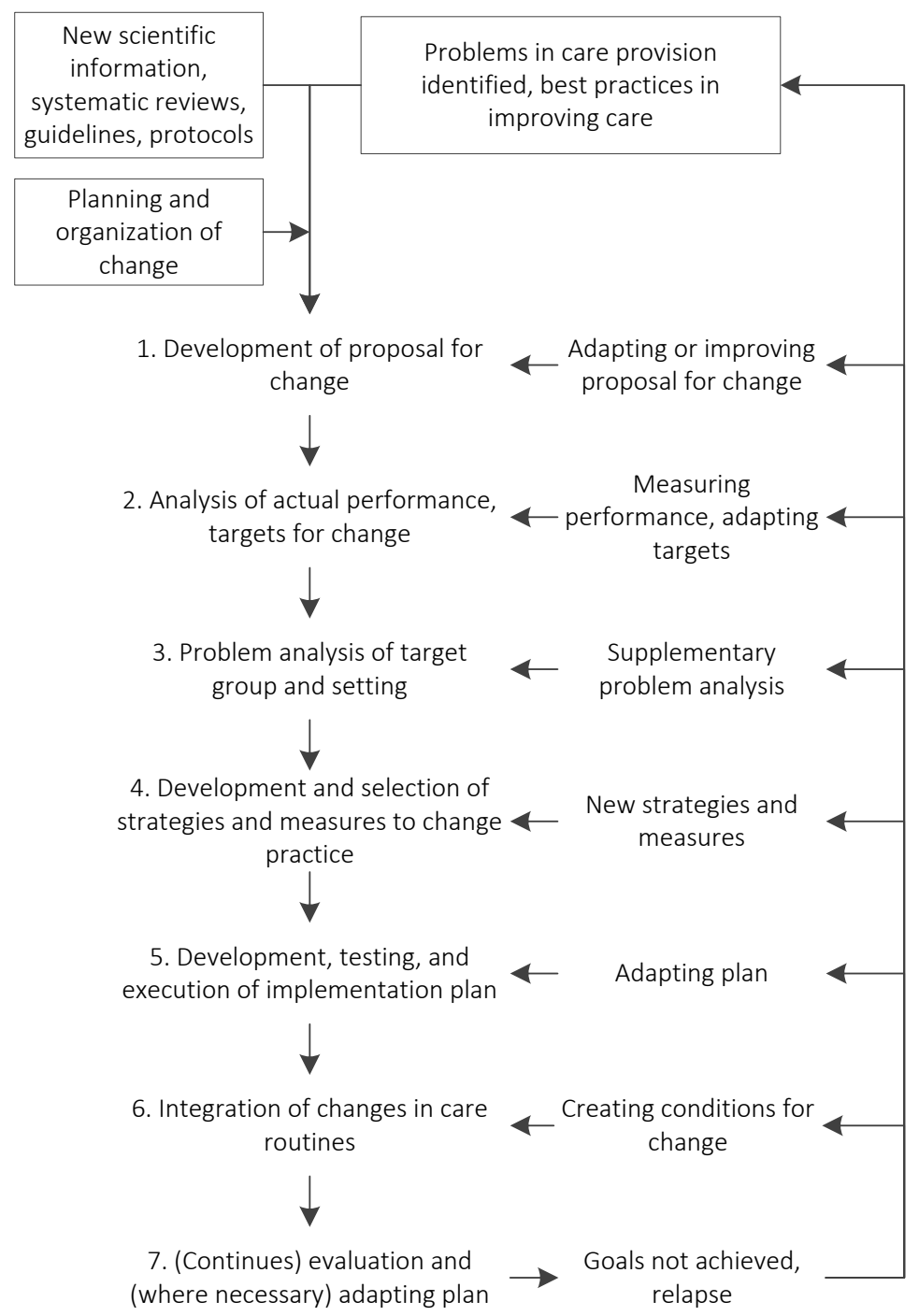

Figure 1.1. The Implementation of Change model. ${ }^{16}$

(Reproduced with permission from John Wiley and Sons, Inc.) 


\section{Nursing homes}

Nursing homes are facilities that provide 24-hour functional support for people who require assistance with (instrumental) activities of daily living and have identified health needs. ${ }^{26}$ How this care is arranged differs by country. ${ }^{26}$ In the Netherlands, long-term nursing home care is provided in psychogeriatric and somatic wards. Psychogeriatric wards provide care to people with cognitive problems such as dementia, while somatic wards mainly provide care to people with chronic physical problems. ${ }^{27}$ Somatic and psychogeriatric long-term care can be organized in traditional large-scale wards, in small-scale wards, or in more innovative facilities such as green care farms. In addition, nursing homes may provide short-term care in rehabilitative wards or palliative wards.

Most nursing homes in the Netherlands are non-profit organizations. ${ }^{28}$ The majority of the direct care is provided by certified nurse assistants with three years of secondaryvocational training (in Dutch: 'verzorgenden'). In addition, care is provided by nurse assistants with two years of secondary-vocational training (in Dutch: 'helpenden'), registered nurses (RNs) with four years of secondary-vocational training (in Dutch: 'MBO verpleegkundigen'), and bachelor-educated RNs (in Dutch: 'HBO verpleegkundigen'). Furthermore, the nursing home staff consist of allied health professionals such as physiotherapists, occupational therapists, speech language therapists, and dieticians. Unique to the Netherlands is the employment of nursing home medical specialists within most nursing homes. ${ }^{26,29}$

The focus of nursing home care is to provide a home-like environment while assisting the residents in maintaining their functional status as long as possible. ${ }^{26}$ In the Netherlands, this home-like environment is often characterized by the fact that meals are taken in the wards, and in many wards small kitchen facilities are available to, for example, prepare breakfast. This provides nursing staff with extra opportunities to promote functional activity among nursing home residents during the day.

\section{Functional activity}

Promoting or encouraging functional activity entails the promotion of activity during daily care moments. This includes the encouragement of activities of daily living (ADL), such as bathing; household activities, such as setting the table; but also more general activities, such as encouraging informal caregivers not to take over activities. Studies have shown that performing functional activities is associated with less anxiety, ${ }^{30}$ less disruptive behavior, ${ }^{30}$ higher self-esteem, ${ }^{31}$ and a higher quality of life ${ }^{32}$ among nursing home residents. It therefore seems essential that nursing home residents are supported in performing these activities.

Because nursing staff are present 24/7, they have the opportunity to promote functional activity among nursing home residents. In fact, promoting functional activity 
is at the core of nursing practice. This is illustrated by the definition of nursing, provided by Henderson:

"The unique function of the nurse is to assist the individual, sick or well, in the performance of those activities contributing to health or its recovery that he would perform unaided if he had the necessary strength, will or knowledge. And to do this in such a way as to help him gain independence as rapidly as possible." 33

The 'individuals' within this definition also include nursing home residents. In this population, the focus might not be on gaining independence; trying to maintain independence, slowing down decline, or contributing to the residents' quality of live can be considered a success. ${ }^{30}$ The importance of promoting activity within this population is also emphasized by the Dutch healthcare inspectorate. ${ }^{34}$

Several studies have focused on the promotion of functional activity by nursing staff - for example by providing function-focused care. ${ }^{30,35,36}$ Still, research shows that nursing home residents are largely inactive. ${ }^{37,38}$ This may indicate that nursing staff do not always encourage residents to perform functional activities - for example because certain barriers inhibit them from promoting functional activity among nursing home residents. Therefore, implementing innovations related to the promotion of functional activity seems highly relevant. This requires insight into the extent to which functional activities are currently promoted and the associated underlying factors. Furthermore, insight is needed into how the implementation of such encouragement can be improved.

\section{Aims and outline}

\section{Aims}

The overall objective of this dissertation is to examine how nursing staff can be supported in implementing innovations in nursing home care. Specifically, this dissertation aims:

1. to provide insight into the extent to which nursing staff in the Netherlands promote functional activity among nursing home residents;

2. to provide insight into nursing staff-experienced barriers towards promoting functional activity among nursing home residents; and

3. to develop an instrument that nursing staff can use to implement innovations related to the promotion of functional activity. 


\section{Outline}

The aims of this dissertation are addressed in different chapters. Chapter 2 reports on the development and usability of the MAastrlcht Nurses Activities INventory (MAINtAIN). This questionnaire was developed to map the extent to which nursing staff promote several functional activities (MAINtAIN-behaviors) and the related barriers they experience (MAINtAIN-barriers). The results of the MAINtAIN-behaviors questionnaire are provided in Chapter 3. This chapter addresses the extent to which nursing staff throughout the Netherlands perceive that they promote functional activity. Furthermore, it provides insight into the professional characteristics, contextual factors, and information-seeking behaviors that are associated with this behavior. Chapter 4 further elaborates on the behavior of nursing staff, but presents the results of an observation study regarding the role of nursing staff in residents' daily activities. It reports on the extent to which nursing staff take over the activities of residents. Chapter 5 describes the barriers nursing staff experience to promoting functional activity. It shows which barriers are most often experienced among nursing staff in the Netherlands and which barriers are most strongly associated with their perceived behavior. To be able to improve the extent to which functional activities are promoted and to take away the experienced barriers, implementation activities are needed that nurses can use to implement innovations. Chapter 6 reports the results of a study that used the World Café method to identify practical implementation activities aimed at improving functional activity among nursing home residents. Chapter 7 provides the results of an in-depth mixed-methods study evaluating the feasibility of the Translating Innovations into Practice-toolbox (TIP-toolbox). The TIP-toolbox is an instrument that nursing staff can use to develop an implementation plan to implement innovations. Finally, Chapter 8 summarizes the main findings of this dissertation, reflects on some methodical and theoretical considerations, and ends with a discussion of the findings' implications for practice, education, and research.

\section{Research line nurses on the move and living lab in ageing and long- term care}

The research in this dissertation was conducted as part of the research line 'Nurses on the Move: towards high quality care in nursing homes,' which was funded by ZonMw, The Netherlands Organization for Health Research and Development (grant 520001003). The overall aim of this research line is to contribute to the improvement of functional status and the reduction of disability among nursing home residents specifically, and to the improvement of quality of care in general. The research line consists of three interrelated projects: 1) Encouraging daily activities and independence among residents; 2) Supporting nursing staff in implementing innovations; and 3) Direct 
nursing care staffing and quality of care. This dissertation encompasses the second project.

The conducted research was, furthermore, embedded in the Living Lab in Ageing and Long-Term Care, a formal collaboration between Maastricht University, Zuyd University of Applied Sciences, and seven large long-term care organizations, all located in the southern part of the Netherlands. ${ }^{39}$ The aim of this multidisciplinary collaboration is to improve the quality of long-term care. 


\section{References}

1. Dharamsi S, Jivani K, Dean C, Wyatt C. Oral care for frail elders: Knowledge, attitudes, and practices of long-term care staff. J Dent Educ. 2009;73(5):581-588.

2. Mody L, Saint S, Galecki A, Chen S, Krein SL. Knowledge of evidence-based urinary catheter care practice recommendations among healthcare workers in nursing homes. J Am Geriatr Soc. 2010;58(8):15321537.

3. Meesterberends E, Wilborn D, Lohrmann C, Schols JM, Halfens RJ. Knowledge and use of pressure ulcer preventive measures in nursing homes: A comparison of Dutch and German nursing staff. J Clin Nurs. 2014;23(13-14):1948-1958.

4. Boström AM, Slaughter SE, Chojecki D, Estabrooks CA. What do we know about knowledge translation in the care of older adults? A scoping review. J Am Med Dir Assoc. 2012;13(3):210-219.

5. McGilton KS, Bowers BJ, Heath $\mathrm{H}$, et al. Recommendations from the International Consortium on Professional Nursing Practice in Long-Term Care Homes. J Am Med Dir Assoc. 2016;17(2):99-103.

6. Backhaus $R$, van Rossum $E$, Verbeek $H$, et al. Relationship between the presence of baccalaureateeducated RNs and quality of care: A cross-sectional study in Dutch long-term care facilities. BMC Health Serv Res. 2017;17:53.

7. Stewart GL, Manges KA, Ward MM. Empowering sustained patient safety: The benefits of combining topdown and bottom-up approaches. J Nurs Care Qual. 2015;30(3):240-246.

8. Holleman G, van Tol M, Schoonhoven L, Mintjes-de Groot J, van Achterberg T. Empowering nurses to handle the guideline implementation process: Identification of implementation competencies. J Nurs Care Qual. 2014;29(3):E1-6.

9. Thompson GN, Estabrooks CA, Degner LF. Clarifying the concepts in knowledge transfer: A literature review. J Adv Nurs. 2006;53(6):691-701.

10. Greenhalgh T, Robert G, Macfarlane F, Bate $P$, Kyriakidou O. Diffusion of innovations in service organizations: Systematic review and recommendations. Milbank Q. 2004;82(4):581-629.

11. Rabin BA, Brownson RC, Haire-Joshu D, Kreuter MW, Weaver NL. A glossary for dissemination and implementation research in health. J Public Health Manag Pract. 2008;14(2):117-123.

12. Tabak RG, Khoong EC, Chambers DA, Brownson RC. Bridging research and practice: Models for dissemination and implementation research. Am J Prev Med. 2012;43(3):337-350.

13. Nilsen P. Making sense of implementation theories, models and frameworks. Implement Sci. 2015;10:53.

14. Rogers EM. Diffusion of Innovations. 5th ed. New York: Free Press; 2003.

15. Greenhalgh T, Robert G, Bate P, Macfarlane F, Kyriakidou O. Diffusion of innovations in health service organisations: A Systematic literature review. Oxford: John Wiley \& Sons; 2008.

16. Grol R, Wensing M. What drives change? Barriers to and incentives for achieving evidence-based practice. Med J Aust. 2004;180(6 Suppl):S57-60.

17. Rycroft-Malone J. The PARIHS framework-A framework for guiding the implementation of evidencebased practice. J Nurs Care Qual. 2004;19(4):297-304.

18. Grol RP, Bosch MC, Hulscher ME, Eccles MP, Wensing M. Planning and studying improvement in patient care: The use of theoretical perspectives. Milbank Q. 2007;85(1):93-138.

19. Grol R, Wensing M, Eccles M, Davis D. Improving patient care: The implementation of change in health care. Oxford: John Wiley \& Sons; 2013.

20. van Achterberg T, Schoonhoven L, Grol R. Nursing implementation science: How evidence-based nursing requires evidence-based implementation. J Nurs Scholarsh. 2008;40(4):302-310.

21. Polit DF. Nursing research: Generating and assessing evidence for nursing practice. Philadelphia: Wolters Kluwer Health; 2017.

22. Baker R, Camosso-Stefinovic J, Gillies C, et al. Tailored interventions to address determinants of practice. Cochrane Database Syst Rev. 2015;4:CD005470.

23. Grimshaw JM, Thomas RE, MacLennan G, et al. Effectiveness and efficiency of guideline dissemination and implementation strategies. Health Technol Assess. 2004;8(6):1-72. 
24. de Veer AJ, Fleuren MA, Bekkema N, Francke AL. Successful implementation of new technologies in nursing care: A questionnaire survey of nurse-users. BMC Med Inform Decis Mak. 2011;11:67.

25. Rahman AN, Applebaum RA, Schnelle JF, Simmons SF. Translating research into practice in nursing homes: Can we close the gap? Gerontologist. 2012;52(5):597-606.

26. Sanford AM, Orrell M, Tolson D, et al. An international definition for "nursing home". J Am Med Dir Assoc. 2015;16(3):181-184.

27. Schols JMGA, Crebolder HFJM, van Weel C. Nursing home and nursing home physician: The Dutch experience. J Am Med Dir Assoc. 2004;5(3):207-212.

28. Bos A, Boselie P, Trappenburg M. Financial performance, employee well-being, and client well-being in for-profit and not-for-profit nursing homes. Health Care Manage Rev. 2016:1.

29. Koopmans RT, Lavrijsen JC, Hoek F. Concrete steps toward academic medicine in long term care. J Am Med Dir Assoc. 2013;14(11):781-783.

30. Resnick B, Galik E, Boltz M. Function focused care approaches: Literature review of progress and future possibilities. J Am Med Dir Assoc. 2013;14(5):313-318.

31. Blair CE. Effect of self-care ADLs on self-esteem of intact nursing home residents. Issues Ment Health Nurs. 1997;20(6):559-570.

32. Edvardsson D, Petersson L, Sjogren K, Lindkvist M, Sandman PO. Everyday activities for people with dementia in residential aged care: Associations with person-centredness and quality of life. Int J Older People Nurs. 2014;9(4):269-276.

33. Henderson V. The nature of nursing. Am J Nurs. 1964;64(8):62-68.

34. Inspectie voor de Gezondheidszorg (Dutch Health Care Inspectorate). In: State of health care 2012 Prevention in curative and long-term care: The need for vulnerable groups. [In Dutch: Staat van de gezondheidszorg 2012. Preventie in de curatieve en langdurige zorg: Noodzaak voor kwetsbare groepen]. 2012. https://www.rijksoverheid.nl/documenten/rapporten/2012/11/29/staat-van-degezondheidszorg-2012 Accessed 28 November 2016.

35. Galik EM, Resnick B, Pretzer-Aboff I. 'Knowing what makes them tick': Motivating cognitively impaired older adults to participate in restorative care. Int J Nurs Pract. 2009;15(1):48-55.

36. Resnick B, Simpson M, Bercovitz A, et al. Testing of the Res-Care Pilot Intervention: Impact on nursing assistants. Geriatr Nurs. 2004;25(5):292-297.

37. den Ouden M, Bleijlevens MH, Meijers JM, et al. Daily (in)activities of nursing home residents in their wards: An observation study. J Am Med Dir Assoc. 2015;16(11):963-968.

38. Palese A, Del Favero C, Antonio Zuttion R, et al. Inactive residents living in nursing homes and associated predictors: Findings from a regional-based, Italian retrospective study. I Am Med Dir Assoc. 2016;17(12):1099-1105.

39. Verbeek H, Zwakhalen SM, Schols JM, Hamers JP. Keys to successfully embedding scientific research in nursing homes: A win-win perspective. J Am Med Dir Assoc. 2013;14(12):855-857. 



\section{CHAPTER 2}

\section{Development and usability of the MAINtAIN,}

an inventory assessing nursing staff behavior to optimize and maintain functional activity among nursing home residents: A mixedmethods approach

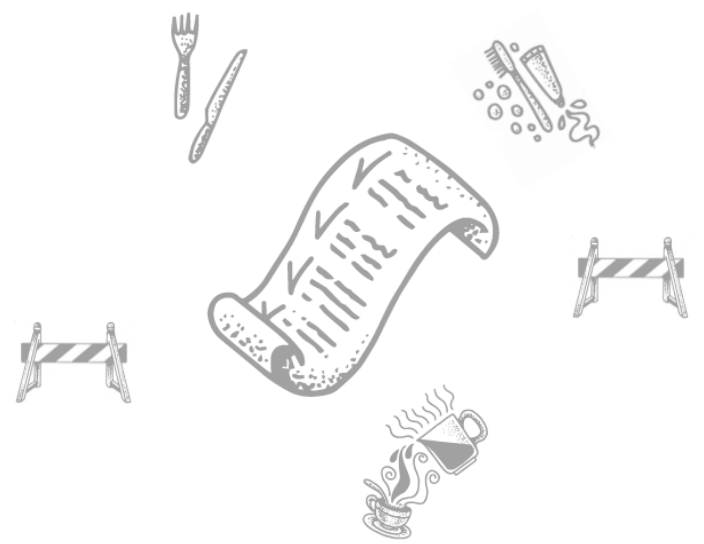

This chapter was published as:

Kuk NO, Zijlstra GAR, Bours GJJW, Hamers JPH, Kempen GIJM. Development and usability of the MAINtAIN, an inventory assessing nursing staff behavior to optimize and maintain functional activity among nursing home residents: A mixed-methods approach. BMC Health Serv Res. 2016;16:38. doi: 10.1186/s12913-016-1288- 


\section{Abstract}

Background: Functional decline is common in nursing home residents. Nursing staff can help prevent this decline, by encouraging residents to be more active in functional activities. Questionnaires measuring the extent to which nursing staff encourage functional activity among residents are lacking. In addition, there are no measurement instruments to gain insight into nursing staff perceived barriers and facilitators to this behavior. The aim of this study was to develop, and study the usability, of the MAastr/cht Nurses Activities INventory (MAINtAIN), an inventory assessing a) the extent to which nursing staff perceive to perform behaviors that optimize and maintain functional activity among nursing home residents and b) the perceived barriers and facilitators related to this behavior.

Methods: Using a mixed-methods approach the MAINtAIN was developed and its usability was studied. Development was based on literature, expert opinions, focus group $(N=3)$ and individual interviews $(N=14)$ with residents and staff from nine nursing homes in the Netherlands. Usability was studied in a cross-sectional study with 37 nurses and certified nurse assistants; data were analyzed using descriptive statistics.

Results: Development of the MAINtAIN resulted in two distinctive parts: MAINtAINbehaviors and MAINtAIN-barriers. MAINtAIN-behaviors, targeting nursing staff behavior to optimize and maintain functional activity, includes 19 items covering activities of daily living, household activities, and miscellaneous activities. MAINtAIN-barriers addresses the perceived barriers and facilitators related to this behavior and comprises 33 items covering barriers and facilitators related to the residents, the professionals, the social context, and the organizational and economic context. The usability study showed that the inventory was not difficult to complete, that items and response options were clear, and that the number of missing values was low. Few items showed a floor or ceiling effect.

Conclusions: The newly developed inventory MAINtAIN provides a usable method for researchers and nursing homes to obtain insight into nursing staff perceived behavior in optimizing functional activity among residents and their perceived barriers and facilitators related to this behavior. Outcomes of the MAINtAIN may contribute to change in nursing staff behavior and may improve nursing care. Further research with regard to the psychometric properties of the MAINtAIN is recommended. 


\section{Background}

With increasing age, the risk of functional decline increases. This is one of the major risk factors for older people to transfer to a nursing home. ${ }^{1,2}$ Once residing in a nursing home, individuals often have a low activity level ${ }^{3-6}$ and further functional decline is common. ${ }^{7,8}$ However, the functional level of nursing home residents does not, by definition, have to decline. ${ }^{9}$ To maintain their functional level it may be important that nursing home staff encourage residents to perform functional activities and stay as active as possible. ${ }^{10,11}$

Although nursing staff are not the only ones who can play a role, it is particularly relevant for them to provide care that optimizes the functional level of residents as they are generally the professionals that spend time with residents during moments and activities that allow residents' physical engagement. They can encourage residents and provide them with opportunities to be active during daily care activities, instead of taking over the care. However, nursing staff may experience certain barriers that might make it difficult for them to provide the best possible care with regard to optimizing functional activity among nursing home residents. ${ }^{12}$ Identifying these barriers, or in contrast facilitators, is an important step towards improving care. ${ }^{13}$

Before nursing care can be improved, it is essential to gain insight into the care nursing staff currently provide. Although studies measuring low activity levels of residents $^{3-5}$ indicate that nursing staff could encourage residents more often to be active, no data are available that provide insight into the extent to which and during what activities nursing staff think they encourage the functional abilities of residents. To our knowledge, questionnaires addressing this issue are lacking, as well as questionnaires explicitly focusing on nursing staff perceived barriers or facilitators related to optimizing and maintaining functional activity among nursing home residents. Such questionnaires could provide a national overview of the perceived behaviors, barriers and facilitators of nursing staff or could be used as a baseline measure for quality improvement projects in individual nursing homes.

The aim of this study is to develop a usable inventory assessing a) the extent to which nursing staff perceive to perform behavior to optimize and maintain functional activity among nursing home residents and b) the perceived barriers and facilitators related to this behavior. This article describes the process of developing, and studying the usability of, the MAastrlcht Nurses Activities INventory (MAINtAIN). 


\section{Methods}

To develop and study the usability of the MAINtAIN a mixed-methods approach was used, involving a multidisciplinary group of stakeholders. The process consisted of four steps (see Figure 2.1). The results of each step guided the following steps. The MAINtAIN is developed to comprise two parts. Part one aims to assess the behaviors nursing staff perceive to perform during their daily care to optimize and maintain functional activity among residents (MAINtAIN-behaviors). Part two aims to address barriers and facilitators nursing staff perceive when optimizing functional activity among residents (MAINtAIN-barriers). With regard to nursing behaviors, the focus is on behaviors that can be performed by nursing staff during daily nursing care. In this article, the term 'nursing behaviors' is used; however, the inventory is also intended for certified nurse assistants (CNAs) or other direct-care staff. The study was approved by the Medical Ethical Review Committee of Maastricht University (12-5-062).

\section{Development process}

Step 1: Determining the content of the MAINTAIN

In the first step, the content of MAINtAIN-behaviors and MAINtAIN-barriers was determined in two separate, parallel processes, as is shown in Figure 2.1. For MAINTAINbehaviors, data from the literature and experts were retrieved. For MAINtAIN-barriers, literature was reviewed and nursing home professionals and residents were consulted.

Step 1A: Determining content of MAINtAIN-behaviors: nursing behaviors to optimize and maintain functional activity

Based on previous literature, a list of nursing behaviors that may lead to an improvement in functional activity among nursing home residents was formulated. Nursing behaviors focusing on activities that could be incorporated into daily nursing home care were taken into consideration. Sources were retrieved from the PubMed, CINAHL and Google Scholar databases. Search terms included 'nurses,' 'behaviors,' 'interventions,' 'function,' 'functional status,' 'nursing home residents,' 'activities of daily living,' and 'older people.' In addition, snowball search techniques were used, meaning the reference lists of relevant articles were searched for new relevant literature. Furthermore, a search for specific interventions in evidence-based guidelines and protocols, and textbooks was performed. 


\section{Development process}

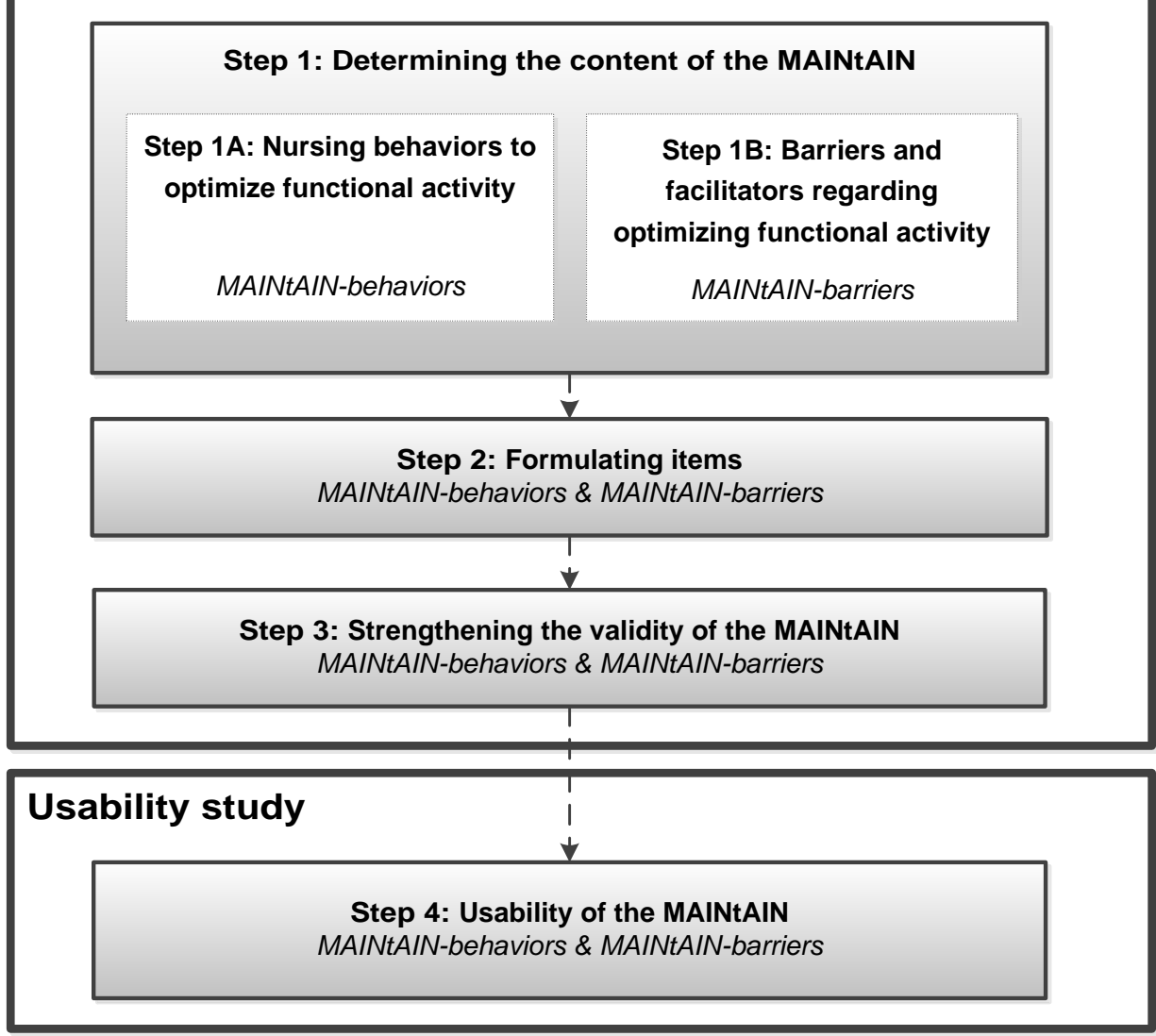

Figure 2.1. Development process of the inventory: a four-step approach.

MAINtAIN = MAastrlcht Nurses Activities INventory.

To determine which of the listed nursing behaviors were relevant for the inventory, the list was sent to 12 experts, working in the field of elderly care or with a nursing background. These experts worked at different departments of Maastricht University $(n=9)$, at Zuyd University of Applied Sciences $(n=2)$, and at a nursing home $(n=1)$ in the south of the Netherlands. Eight of these experts were or had been active as registered nurse (RN). The experts were asked to rank the listed behaviors according to their feasibility and relevance in contributing to the functional activity of nursing home residents. Extra behaviors deemed important could be added. Based on these rankings and the comments of the experts, authors NOK, GARZ, and GJJWB made a selection of behaviors to be incorporated in MAINtAIN-behaviors. 
Step 1B: Determining the content of MAINtAIN-barriers: barriers and facilitators regarding optimizing and maintaining function

First, to gain insight into existing knowledge and identify key articles on nursing staff perceived barriers and facilitators to optimizing and maintaining functional activity among nursing home residents a general literature search was performed in different databases (PubMed, CINAHL, Google Scholar). In addition, these databases were searched for existing questionnaires measuring such barriers or facilitators. Search terms included 'function,' 'functional status,' 'barriers,' 'facilitators,' 'nursing home,' 'older persons,' and 'nurses.' Although the primary interest was in questionnaires assessing barriers or facilitators specifically related to optimizing functional activity, questionnaires measuring barriers and facilitators in general were also taken into account. Snowball search techniques were used as well.

Second, to ensure that MAINtAIN-barriers comprised issues residents and nursing home professionals encounter, focus group interviews and individual interviews were conducted. Residents and staff were recruited from nine nursing homes of two large long-term care organizations in the south of the Netherlands. Although nursing staff will be the end-users of the inventory, a rich information base was ensured by recruiting a heterogeneous sample of participants, based on educational backgrounds and professions.

To begin, three focus group interviews were conducted. To promote an environment in which participants felt comfortable talking, ${ }^{14}$ homogeneity within groups was created based on similarities in educational level. The first group consisted of a nursing home manager $(n=1)$, ward managers $(n=2)$, physiotherapists $(n=3)$, and a nurse practitioner $(n=1)$. The second group consisted of $\mathrm{CNAs}^{\mathrm{a}}(n=2)$, RNs with 4 years of secondary vocational training $(n=3)$, and a bachelor's prepared RN $(n=1)$. The third group consisted of a CNA $(n=1)$ and RNs with 4 years of secondary vocational training $(n=3)$. A topic list was used to guide the focus groups. At the end of each session, barriers and facilitators to optimizing functional activity among nursing home residents were grouped according to different levels based on work by Grol and Wensing ${ }^{13}$ : the innovation (in this case interpreted as the functional activity improving behaviors themselves), the residents, the professionals, the social context, the organizational context, and the economic and political context.

Subsequently, 14 semi-structured individual interviews were conducted with people not participating in the focus groups, i.e., RNs with 4 years of secondary vocational training $(n=3)$, CNAs $(n=3)$, a bachelor's prepared RN $(n=1)$, a nursing home physician $(n=1)$, a physiotherapist $(n=1)$, a location manager $(n=1)$, a policy officer $(n=1)$, and residents (individually or together with their informal caregiver) $(n=3)$. The individual interviews included topics that were also discussed in the focus group interviews.

All interviews were audio-recorded (after the participants gave written informed consent), transcribed and analyzed by author NOK. First, all relevant text was highlighted. Next, the content of the interviews was coded. A directed content analysis 
approach $^{15}$ was used to categorize coded barriers and facilitators according to predetermined levels. These levels are described by Grol and Wensing ${ }^{13}$ (see above).

\section{Step 2: Formulating items}

Based on the data collected in Step 1, author NOK formulated preliminary items for both sections of the MAINtAIN. Multiple items covering the same barriers or facilitators were formulated in order to select the most appropriate items in the next step. Two experts on questionnaire development were consulted regarding methods to prevent social desirability bias when formulating items.

\section{Step 3: Strengthening the validity of the MAINtAIN}

To ensure content validity, the initial versions of the inventory were presented to experts in different disciplines. First, while thinking aloud, a CNA completed the inventory in the presence of author NOK. Ambiguous items were pointed out and difficulties and possible solutions were discussed. In addition, for items measuring the same concept, author NOK and the CNA discussed which option was most clear. Furthermore, the suitability of the response options was evaluated, by discussing which, and why these, response options were used by the CNA. Consequently, the inventory was revised where necessary. Next, authors NOK, GARZ, and GJJWB independently checked if the formulated items still corresponded with the concepts they were intended to measure. Differences in opinion were discussed until consensus was reached. After revisions, the concept version of the inventory was presented to experts in research and practice related to older persons or implementation science $(n=9)$. The experts individually appraised the inventory for missing or redundant items and checked if the items covered the aim of the inventory. In addition, they appraised the order and wording of the items, and the layout of the inventory. Afterwards, the inventory was revised according to their feedback, resulting in a version of the inventory used to study the usability.

\section{Usability study}

Step 4: Usability of the MAINTAIN

In a cross-sectional study, the usability of the MAINtAIN was studied. The convenience sample included 37 staff nurses working on somatic wards, psychogeriatric wards or rehabilitation wards of two large long-term care organizations. Rehabilitation wards were included as it was expected that nursing staff working there were more inclined to encourage functional activities. All respondents were asked to anonymously complete the inventory.

To evaluate the usability of the inventory, 1-item questions were added regarding the time respondents needed to complete the inventory, the clarity of the domains and items, the clarity of the response options, the difficulty of the items in the inventory, 
and suggestions for improvement. Additionally, to gain more in-depth insight into possible difficulties regarding the completion of the inventory, author NOK interviewed a convenience sample of three respondents from one nursing home after they completed the inventory.

\section{Data analyses}

Statistical analyses were performed using SPSS 21 for Windows. Data were analyzed using descriptive statistics. Items were checked for missing values, and floor and ceiling effects were assessed. If individual items had a response of $>50 \%$ for the lowest or highest response option, items were examined more closely. More specifically, for these items it was checked if this effect held true for the general sample, or only for a subgroup that was expected to know more about the encouragement of functional activity. Subgroups were respondents that were mobility-prone (i.e., those working at a rehabilitation ward and those specialized in mobility) versus those that were expected to be not, the non-mobility group (i.e., the remainder of the respondents). In addition, to check the discriminative ability of the inventory, bar charts were produced separately for the general population and the subgroups. Subsequently, based on floor and ceiling effects or bar charts, authors NOK, GARZ, and GJJWB judged and discussed whether or not items should be removed or changed. The outcomes of the usability study resulted in the final version of the MAINTAIN.

\section{Results}

\section{Development process}

Step 1: Determining the content of the MAINtAIN

Step 1A: Determining the content of MAINtAIN-behaviors: nursing behaviors to optimize and maintain functional activity

The literature search yielded four key sources that were used to formulate a list of nursing behaviors that could potentially optimize functional activity. ${ }^{16-19}$ Listed behaviors focused on encouraging nursing home residents to perform activities of daily living (ADL; e.g., dressing or washing) as independently as possible, ${ }^{16-18}$ for example, by providing assistive devices, ${ }^{16,17}$ but also on more general activities (e.g., encouraging residents to be physically active, helping residents maintain their daily routines, and educating informal caregivers about the importance of functional independence ${ }^{19}$ ). Although the literature primarily focused on the independent performance of ADL, additional nursing behaviors that encouraged the performance of instrumental 
activities of daily living, in particular household activities (e.g., making beds, setting and clearing the table, preparing small meals), were also included.

Overall, expert's ranking of the nursing behaviors showed that they deemed the behaviors related to household activities as particularly important opportunities to optimize functional activity. Most nursing behaviors related to general activities (grouped into the category 'miscellaneous activities') were deemed relevant as well. Some behaviors were perceived as redundant, not applicable to psychogeriatric residents, or not suitable in all nursing homes, and therefore the removal of these behaviors was advised (for example: 'encourage residents to buy groceries'). The final selection of the ADL-related nursing behaviors included behaviors that encouraged independence in eating, dressing, moving about the ward, and personal hygiene. The behaviors covering household activities included the encouragement of small activities that could be performed in the ward, for example, preparing sandwiches. The miscellaneous activities were a diverse selection ranging from 'encouraging informal caregivers not to take over activities' to 'discussing activities from the past and trying to maintain them.'

\section{Step 1B: Determining the content of MAINtAIN-barriers: barriers and facilitators} regarding optimizing and maintaining functional activity

The search in the scientific databases resulted in four main articles that provided insight into possible barriers and facilitators towards optimizing function. ${ }^{12,20-22}$ The search did not yield an existing questionnaire that measures barriers or facilitators to optimizing functional activity among nursing home residents. However, studies were found that qualitatively measured barriers and facilitators to restorative care, an approach to optimize function. ${ }^{12,20,21}$ These studies focused on barriers and facilitators as perceived by nursing assistants. Barriers identified included refusal by residents, the lack of nursing support, and the assumption that residents could not perform activities. ${ }^{12,20,21}$ In addition, barriers mentioned in questionnaires generally measuring barriers and facilitators provided input for the inventory. The Measurement Instrument Determinants of Innovations ${ }^{22}$ provided barriers that seemed relevant, despite the fact that this questionnaire was not tailored to the nursing home setting or optimizing functional activity.

Next, focus group and individual interviews provided insight into barriers and facilitators specifically related to optimizing functional activity among nursing home residents, as experienced by nursing staff or residents on a daily basis. Analysis of the relevant data showed that the barriers and facilitators were related to all predetermined levels; three were related to the innovation, eight to the residents and informal caregivers, eight to the professionals, nine the social context, and eleven the organizational and economic context. The exposed barriers and facilitators included, for example, the attitudes of residents, low priority, the support of a manager, and courses provided. 


\section{Step 2: Formulating items}

Based on the outcomes of Step 1, items were formulated for both parts of the inventory. In MAINtAIN-behaviors, comprising 25 items regarding the behaviors nursing staff can perform, a distinction was made between nursing behaviors related to ADL, household activities, and miscellaneous activities. To reduce the risk of socially desirable answers, experts $(N=2)$ recommended the formulation of items on a less individual level, i.e., instead of stating 'I encourage...' the items stated 'On my ward, we encourage residents to help set and clear the table,' or 'On my ward, we compliment residents when they dress and undress themselves.' In MAINtAIN-barriers, comprising 62 items regarding perceived barriers and facilitators, a distinction was made between barriers and facilitators related to residents (e.g., 'Residents are afraid to walk on their own'), to professionals (e.g., 'It is primarily the responsibility of the physiotherapist/occupational therapist to encourage residents to perform activities'), to the social context (e.g., 'My colleagues expect me to encourage residents to help carry out household activities'), and to the organizational and economic context (e.g., 'In my organization, encouraging physical activity is a high priority'). For practical reasons, barriers related to the innovation were grouped with those related to the residents.

\section{Step 3: Strengthening the validity of the MAINTAIN}

The interview with the CNA led to a change in the wording of some of the items and a reduction of the number of items. Two redundant items from MAINtAIN-behaviors and 23 redundant items from MAINtAIN-barriers were removed, resulting in 23 and 39 remaining items, respectively. Regarding the response options, the remarks of the CNA revealed that she was reluctant to use the extremes of the scale. To avoid 'end-aversion bias', $^{23}$ it was therefore decided to add extra response options, resulting in a change from a five- to a nine-point scale. Next, wording for some items was changed following the check by authors NOK, GARZ, and GJJWB regarding the correspondence of the items with the concepts they intended to measure. In addition, some items measuring the same barriers or facilitators were merged. Lastly, experts $(N=9)$ reviewed the content and layout of the inventory and generally agreed with both. Their feedback led to minor changes in the formulation of items to prevent ambiguous phrasing and acquiescence bias, the tendency of respondents to respond to all items in the same way. Some positively phrased items were changed into negatively phrased items and vice versa. The revisions resulted in an inventory comprised of a total of 58 items: 22 in MAINtAINbehaviors and 36 in MAINtAIN-barriers. 


\section{Usability study}

Step 4: Usability of the MAINTAIN

Of the 37 respondents that completed the inventory, 13 worked in somatic wards, 10 in psychogeriatric wards, and 14 in rehabilitation wards. The majority were CNAs (86.5\%). Table 2.1 describes the characteristics of the study population.

Table 2.1 Study population characteristics $(N=37)$.

\begin{tabular}{|c|c|c|}
\hline & $N$ & $(\%)$ \\
\hline \multicolumn{3}{|l|}{ Gender } \\
\hline Female & 32 & $(86.5)$ \\
\hline \multicolumn{3}{|l|}{ Ward } \\
\hline Somatic & 13 & $(35.1)$ \\
\hline Psychogeriatric & 10 & $(27.0)$ \\
\hline Rehabilitation & 14 & $(37.8)$ \\
\hline \multicolumn{3}{|l|}{ Profession } \\
\hline Certified nurse assistants & 29 & $(78.4)$ \\
\hline Registered nurses with 4 years of secondary vocational training & 7 & $(18.9)$ \\
\hline \multirow[t]{2}{*}{ Bachelor's prepared registered nurses } & 1 & $(2.7)$ \\
\hline & \multicolumn{2}{|c|}{ Mean $\pm S D$} \\
\hline Age (years) & 38.2 & \pm 12.2 \\
\hline Years working in geriatric care & 14.3 & \pm 9.5 \\
\hline Contract hours per week & 29.1 & \pm 6.2 \\
\hline
\end{tabular}

The mean response rate per item was $98.9 \%$ (ranging from 91.9 to 100\%). The mean time required to complete the full inventory was 14 minutes (range 7-30 minutes). Respondents indicated that the domains and items were clear and that the inventory was not difficult. In addition, respondents, including the interviewed respondents, unanimously answered that the response options were clear. The interviewed respondents provided only minor suggestions regarding the wording of the items.

Analyses revealed that five of the 58 items showed a floor- or ceiling effect, i.e., one of the extreme response options was chosen by $>50 \%$ of the respondents (see Table 2.2). As Table 2.2 shows, these floor and ceiling effects were mainly present in the mobility-prone group. After further discussion, the researchers decided to remove one of these five items, i.e., an item regarding instructing residents how to use walking aids. The researchers agreed that a broader item, encouraging residents to move about independently, covered this item. The other four items were retained for theoretical reasons. Visual inspection of bar charts, in particular for the items of MAINtAINbehaviors, indicated that the inventory distinguished between the mobility-prone group and the non-mobility group. 
Table 2.2 Inventory items that showed a floor or ceiling effect in the study population.

\begin{tabular}{|c|c|c|c|c|c|c|c|}
\hline \multirow[b]{2}{*}{ Item } & \multirow[t]{2}{*}{ Extreme value } & \multicolumn{2}{|c|}{$\begin{array}{l}\text { Total } \\
(N=37)\end{array}$} & \multicolumn{2}{|c|}{$\begin{array}{l}\text { Mobility-prone } \\
\text { group }^{a} \\
(n=16)\end{array}$} & \multicolumn{2}{|c|}{$\begin{array}{l}\text { Non-mobility } \\
\text { group }^{\text {b }} \\
(n=21)\end{array}$} \\
\hline & & $n$ & (\%) & $n$ & $(\%)$ & $n$ & $(\%)$ \\
\hline \multicolumn{8}{|l|}{ MAINtAIN-behaviors } \\
\hline $\begin{array}{l}\text { It is not relevant for residents in } \\
\text { my ward to independently } \\
\text { perform ADL (such as bathing } \\
\text { and dressing). }\end{array}$ & $\begin{array}{l}\text { Completely } \\
\text { disagree }^{c}\end{array}$ & 20 & $(55.6)^{*}$ & 10 & $(66.7)^{*}$ & 10 & $(47.6)$ \\
\hline \multicolumn{8}{|l|}{ MAINtAIN-barriers } \\
\hline \multicolumn{8}{|l|}{ In my ward... } \\
\hline $\begin{array}{l}\text {...we compliment residents } \\
\text { when they manage to dress } \\
\text { and undress themselves. }\end{array}$ & Always $^{d}$ & $20^{\mathrm{e}}$ & $(54.1)^{\mathrm{e}, *}$ & $10^{\mathrm{e}}$ & $(62.5)^{\mathrm{e}, *}$ & 10 & $(47.6)$ \\
\hline $\begin{array}{l}\text {...we closely follow the extent to } \\
\text { which residents can move } \\
\text { about independently. }\end{array}$ & Always $^{d}$ & 22 & $(59.5)^{*}$ & 8 & $(50.0)$ & 14 & $(66.7)^{*}$ \\
\hline $\begin{array}{l}\text {...residents are encouraged to } \\
\text { move about independently } \\
\text { (e.g., to the living room, the } \\
\text { toilet, the activity room). }\end{array}$ & Always $^{d}$ & 23 & $(62.2)^{*}$ & 10 & $(62.5)^{*}$ & 13 & $(61.9)^{*}$ \\
\hline $\begin{array}{l}\text {...we instruct residents how they } \\
\text { can use walking aids to move } \\
\text { about independently. }\end{array}$ & Always $^{d}$ & 22 & $(59.5)^{*}$ & 12 & $(75.0)^{*}$ & 10 & $(47.6)$ \\
\hline
\end{tabular}

*Floor or ceiling effect present (endorsement frequency of extreme value $>50 \%$ of population)

No statistical testing was performed.

${ }^{a}$ Mobility-prone group: nursing staff working in a rehabilitation ward or nursing staff specialized in mobility

${ }^{\mathrm{b}}$ Non-mobility group: nursing staff not working in a rehabilitation ward and nursing staff not specialized in mobility

${ }^{\mathrm{c}}$ Range: completely disagree - completely agree

${ }^{d}$ Range: never - always

${ }^{\mathrm{e}}$ Item was completed by a total of 36 respondents.

Based on comments of respondents and a last discussion by authors NOK, GARZ, and GJJWB, some final adjustments in wording of items were made and five items that were covered by other items were removed.

\section{Final inventory}

The final version of the MAINtAIN is included in Appendix 2.1 (the Dutch version of the MAINtAIN is available upon request). MAINtAIN-behaviors, regards the functional activity optimizing behaviors nursing staff can perform and is comprised of 19 items. 
Each item is rated on a nine-point scale ranging from 'never' to 'always,' labeling the extremes and the middlemost response option. MAINtAIN-barriers, regarding the perceived barriers and facilitators to optimizing functional activity among residents is comprised of 33 items. Again, each item is rated on a nine-point scale, ranging from 'never' to 'always' for 12 items, and 'completely disagree' to 'completely agree' for 21 items. The extremes and the middlemost response options are also labeled. A general overview of the nursing behaviors and barriers and facilitators incorporated in the inventory is provided in Table 2.3.

Table 2.3 Overview of items and concepts in the MAINtAIN.

\section{MAINtAIN-behaviors: Nursing behaviors to optimize function}

\begin{tabular}{ll}
\hline Items & Nursing behaviors related to type of activity \\
Item 1 to 8: & Nursing behavior related to activities of daily living \\
Item 9 to 14: & Nursing behaviors related to household activities \\
Item 15 to 19: & $\quad$ Nursing behaviors related to more general activities
\end{tabular}

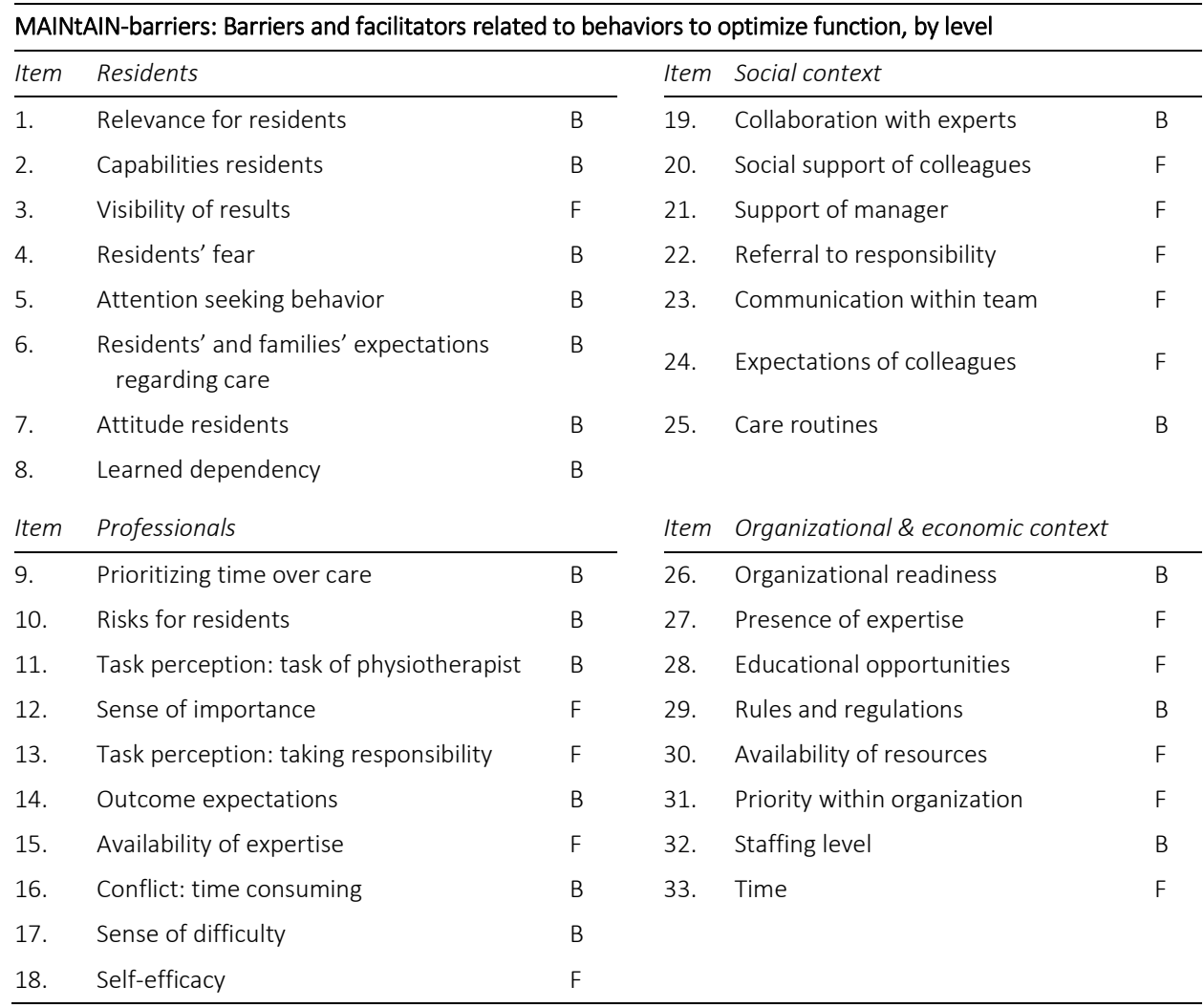

$\mathrm{B}=$ Item formulated as barrier; $\mathrm{F}=$ Item formulated as facilitator. Levels of barriers and facilitators are derived from Grol and Wensing. ${ }^{13}$

Appendix 2.1 includes the MAINtAIN. 


\section{Discussion}

In a step-wise comprehensive mixed-methods study, involving a multidisciplinary group of stakeholders, MAastrlcht Nurses Activities INventory (MAINtAIN), was developed. The MAINtAIN gains insight into the extent to which nursing staff perceive to perform behaviors to optimize functional activity among nursing home residents, and their perceived barriers and facilitators related to this behavior. It assesses nursing staff behavior during a broad range of activities, i.e., ADL, household activities and miscellaneous activities. Additionally, it addresses barriers and facilitators related to different levels, i.e., the residents, the professionals, the social context, and the organizational and economic context. A cross-sectional study showed that the MAINtAIN is a usable inventory to collect data on these topics.

The comprehensive development process of the MAINtAIN (including various strategies, e.g., literature searches, expert consultations, interviews with a heterogeneous sample of individuals) resulted in an inventory including behaviors, and barriers and facilitators that are considered important by the stakeholders. Although nursing staff will be the end-users of the MAINtAIN, the heterogeneous sample of experts involved in the study warrants the inclusion of important behaviors, barriers and facilitators. According to different experts the selected nursing behaviors are both relevant and feasible, and together they provide an overview of the extent to which nursing staff perceive to perform functional activity-optimizing behaviors. In addition, the broad range of barriers and facilitators selected here are relevant to nursing staff, covering topics on several levels, from factors relating to residents to factors relating to the organizational context. Mapping such a variety of factors is important in order to address factors to improve care. ${ }^{24}$

Although the MAINtAIN was developed in the Netherlands, the incorporated nursing behaviors, barriers and facilitators are generalizable to other countries with different healthcare systems as international literature was used to develop the inventory. Barriers and facilitators included in the MAINtAIN overlap with those described in previous research regarding function focused care. ${ }^{12,20}$ In addition, included barriers and facilitators correspond with barriers and facilitators mentioned in international studies of evidence-based practice or innovations in general. ${ }^{25}$ Nonetheless, nursing home populations can differ within and between countries. To be able to interpret and compare results from different studies that use the MAINtAIN, carefully describing populations within studies is recommended.

To our knowledge there are no other inventories or questionnaires available that measure the extent to which nursing staff report to provide functional activity optimizing care, as MAINtAIN-behaviors does. Although studies indicate that nursing home residents are largely inactive, ${ }^{4-6}$ and participation in household activities is low, ${ }^{3,6}$ there are no studies that provide insight into the behaviors nursing staff generally perform to encourage the broad range of activities in which nursing home residents can 
play an active role. Resnick et al. ${ }^{17}$ developed and applied an observational checklist to measure an approach to improve function. This instrument assesses ADL activities and exercise. In the development process of the current study, this checklist, as well as various other sources, was considered. This provided valuable information and resulted in the inclusion of a broader range of items on nursing behaviors. MAINtAIN-behaviors, for example, also includes the encouragement of household activities. Although direct observations provide valuable information, the advantages of the MAINtAIN are that it is easy and quick for nursing staff to use and applicable on a large scale. Furthermore, it takes into account the perceptions of the nursing staff. Quality improvement projects could use a combination of direct observations and the MAINtAIN-behaviors to reveal possible misperceptions among nursing staff. With regard to MAINtAIN-barriers, there are no other inventories that measure barriers and facilitators tailored to this specific problem and this specific setting. This is significant since literature shows that barriers and facilitators are setting-specific and related to the addressed problem. ${ }^{26}$ The MAINtAIN fills this gap.

\section{Limitations}

There are some limitations to this study that should be addressed. First, this article focuses on the development process of the MAINtAIN. Although content validity was assessed, it is recommended that future studies extensively investigate multiple psychometric properties of both parts of the MAINtAIN. Such a study could address the MAINtAIN's construct validity, reliability, and its sensitivity to change. For MAINtAINbehaviors the internal consistency of the items related to ADL, household activities, and miscellaneous activities can be determined. Due to the small sample size of our usability study $(N=37)$, this was not possible in the present study. Second, although research shows that social desirability bias does not, by definition, have to occur, ${ }^{27}$ nursing staff may consciously or subconsciously present themselves or their ward in a positive light. This may be particularly important for MAINtAIN-behaviors. However, in the development process of the inventory, actions were taken to prevent social desirability, e.g., by formulating items on a less individual level. In addition, the anonymous administration of the inventory is recommended to prevent social desirable responses. Moreover, the MAINtAIN assesses self-reported behavior and barriers and facilitators as perceived by the nursing staff; it provides information on perceptions that may or may not accurately reflect the actual situation. Users of the inventory need to keep this in mind when they use and interpret the results of the MAINtAIN.

\section{Implications for research and practice}

The next step is to administer the MAINtAIN on a large scale. Not only would this make it possible to investigate its psychometric properties, the information obtained with the 
MAINtAIN would provide researchers and practitioners opportunities to improve nursing care. Based on this information, strategies can be developed to promote nursing behavior, tackle specific barriers, and promote certain facilitators. This could lead to an improvement in nursing behaviors and eventually lead to optimized or maintained functional activity among nursing home residents.

Furthermore, the MAINtAIN offers nursing homes the possibility to see where their priorities lie, what kind of nursing behaviors are performed according to the nursing staff, and to see what barriers and facilitators are particularly relevant for their nursing home. The outcomes of the current study showed that the MAINtAIN is easy to use in daily practice. Nursing staff themselves can assess factors that have to be addressed in order to improve care.

\section{Conclusion}

The MAINtAIN is a usable method for researchers and nursing staff to obtain insight into the perceived behaviors nursing staff perform to optimize and maintain functional activity among residents. In addition, it maps nursing staff perceived barriers and facilitators to this behavior. Although further psychometric research is recommended, the present inventory provides researchers and practitioners with the opportunity to gain insight into these factors and eventually an opportunity to improve care in nursing homes.

Endnote: ${ }^{a}$ In this article nurses with three years of secondary vocational training are called CNAs, they are comparable to Licensed Practical Nurses in the United States. ${ }^{28}$ CNAs form the major workforce in nursing homes in the Netherlands. 


\section{References}

1. Luppa M, Luck T, Matschinger H, Konig HH, Riedel-Heller SG. Predictors of nursing home admission of individuals without a dementia diagnosis before admission - results from the Leipzig Longitudinal Study of the Aged (LEILA 75+). BMC Health Serv Res. 2010;10:186.

2. Luppa M, Luck T, Weyerer S, Konig HH, Brahler E, Riedel-Heller SG. Prediction of institutionalization in the elderly. A systematic review. Age Ageing. 2010;39(1):31-38.

3. Edvardsson D, Petersson L, Sjogren K, Lindkvist M, Sandman PO. Everyday activities for people with dementia in residential aged care: Associations with person-centredness and quality of life. Int J Older People Nurs. 2014;9(4):269-276.

4. Ice HG. Daily life in a nursing home: Has it changed in 25 years? J Aging Stud. 2002;16(4):345-359.

5. MacRae PG, Schnelle JF, Simmons SF, Ouslander JG. Physical activity levels of ambulatory nursing home residents. J Aging Phys Activ. 1996;4:264-278.

6. den Ouden M, Bleijlevens MH, Meijers JM, et al. Daily (in)activities of nursing home residents in their wards: An observation study. J Am Med Dir Assoc. 2015;16(11):963-968.

7. Carpenter GI, Hastie CL, Morris JN, Fries BE, Ankri J. Measuring change in activities of daily living in nursing home residents with moderate to severe cognitive impairment. BMC Geriatr. 2006;6:7.

8. Rosen AK, Berlowitz DR, Anderson JJ, Ash AS, Kazis LE, Moskowitz MA. Functional status outcomes for assessment of quality in long-term care. Int J Qual Health Care. 1999;11(1):37-46.

9. Walk D, Fleishman R, Mandelson J. Functional improvement of elderly residents of institutions. Gerontologist. 1999;39(6):720-728.

10. Lahmann NA, Tannen A, Kuntz S, et al. Mobility is the key! Trends and associations of common care problems in German long-term care facilities from 2008 to 2012. Int J Nurs Stud. 2015;52(1):167-174.

11. Resnick B, Galik E, Boltz M. Function focused care approaches: Literature review of progress and future possibilities. J Am Med Dir Assoc. 2013;14(5):313-318.

12. Resnick B, Petzer-Aboff I, Galik E, et al. Barriers and benefits to implementing a restorative care intervention in nursing homes. J Am Med Dir Assoc. 2008;9(2):102-108.

13. Grol R, Wensing M. What drives change? Barriers to and incentives for achieving evidence-based practice. Med J Aust. 2004;180(6 Suppl):S57-60.

14. Polit DF, Beck CT. Nursing research : Generating and assessing evidence for nursing practice. 9th ed. Philadelphia: Wolters Kluwer Health/Lippincott Williams \& Wilkins; 2012.

15. Hsieh HF, Shannon SE. Three approaches to qualitative content analysis. Qual Health Res. 2005;15(9):1277-1288.

16. Bulechek GM, Butcher HK, Dochterman JMM, Wagner C. Nursing interventions classification (NIC). St. Louis, MO: Elsevier/Mosby; 2013.

17. Resnick B, Rogers V, Galik E, Gruber-Baldini AL. Measuring restorative care provided by nursing assistants: Reliability and validity of the Restorative Care Behavior Checklist. Nurs Res. 2007;56(6):387398.

18. Resnick B, Gruber-Baldini AL, Zimmerman S, et al. Nursing home resident outcomes from the Res-Care intervention. J Am Geriatr Soc. 2009;57(7):1156-1165.

19. Capezuti L. Evidence-based geriatric nursing protocols for best practice. 4th ed. New York: Springer Publishing Company; 2012.

20. Resnick B, Simpson M, Galik E, et al. Making a difference: Nursing assistants' perspectives of restorative care nursing. Rehabil Nurs. 2006;31(2):78-86.

21. Galik EM, Resnick B, Pretzer-Aboff I. 'Knowing what makes them tick': Motivating cognitively impaired older adults to participate in restorative care. Int J Nurs Pract. 2009;15(1):48-55.

22. Fleuren M, Paulussen TGWM, Dommelen Pv, Buuren Sv. Meetinstrument voor determinanten van innovaties (MIDI). Leiden: TNO; 2012.

23. Streiner DL, Norman GR. Health measurement scales: A practical guide to their development and use. New York: Oxford university press; 2014. 
24. Grol RP, Bosch MC, Hulscher ME, Eccles MP, Wensing M. Planning and studying improvement in patient care: The use of theoretical perspectives. Milbank Q. 2007;85(1):93-138.

25. Kaasalainen S, Williams J, Hadjistavropoulos T, et al. Creating bridges between researchers and longterm care homes to promote quality of life for residents. Qual Health Res. 2010;20(12):1689-1704.

26. Baker R, Camosso-Stefinovic J, Gillies C, et al. Tailored interventions to overcome identified barriers to change: Effects on professional practice and health care outcomes. Cochrane Db Syst Rev. 2010;3.

27. Van de Mortel TF. Faking it: Social desirability response bias in self-report research. Aust J Adv Nurs. 2008;25(4):40-48.

28. Verkaik R, Francke AL, van Meijel B, Ribbe MW, Bensing JM. Comorbid depression in dementia on psychogeriatric nursing home wards: Which symptoms are prominent? Am J Geriat Psychiat. 2009;17(7):565-573. 


\section{Appendix 2.1. The maintain}

This appendix comprises the English version of the MAINtAIN. The MAINtAIN was translated from Dutch to English using forward-backward translation procedures. ${ }^{1}$ The translation procedure consisted of three phases. First, the MAINtAIN was translated into English by two bilingual independent translators. One of them had a nursing background; the other was a professional translator. Differences were discussed and from these two translations one version was created. Second, this version was translated back into Dutch by two other independent bilingual translators. Consensus was reached on one final Dutch translation. Lastly, the authors (NOK, GARZ, GJJWB) checked the accuracy of the English translation, by comparing all translations.

1. Beaton DE, Bombardier C, Guillemin F, Ferraz MB. Guidelines for the process of cross-cultural adaptation of self-report measures. Spine. 2000;25(24):3186-91. 


\section{Maintain-behaviors: activity in the care for resident}

Please indicate for each of the following questions which answer best describes how things work in your ward. When answering these questions, consider the residents for whom this is relevant; the questions are not applicable for completely paralyzed or terminal residents. Only cross one circle for each question.

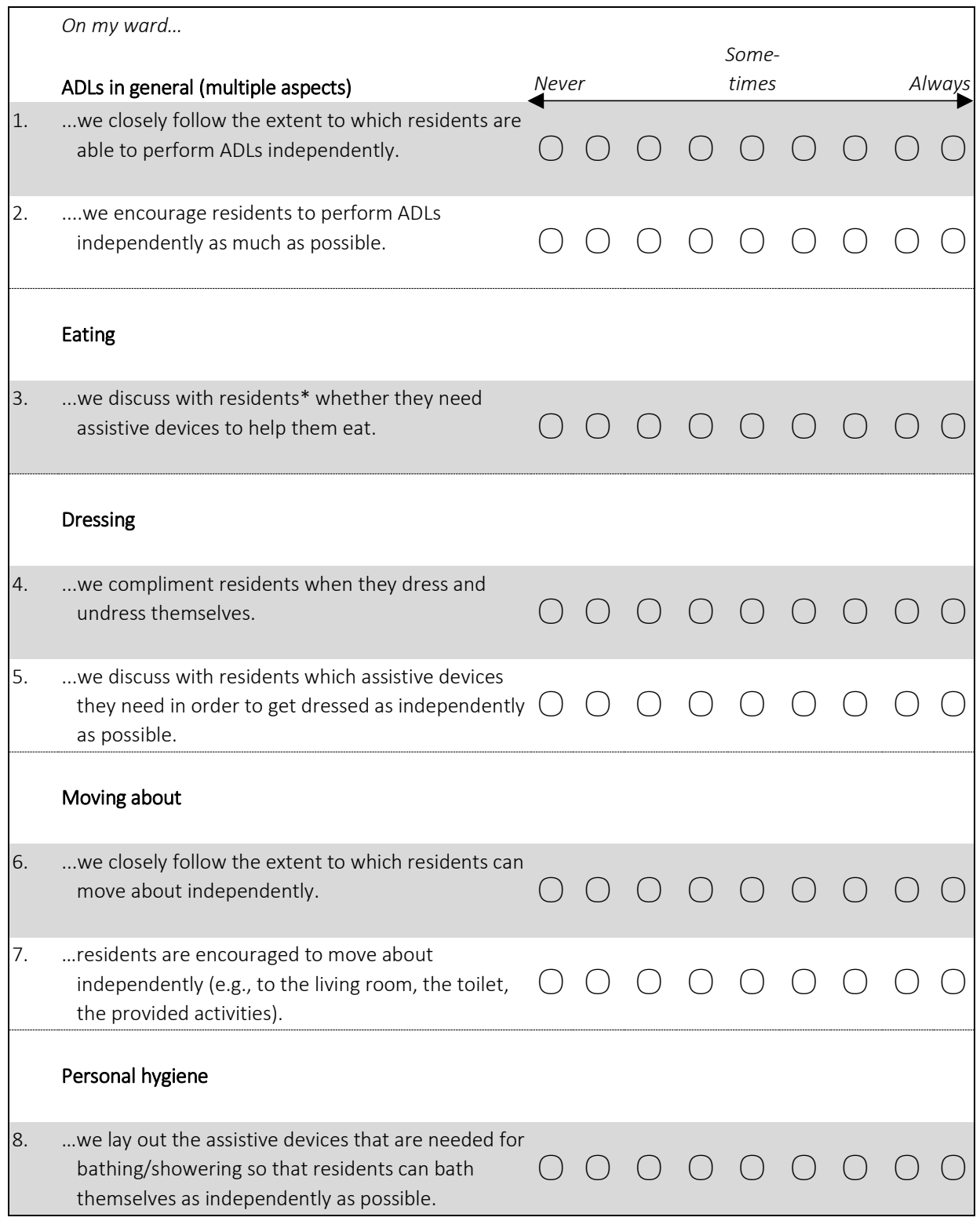

*If residents cannot give a good indication of this themselves, this can read: residents and/or family 
For the following questions, consider residents for whom this is relevant: the questions are not applicable for completely paralyzed or terminal residents.

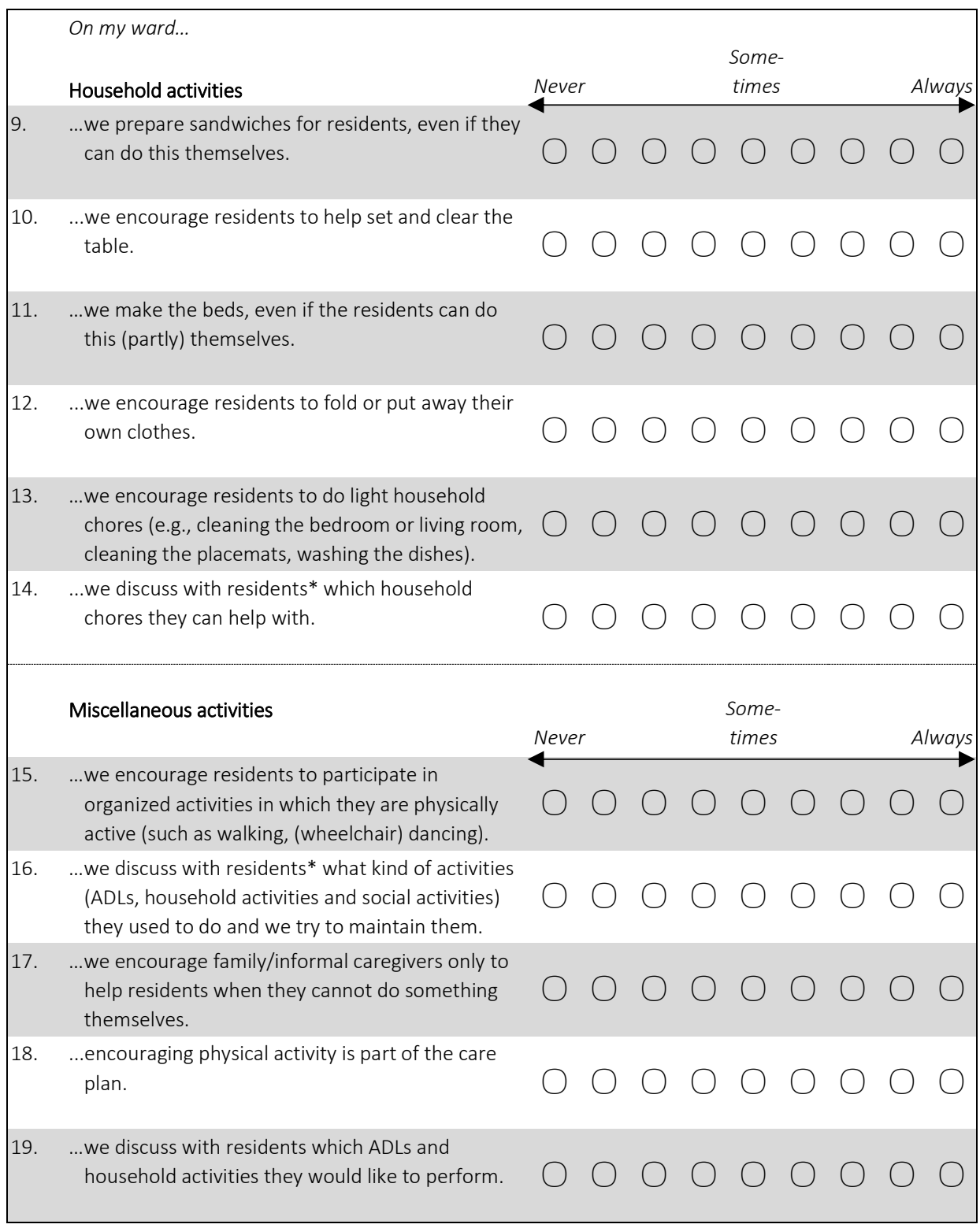

*If residents cannot give a good indication of this themselves, this can read: residents and/or family 


\section{Maintain-barriers: encouraging activity - underlying factors}

In the following statements, encouraging activity under residents is described. The terms 'physical activity' or 'activities' are used to describe the activities of daily living (ADL) or household activities performed by residents.

ADL: activities such as bathing, dressing, toileting, moving about the ward and eating Household activities: activities such as preparing breakfast and lunch, cleaning, setting the table and washing the dishes.

Please indicate for each of the following questions or statements which answer best describes how things generally work on your ward. Only cross one circle for each question. There are no right or wrong answers; we are asking about your opinion.

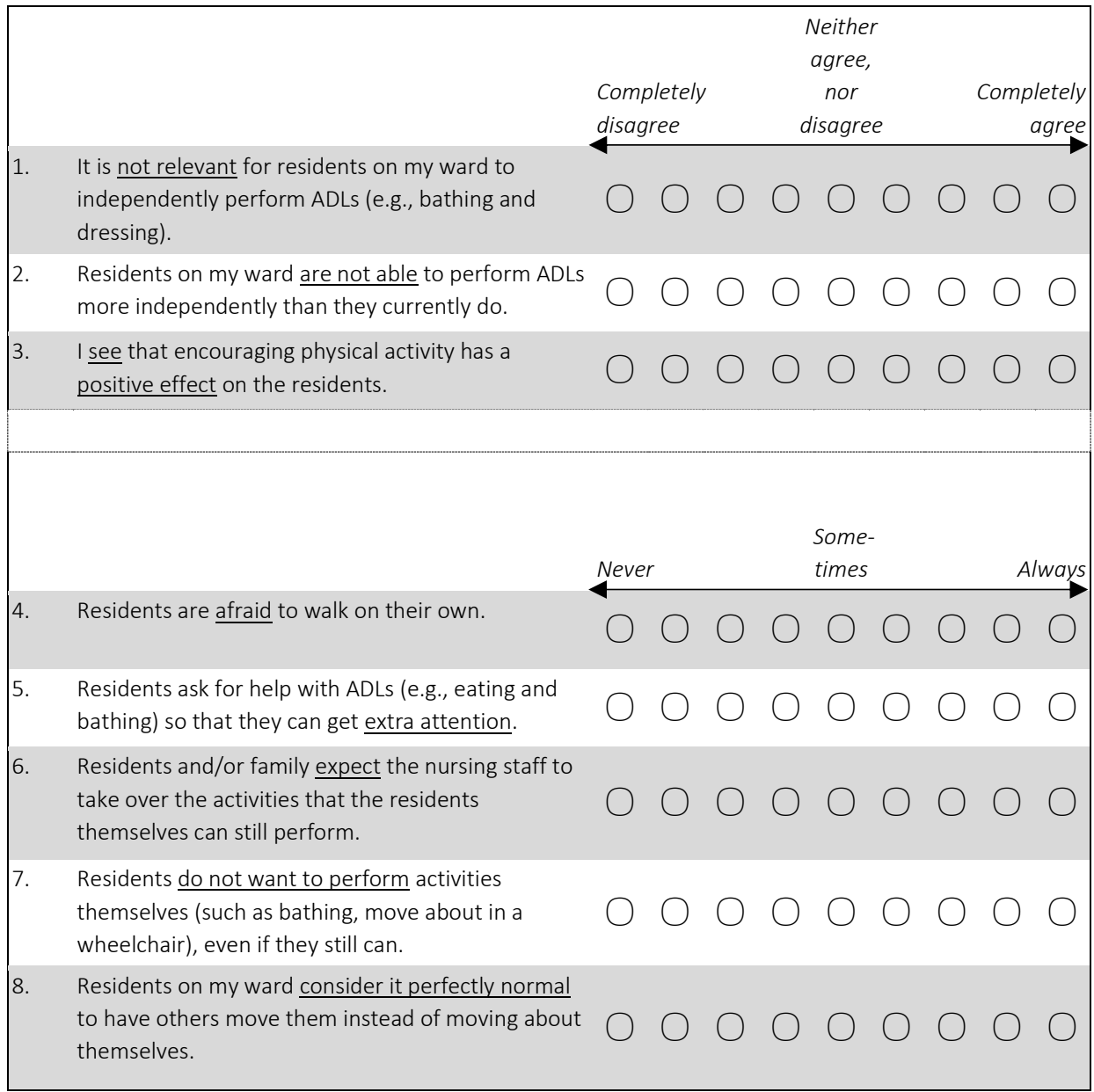




\section{Physical activity \& activities}

ADL: activities such as bathing, dressing, toileting, moving about the ward and eating

Household activities: activities such as preparing breakfast and lunch, cleaning, setting the table and washing the dishes

\section{Factors concerning the professionals: what you and your colleagues experience}

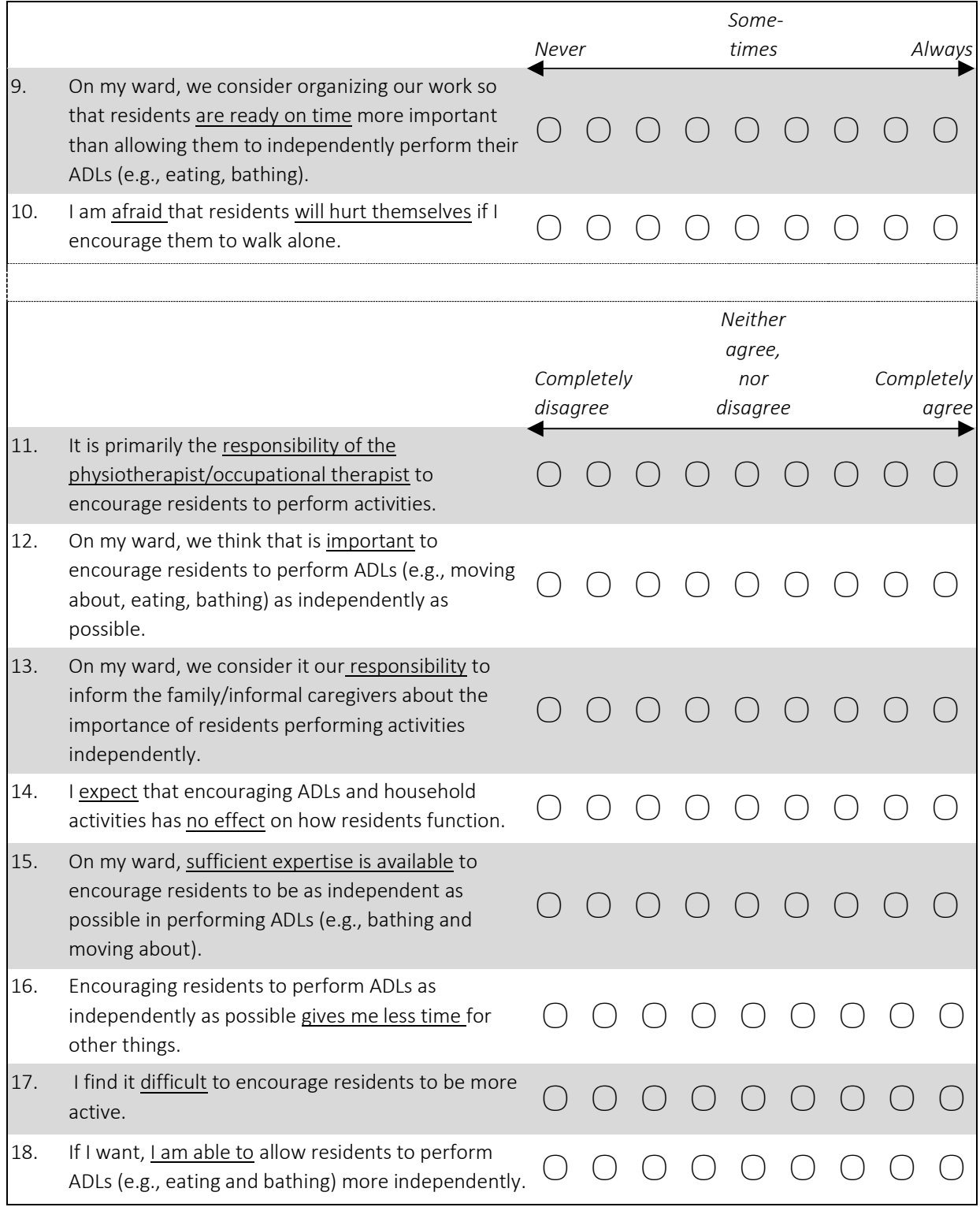




\section{Physical activity \& activities}

ADL: activities such as bathing, dressing, toileting, moving about the ward and eating

Household activities: activities such as preparing breakfast and lunch, cleaning, setting the table and washing the dishes.

\section{Factors concerning the social environment: how the team functions}

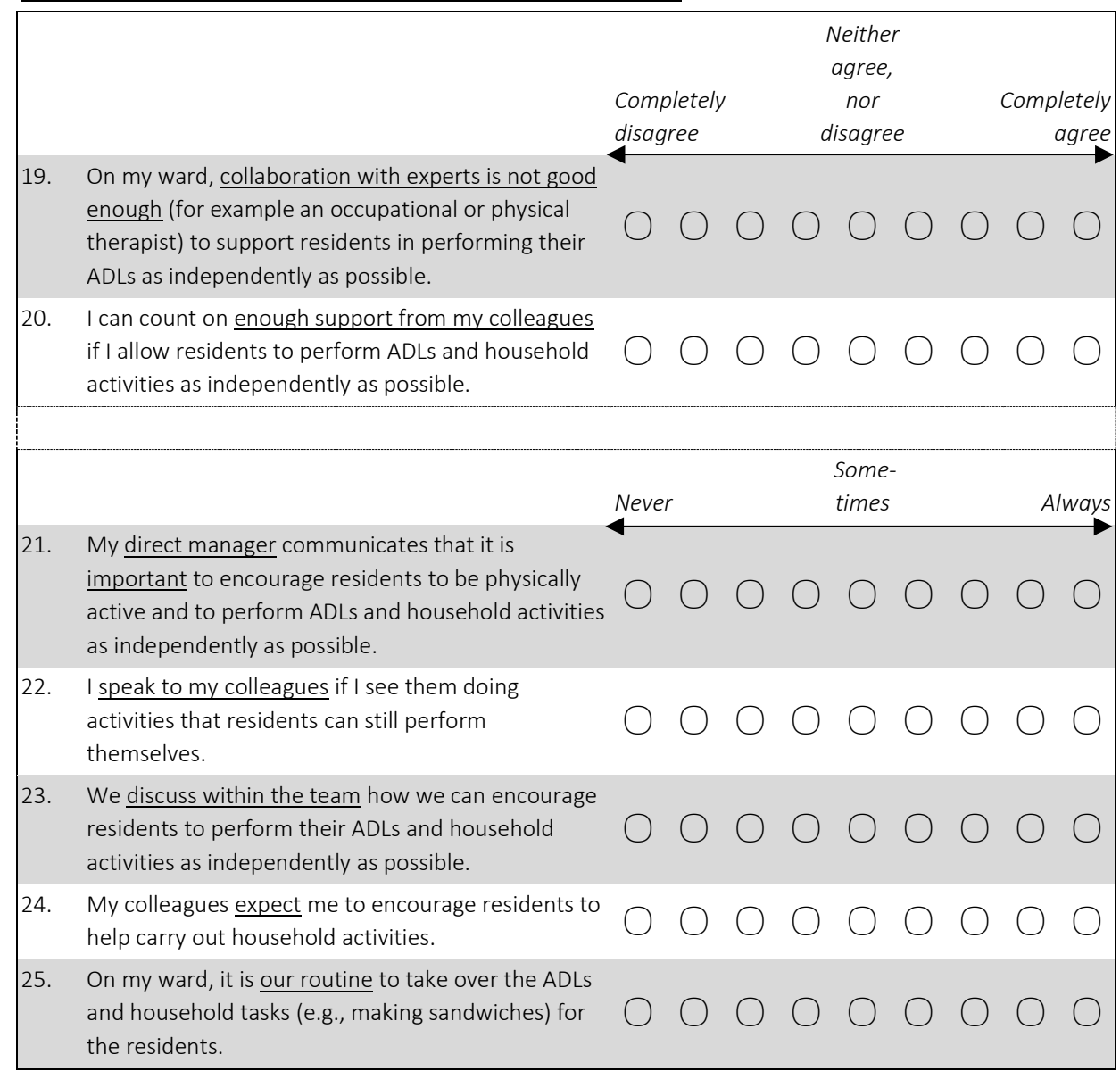




\section{Physical activity \& activities}

ADL: activities such as bathing, dressing, toileting, moving about the ward and eating

Household activities: activities such as preparing breakfast and lunch, cleaning, setting the table and washing the dishes.

\section{Factors concerning your organization: how things work in your nursing home}

\begin{tabular}{|c|c|c|}
\hline & & $\begin{array}{l}\text { Neither } \\
\text { agree, } \\
\text { nor } \\
\text { disagree }\end{array}$ \\
\hline 26. & $\begin{array}{l}\text { My organization is not geared towards involving } \\
\text { residents in doing household activities (such as } \\
\text { preparing meals and cleaning rooms). }\end{array}$ & $\bigcirc \bigcirc \bigcirc \bigcirc$ \\
\hline 27. & $\begin{array}{l}\text { There are enough people in my organization with } \\
\text { knowledge about how to encourage residents to be } \\
\text { physically active and perform activities } \\
\text { independently. }\end{array}$ & $\bigcirc$ \\
\hline 28. & $\begin{array}{l}\text { My organization offers the possibility to attend } \\
\text { internal or external courses that address how to } \\
\text { encourage physical activity among residents. }\end{array}$ & $\bigcirc \bigcirc \bigcirc 0$ \\
\hline 29. & $\begin{array}{l}\text { My organization has no agreements or guidelines } \\
\text { on how to encourage residents to be physically } \\
\text { active. }\end{array}$ & D \\
\hline 30. & $\begin{array}{l}\text { The organization has sufficient resources (e.g., } \\
\text { funding or facilities) to enable nursing staff to } \\
\text { encourage residents to be physically active. }\end{array}$ & $\bigcirc$ \\
\hline 31. & $\begin{array}{l}\text { In my organization, encouraging physical activity is } \\
\text { a high priority. }\end{array}$ & $\bigcirc \bigcirc \bigcirc \bigcirc \bigcirc \bigcirc \bigcirc \bigcirc \bigcirc$ \\
\hline 32. & $\begin{array}{l}\text { There is a structural shortage of staff available to } \\
\text { try to encourage residents to perform ADLs (e.g., } \\
\text { eating and bathing) as independently as possible. }\end{array}$ & $\bigcirc \circ \bigcirc \bigcirc \bigcirc \bigcirc \bigcirc \bigcirc \bigcirc$ \\
\hline 33. & $\begin{array}{l}\text { There is sufficient time to allow residents to } \\
\text { perform ADLs themselves (e.g., bathing, eating, and } \\
\text { dressing). }\end{array}$ & $\circ \bigcirc \bigcirc \bigcirc \bigcirc \bigcirc \bigcirc \bigcirc \bigcirc$ \\
\hline
\end{tabular}





\section{CHAPTER 3}

Do nursing staff encourage functional activity among nursing home residents?

A cross-sectional study of nursing staff

perceived behaviors and associated factors
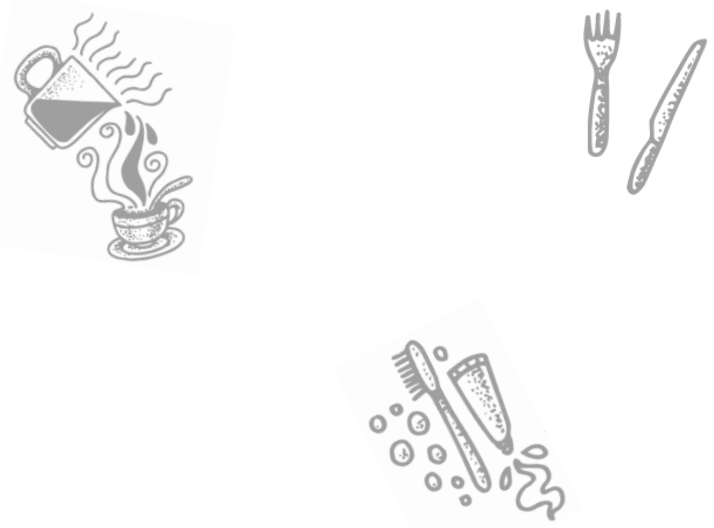

This chapter was published as:

Kuk NO, den Ouden M, Zijlstra GAR, Hamers JPH, Kempen GIJM, Bours GJJW. Do nursing staff encourage functional activity among nursing home residents? A cross-sectional study of nursing staff perceived behaviors and associated factors. BMC Geriatrics. 2017;17:18. doi: 10.1186/s12877-017-0412-9. 


\section{Abstract}

Background: Nursing home residents are mainly inactive. Nursing staff can encourage residents to perform functional activities during daily care activities. This study examines 1 ) the extent to which nursing staff perceive that they encourage functional activity in nursing home residents and 2) the associations between these nursing behaviors and professional characteristics, contextual factors, and information-seeking behaviors.

Methods: In this cross-sectional study, 368 registered nurses and certified nurse assistants, working in somatic and psychogeriatric wards of forty-one nursing homes throughout the Netherlands participated. Self-reported data were collected with a questionnaire, comprising the MAINtAIN-behaviors, which assesses the extent to which nursing staff encourage functional activities, including different activities of daily living $(A D L)$, household activities, and miscellaneous encouraging activities (e.g., discouraging informal caregivers from taking over activities residents can do themselves). Additional data collected included professional characteristics (e.g., age), contextual factors (e.g., ward type), and information-seeking behaviors (e.g., reading professional journals). Descriptive statistics were used to determine the extent to which functional activities were encouraged. Hierarchical linear regression analyses were performed to determine the associations between the encouragement of functional activities and other factors.

Results: Nursing staff perceived that household activities (mean 4.1 [scale range 1-9], SD 1.9) were less often encouraged than ADL (mean 6.9, SD 1.2) or miscellaneous activities (mean 6.7, SD 1.5). The percentage of nursing staff stating that different household activities, ADL, or miscellaneous activities were almost always encouraged ranged from $11 \%$ to $45 \%, 41 \%$ to $86 \%$, and $50 \%$ to $83 \%$ per activity, respectively. The extent to which these activities were encouraged differed for some of the professional characteristics, contextual factors, or information-seeking behaviors, but no consistent pattern in associations emerged.

Conclusions: According to nursing staff, household activities are not as often encouraged as ADL or miscellaneous activities. Professional characteristics, contextual factors, and information-seeking behaviors are not consistently associated with the encouragement of functional activity. Nursing staff should also focus on improving the encouragement of household activities. Future research could examine the role of other factors in encouraging functional activity, such as experienced barriers, and assess to what extent the perception of nursing staff corresponds with their actual behavior. 


\section{Background}

The importance of encouraging functional activity among nursing home residents is widely recognized. Research shows that being active and performing functional activities is associated with less anxiety, ${ }^{1}$ less disruptive behavior, ${ }^{1}$ higher self-esteem, ${ }^{2}$ and a higher quality of life $^{3}$ in nursing home residents. In the United States, federal regulations require the provision of care to maintain the highest level of function among nursing home residents. ${ }^{4}$ In the Netherlands, the Health Care Inspectorate emphasizes that nursing homes need to provide care that stimulates activity among residents, encouraging them to be active and perform functional activities on their own, instead of nursing staff taking over activities. ${ }^{5}$ Encouragement could take place during activities of daily living ( $A D L$ ) or during household activities, but also, for example, by discussing with the residents themselves which activities they previously conducted and motivating them to keep on performing them.

Promoting functional activity among residents is not only an opportunity nursing staff have, but also an important part of their job. In the past, nursing homes were mainly organized according to a medical model, ${ }^{6}$ in which nursing staff focused on taking care of the physical needs of residents. Currently, the autonomy of residents is crucial and more nursing homes strive to provide homelike environments, in which nursing staff encourage residents to continue their previous activities, including functional ones, as much as possible. ${ }^{7}$ In spite of this, research has shown that residents are largely inactive. ${ }^{8-10}$ Residents' participation in, for example, household activities is low. ${ }^{3,10}$ Nursing staff may be able to play a more substantial role in encouraging functional activities. ${ }^{10}$

There is a lack of research regarding the extent to which nursing staff stimulate residents to be active. In addition, it is unknown how this encouraging behavior varies. Research regarding the use of evidence-based or best practices in nursing care indicates that different factors come into play, ${ }^{11-14}$ including professional characteristics of the nursing staff, such as age, ${ }^{11}$ educational level, ${ }^{12,13}$ or years of professional experience; ${ }^{11}$ and contextual circumstances, such as staff mix $^{15}$ or ward type. ${ }^{11,12}$ In addition, studies have shown that the information-seeking behavior (for example, reading professional journals) of nursing staff may be associated with the use of evidence-based practices. $^{12,14}$

It is not known how professional characteristics, contextual factors, or informationseeking behaviors are associated with the extent to which nursing staff encourage functional activity among nursing home residents. Therefore, we have conducted a cross-sectional study with a twofold purpose: first, to examine the extent to which nursing staff in the Netherlands perceive that they encourage functional activity in nursing home residents; and, second, to examine the association between these perceptions and various professional characteristics, contextual factors, and information-seeking behaviors of nursing staff. 


\section{Methods}

\section{Context: Nursing homes in the Netherlands}

In nursing homes in the Netherlands, a distinction is made between residents with chronic physical problems, who live in somatic wards, and residents with psychogeriatric problems, such as dementia, who live in psychogeriatric wards. ${ }^{16}$ Dutch nursing homes provide more complex continuing care and monitoring compared with residential care homes. ${ }^{16}$ The meals are often taken in the wards and in many nursing homes small kitchen facilities are available in the ward, for example to prepare breakfast. The majority of the workforce in Dutch nursing homes are certified nurse assistants (CNAs) who receive three years of secondary-vocational training. In addition, care is provided by vocationally-trained or bachelor-educated registered nurses (RNs) who receive four years of training. Nursing homes are primarily non-profit organizations that are united in Actiz, the Dutch organization of healthcare providers. In contrast to some other countries, in the Netherlands there are no national databases comprising detailed information on all nursing homes (such as resident characteristics, or the number or type of staff).

\section{Design and sample}

A cross-sectional study was conducted among nursing staff of nursing homes in the Netherlands. From a list of nursing homes provided by Actiz, a random proportionate sample of 100 nursing homes was drawn by author NOK using the sampling procedure from IBM SPSS Statistics for Windows (Version 22.0. Armonk, NY: IBM Corp). Nursing homes were stratified according to five regions in the Netherlands (north, east, south, west, and central) and from each region a number of random nursing homes was drawn, proportionate to the total number of nursing homes in that region. Next, to warrant the exclusion of care homes with a single small nursing home ward, author NOK verified by telephone if the 100 selected nursing homes provided care to at least 25 somatic and/or 25 psychogeriatric nursing home residents. Twenty-five facilities were excluded because they did not meet this criterion and one nursing home no longer existed at the time of recruitment. Of the remaining 74 nursing homes, 46 agreed to participate (see Figure 3.1 for a flowchart). In this sample, nursing homes from all regions were represented, they were distributed largely according to the proportionate sample that was drawn; $11 \%$ of the nursing homes were situated in the north, $9 \%$ in the east, $39 \%$ in the south, $37 \%$ in the west, and $4 \%$ in the central region of the Netherlands. 


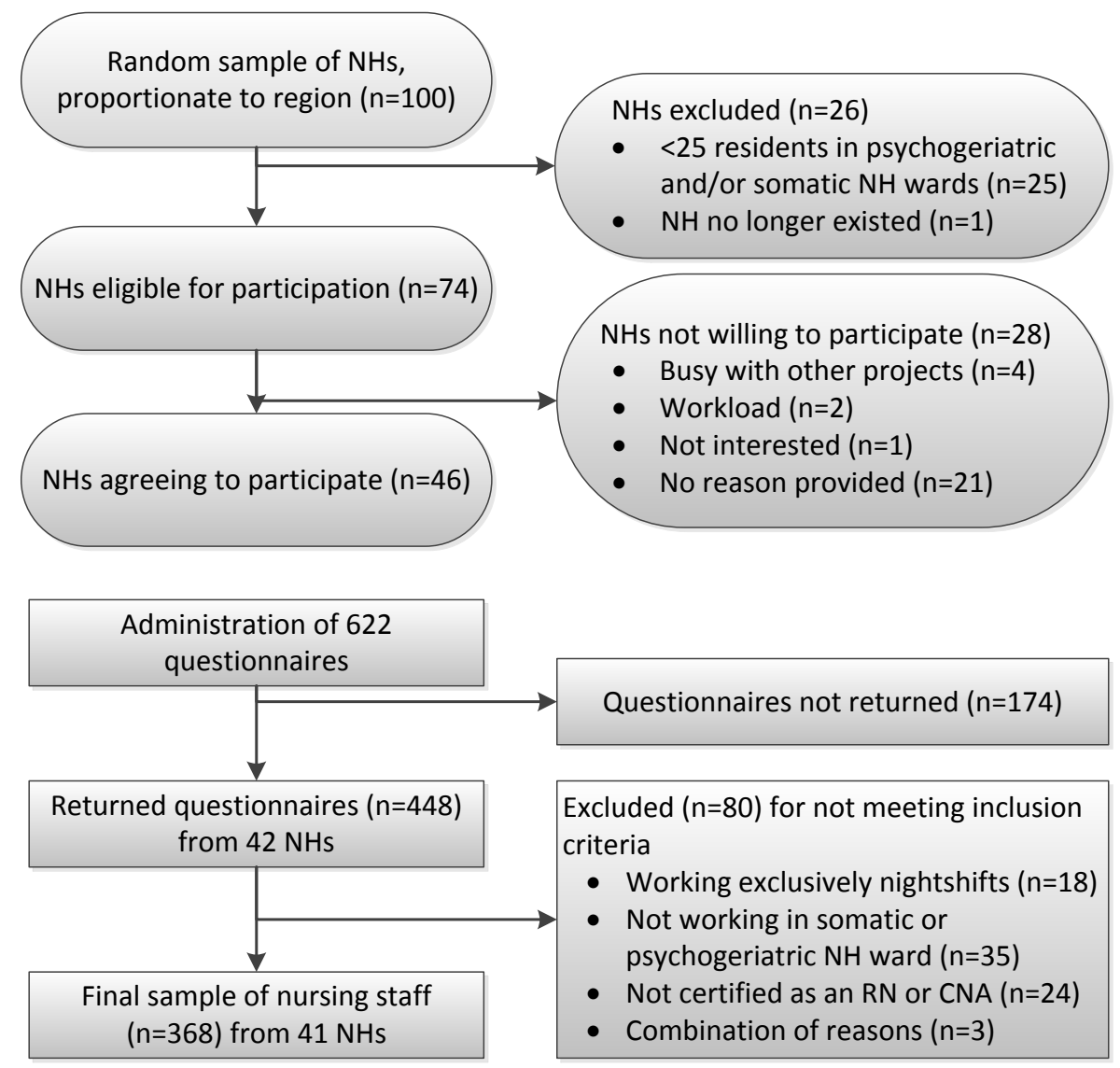

Figure 3.1. Flowchart of the study sample.

$\mathrm{CNA}=$ certified nurse assistant; $\mathrm{NH}=$ nursing home; $\mathrm{RN}=$ registered nurse.

Based on practical considerations, nursing homes with both somatic and psychogeriatric wards were asked to administer 16 questionnaires among the nursing staff (eight from each ward type); nursing homes with only one of these ward types were asked to administer ten questionnaires among the nursing staff. In total, 622 questionnaires were administered.

Nursing staff were eligible if they were RNs or CNAs. Nursing staff working exclusively on night shifts and nursing staff who did not have a contract for at least $12 \mathrm{~h}$ per week were excluded from this study because of their limited opportunities to encourage functional activities. 


\section{Data collection}

In each participating nursing home a local contact person was asked to distribute the questionnaires among eligible nursing staff, these nursing staff did not have to work on the same ward. The contact persons would collect and return the anonymouslycompleted questionnaires to the research team within two weeks. If the research team had not received the questionnaires within three weeks, they would either telephone or send an email reminder to the contact person. All data were collected in January and February 2014.

\section{Measures}

Encouragement of functional activities (dependent variables)

The MAastrlcht Nurses Activities INventory-behaviors (MAINtAIN-behaviors) questionnaire $^{17}$ was used to measure the extent to which nursing staff perceive that they encourage residents to perform functional activities. The MAINtAIN-behaviors was developed using a comprehensive method in which its usability and content validity were established in a study involving experts, nursing staff, residents and other nursing home professionals. ${ }^{17}$ The MAINtAIN-behaviors comprises three subscales assessing the degree to which nursing staff perceive they encourage residents to perform various types of activities: first, an 8-item subscale for encouraging ADL, for example, encouraging independent bathing or showering; second, a 6-item subscale for encouraging household activities, such as encouraging setting and clearing the table; third, a 5-item subscale for miscellaneous encouraging activities, such as promoting participation in organized activities, discussing and maintaining previous activities, encouraging informal caregivers not to take over activities, discussing the residents' preferred activities, and encouraging activity as part of the residents' care plan. For each item of the MAINtAIN-behaviors, respondents could rate to what extent a certain activity was encouraged in their ward ("in my ward, we encourage..."). Answer options ranged from ' 1 = never' to ' 9 = always.' Internal consistency for the subscales, using Cronbach's alpha, in the present study was 0.83 for the ADL subscale, 0.79 for the household activities subscale, and 0.77 for the miscellaneous activities subscale.

\section{Professional characteristics, contextual factors, and information-seeking behaviors}

(independent variables)

Based on literature several professional characteristics, contextual factors, and information-seeking behaviors were selected. ${ }^{11-15}$ The professional characteristics comprised gender, age ( $\leq 35$ years, $>35$ years $\leq 50,>50$ years), profession (CNA or RN), years of professional experience in the care for older persons $(\leq 10$ years, $>10$ years $\leq$ $20,>20$ years), and number of work hours per week ( $\geq 12 \mathrm{~h}$ per week $\leq 26,>26 \mathrm{~h}$ per week $<32, \geq 32 \mathrm{~h}$ per week). The contextual factors consisted of ward type 
(psychogeriatric or somatic), and staff mix (proportion of RNs in the ward, i.e., the number of RNs divided by the total number of RNs and CNAs that worked in the ward, according to the respondent).

The information-seeking behaviors included how often respondents referred to specific information sources on care problems (websites, Dutch professional journals, English-language journals, guidelines, colleagues, and experts) or how often they attended specific activities to keep their professional skills and knowledge up-to-date (conferences, courses within their organization, courses outside of their organization, clinical courses in the ward, and reading groups). The behaviors were assessed using single-item questions that were developed for this study. First, it was assessed how often respondents used specific information sources in the past three months. Second, respondents indicated how often they attended professional development activities in the past 12 months. After recoding, the answer categories for each source of information or activity comprised 'never' or ' $\geq 1$ time' in the past three or 12 months.

\section{Statistical analyses}

Descriptive statistics were used to determine percentages for the categorical variables. Mean scores and standard deviations were determined for each subscale of the MAINtAIN-behaviors. For each subscale, missing values on the items were imputed with the respondent's average score for the other items, if at least $75 \%$ of the items of that subscale had been completed. Missing values for the ADL, household, and miscellaneous subscales were imputed for a total of $4.9 \%, 2.4 \%$, and $1.9 \%$ of the respondents, respectively.

Mean scores of the three subscales were compared by conducting paired-samples ttests, with a Bonferroni correction to account for multiple testing. Additional analyses were performed to provide an overview of the extent to which respondents encouraged activity among residents. For these analyses, the answer options of the MAINtAINbehaviors items were categorized into '(almost) never' (score 1-3), 'sometimes' (score 4-6), and '(almost) always' (score 7-9).

For each independent variable (professional characteristics, contextual factors, and information-seeking behaviors) mean scores and standard deviations of the three MAINtAIN-behaviors subscales were calculated. Hierarchical linear regression analyses (random intercept) were performed to determine the association between each independent variable and each subscale of the MAINtAIN-behaviors (possible range 1-9). In each model one independent variable was used, no additional variables were added to these models. In order to account for the hierarchical structure of the data, nursing staff (level one) were grouped by nursing home (level two). For all models, estimated marginal means, standard errors, $p$-values, and intraclass correlation coefficients (ICCS) were determined. For the independent variables with three categories (i.e., age, professional experience, and work hours per week), each category 
was used as a reference for the other two categories in the analyses (i.e., the first category was compared with the second category, the second category was compared with the last category and the last category was compared with the first category). Pvalues < 0.05 were considered statistically significant. Sensitivity analyses were conducted by imputing missing values on the items of the ADL, household, and miscellaneous subscales with 1 and with 9 instead of the respondent's average score of the other items within that scale. All statistical analyses were performed using IBM SPSS Statistics for Windows (Version 22.0. Armonk, NY: IBM Corp).

\section{Results}

\section{Sample characteristics}

A total of 448 respondents from 42 nursing homes completed the MAINtAIN-behaviors (response rate $72 \%$; range per nursing home $50-100 \%$ ), but 80 questionnaires had to be excluded, because the respondents did not meet the inclusion criteria (see Figure 3.1). The 368 eligible respondents represented 41 nursing homes (sample characteristics are displayed in Table 3.1); 275 (75\%) of them were CNAs and 231 (63\%) worked in a psychogeriatric ward. Information-seeking behaviors varied, e.g., 5\% had searched for information in an English-language journal in the past three months, whereas $99 \%$ had consulted a colleague.

Table 3.1. Sample characteristics $\left(N=368^{*}\right)$.

\begin{tabular}{lcc}
\hline & $N$ & $(\%)$ \\
\hline Professional characteristics & & \\
Gender & & \\
Female & 346 & $(94)$ \\
Age & & \\
$\leq 35$ years & 116 & $(33)$ \\
$>35$ years $\leq 50$ & 141 & $(40)$ \\
$>50$ years & 95 & $(27)$ \\
Profession/educational level & & \\
CNA & 275 & $(75)$ \\
RN & 93 & $(25)$ \\
Professional experience & & \\
$\leq 10$ years & 127 & $(38)$ \\
$>10$ years $\leq 20$ & 100 & $(30)$ \\
$>20$ years & 108 & $(32)$ \\
\hline
\end{tabular}




\begin{tabular}{lll}
\hline & $N$ & $(\%)$ \\
\hline Work hours per week & 109 & $(30)$ \\
$\geq 12$ hours per week $\leq 26$ & 83 & $(23)$ \\
$>26$ hours per week $<32$ & 169 & $(47)$ \\
$\geq 32$ hours per week & & \\
& & \\
Contextual factors & & \\
Ward type & 231 & $(63)$ \\
Psychogeriatric ward & 137 & $(37)$ \\
Somatic ward & & \\
Staff mix: proportion of RNs in the ward & 153 & $(49)$ \\
$\leq 0.11$ & 160 & $(51)$ \\
$>0.11$ & & \\
Information-seeking behaviors & & \\
$\geq 1 x$ past three months & & \\
Reading on websites & 68 & $(19)$ \\
Reading Dutch professional journals & 171 & $(49)$ \\
Reading English-language journals & 16 & $(5)$ \\
Reading guidelines & 343 & $(96)$ \\
Consulting a colleague & 358 & $(99)$ \\
Consulting an expert & 276 & $(75)$ \\
1x past year & & $(31)$ \\
Attending a conference & 133 & $(38)$ \\
Attending a course within the organization & 254 & $(70)$ \\
Participating in a clinical course in the ward & 15 & $(4)$ \\
Participating in a reading group regarding care & & \\
\hline
\end{tabular}

$\mathrm{CNA}=$ certified nurse assistant; $\mathrm{RN}$ = vocationally-trained or bachelor-educated registered nurse.

${ }^{*} \mathrm{~N}$ does not always add up to 368 due to missing data.

\section{Encouragement of functional activities}

Table 3.2 displays the perceived encouragement of functional activities. The mean scores for the ADL subscale, the household activities subscale, and the miscellaneous activities subscale were 6.9 (SD 1.2), 4.1 (SD 1.9), and 6.7 (SD 1.5), respectively, out of a theoretical range from 1 to 9 . These mean subscale scores differed significantly from each other ( $p<0.001$ for all comparisons after Bonferroni correction). More than half of the respondents (66-86\%) stated that ADL were (almost) always encouraged, but the 
need for assistive devices for independent dressing was not always discussed (41\%). Less than half of the respondents reported that household activities were (almost) always encouraged (ranging from 11\% for folding or putting away clothes to $45 \%$ for preparing sandwiches). Regarding miscellaneous encouraging activities, the majority of the respondents (50-83\%) indicated that all activities were (almost) always performed. For example, according to $83 \%$ of the respondents, residents were (almost) always encouraged to participate in organized activities, such as wheelchair dancing.

Table 3.2. Perceived encouragement of ADL, household activities, and miscellaneous activities: means and item-scores per subscale $\left(N=368^{*}\right)$.

\begin{tabular}{|c|c|c|c|}
\hline Subscales & & Mean \pm SD & \\
\hline$A D L$ & & $6.9 \pm 1.2$ & \\
\hline Household activities & & $4.1 \pm 1.9$ & \\
\hline \multirow[t]{4}{*}{ Miscellaneous activities } & & $6.7 \pm 1.5$ & \\
\hline & (Almost) & & (Almost) \\
\hline & never & Sometimes & always \\
\hline & $N(\%)$ & $N(\%)$ & $N(\%)$ \\
\hline \multicolumn{4}{|l|}{ Items ADL subscale } \\
\hline Closely follow independent ADL performance & $14(4)$ & $109(30)$ & $243(66)$ \\
\hline Encourage independent performance of ADLs & $11(3)$ & $92(25)$ & $263(72)$ \\
\hline Discuss assistive devices for eating & $31(8)$ & $93(25)$ & $242(66)$ \\
\hline Compliment residents on dressing and undressing & $11(3)$ & $58(16)$ & $297(81)$ \\
\hline Discuss assistive devices for independent dressing & $89(24)$ & $126(34)$ & $151(41)$ \\
\hline Closely follow independent movement & $1(<1)$ & $61(17)$ & $304(83)$ \\
\hline Encourage independent movement & $6(2)$ & $46(13)$ & $314(86)$ \\
\hline Provide assistive devices for bathing & $25(7)$ & $89(24)$ & $252(70)$ \\
\hline \multicolumn{4}{|l|}{ Items household activities subscale } \\
\hline Prepare sandwiches & $51(14)$ & $149(41)$ & $166(45)$ \\
\hline Encourage setting and clearing the table & $89(24)$ & $120(33)$ & $157(43)$ \\
\hline Make the beds & $204(56)$ & $94(26)$ & $68(19)$ \\
\hline Encourage folding or putting away clothes & $222(61)$ & $104(28)$ & $39(11)$ \\
\hline Encourage light household activities & $175(48)$ & $108(30)$ & $82(22)$ \\
\hline Discuss with residents household chores they can help with & $166(45)$ & $116(32)$ & $84(23)$ \\
\hline \multicolumn{4}{|l|}{ Items miscellaneous activities subscale } \\
\hline Encourage participation in organized activities & $8(2)$ & $56(15)$ & $302(83)$ \\
\hline Discuss and maintain the residents' previous activities & $23(6)$ & $100(27)$ & $242(66)$ \\
\hline $\begin{array}{l}\text { Encourage family/informal caregivers to only help } \\
\text { residents when they cannot do something themselves }\end{array}$ & $47(13)$ & $135(37)$ & $183(50)$ \\
\hline Encouraging physical activity is part of care plan & $35(10)$ & $98(27)$ & $233(64)$ \\
\hline Discuss preferred activities & $60(16)$ & $105(29)$ & $201(55)$ \\
\hline
\end{tabular}

$\mathrm{ADL}=$ activities of daily living.

*N does not always add up to 368 due to missing data. Answers scored on the 9-point scale were categorized into '(almost) never' (scores 1-2-3), 'sometimes' (4-5-6) and '(almost) always' (7-8-9).

Mean subscale scores are calculated based on the means of the original 9-point scale scores of all the items within that subscale; the scores can range from 1 (never encouraged) to 9 (always encouraged). 


\section{Factors associated with the perceived encouragement of functional activity}

Table 3.3 shows the unadjusted mean scores for the ADL activities subscale, for the household activities subscale, and for the miscellaneous activities subscale per professional characteristic and contextual factor. These scores are similar to the estimated marginal means that resulted from the hierarchical linear regression analyses, therefore, only the unadjusted means are presented. The largest difference in the perceived encouragement of activities, in particular household activities, was between respondents working in different ward types. The hierarchical linear regression analyses showed that respondents working in psychogeriatric wards reported significantly more often that household activities were encouraged compared with respondents working in somatic wards $(p<0.001$, mean score 4.8, SD 1.6 and 3.7, SD 1.6, respectively). The perceived encouragement of miscellaneous activities also differed significantly between respondents from psychogeriatric and from somatic wards, but the difference was smaller ( $p=0.001$, mean score 6.9, SD 1.4 and 6.4, SD 1.4, respectively). As Table 3.3 shows, the only other professional characteristics or contextual factors significantly associated with the encouragement of activities were age and work hours per week (associated with the subscale of miscellaneous activities).

Table 3.3. Mean encouragement of ADL, household activities and miscellaneous activities per professional characteristic and contextual factor.

\begin{tabular}{|c|c|c|c|c|c|c|}
\hline & \multicolumn{2}{|c|}{ ADL subscale } & \multicolumn{2}{|c|}{$\begin{array}{l}\text { Household } \\
\text { activities subscale }\end{array}$} & \multicolumn{2}{|c|}{$\begin{array}{l}\text { Miscellaneous } \\
\text { activities subscale }\end{array}$} \\
\hline & \multicolumn{2}{|c|}{$\operatorname{Mean}^{\mathrm{a}} \pm$ SD } & \multicolumn{2}{|c|}{ Mean $^{a} \pm$ SD } & \multicolumn{2}{|c|}{ Mean $^{a} \pm S D$} \\
\hline \multicolumn{7}{|l|}{ Gender } \\
\hline Male & 6.9 & \pm 1.2 & 4.5 & \pm 1.8 & 6.6 & \pm 1.3 \\
\hline Female & 7.0 & \pm 1.2 & 4.4 & \pm 1.7 & 6.7 & \pm 1.5 \\
\hline \multicolumn{7}{|l|}{$\mathrm{Age}^{\mathrm{b}}$} \\
\hline$\leq 35$ years & 6.9 & \pm 1.2 & 4.2 & \pm 1.6 & $6.5^{c}$ & \pm 1.5 \\
\hline$>35$ years $\leq 50$ & 7.1 & \pm 1.1 & 4.6 & \pm 1.7 & $6.9^{c}$ & \pm 1.3 \\
\hline$>50$ years & 7.1 & \pm 1.3 & 4.4 & \pm 1.8 & 6.7 & \pm 1.6 \\
\hline \multicolumn{7}{|c|}{ Profession/educational level } \\
\hline CNA & 7.1 & \pm 1.2 & 4.4 & \pm 1.7 & 6.8 & \pm 1.5 \\
\hline RN & 6.9 & \pm 1.2 & 4.4 & \pm 1.8 & 6.5 & \pm 1.4 \\
\hline \multicolumn{7}{|c|}{ Professional experience ${ }^{b}$} \\
\hline$\leq 10$ years & 7.0 & \pm 1.2 & 4.3 & \pm 1.7 & 6.7 & \pm 1.5 \\
\hline$>10$ years $\leq 20$ & 6.9 & \pm 1.2 & 4.3 & \pm 1.7 & 6.6 & \pm 1.6 \\
\hline$>20$ years & 7.1 & \pm 1.2 & 4.6 & \pm 1.8 & 6.8 & \pm 1.4 \\
\hline
\end{tabular}




\begin{tabular}{|c|c|c|c|c|c|c|}
\hline & \multicolumn{2}{|c|}{ ADL subscale } & \multicolumn{2}{|c|}{$\begin{array}{l}\text { Household } \\
\text { activities subscale }\end{array}$} & \multicolumn{2}{|c|}{$\begin{array}{l}\text { Miscellaneous } \\
\text { activities subscale }\end{array}$} \\
\hline & \multicolumn{2}{|c|}{$\operatorname{Mean}^{a} \pm S D$} & \multicolumn{2}{|c|}{$\operatorname{Mean}^{a} \pm S D$} & \multicolumn{2}{|c|}{ Mean $^{\mathrm{a}} \pm$ SD } \\
\hline \multicolumn{7}{|l|}{ Work hours per week ${ }^{b}$} \\
\hline$\geq 12$ hours per week $\leq 26$ & 7.0 & \pm 1.2 & 4.3 & \pm 1.5 & 6.6 & \pm 1.4 \\
\hline$>26$ hours per week $<32$ & 7.0 & \pm 1.0 & 4.5 & \pm 1.7 & $6.5^{\mathrm{d}}$ & \pm 1.5 \\
\hline$\geq 32$ hours per week & 7.0 & \pm 1.3 & 4.4 & \pm 1.9 & $6.9^{d}$ & \pm 1.4 \\
\hline \multicolumn{7}{|l|}{ Contextual factors } \\
\hline \multicolumn{7}{|l|}{ Ward type } \\
\hline Psychogeriatric ward & 7.1 & \pm 1.2 & $4.8^{\mathrm{e}}$ & \pm 1.6 & $6.9^{d}$ & \pm 1.4 \\
\hline Somatic ward & 6.9 & \pm 1.2 & $3.7^{\mathrm{e}}$ & \pm 1.6 & $6.4^{d}$ & \pm 1.4 \\
\hline \multicolumn{7}{|c|}{ Staff mix: proportion of nurses in the ward } \\
\hline$\leq 0.11$ & 7.0 & \pm 1.2 & 4.4 & \pm 1.7 & 6.8 & \pm 1.5 \\
\hline$>11$ & 7.0 & \pm 1.2 & 4.4 & \pm 1.8 & 6.6 & \pm 1.4 \\
\hline
\end{tabular}

CNA = certified nurse assistant; RN = vocationally-trained or bachelor-educated registered nurse.

a Unadjusted means are presented, these are similar to the estimated marginal means resulting from the hierarchical linear regression analyses (random intercept; level 1 - nursing staff, level 2 - nursing home) between each independent variable and each subscale of the MAINtAIN-behaviors (range 1-9). Indicated statistical significant differences $(p<0.05)$ are based on these analyses. No additional variables were added to the models. ICCs range from 0.06-0.10, 0.16-0.19 and 0.02-0.05 for the models with the outcome measure $\mathrm{ADL}$, household activities and miscellaneous activities, respectively. ${ }^{\mathrm{b}}$ For variables with three categories, each category was used as a reference for the other two. Because of these variables and to increase the comprehensibility of the table, no $p$-values are presented. ' Statistical significant differences between age 's 35 years' and '> 35 years $\leq 50$.' ' Statistical significant difference between working '> 26 hours per week < 32 ' and ' $\geq 32$ hours per week.' ' Statistical significant difference between psychogeriatric ward and somatic ward. Due to missing data, sample size for each analysis varies from 311 to 366.

Table 3.4 presents the unadjusted mean scores for the functional activity subscales for each information-seeking behavior. Again, these mean scores were similar to the estimated marginal means resulting from the hierarchical linear regression analyses. On the whole, few of the information-seeking behaviors were significantly associated with the encouragement of functional activities, most of the associations found were with the encouragement of household activities. The hierarchical linear regression analyses revealed that respondents who searched on websites, attended conferences, participated in clinical courses in the ward, or in reading groups regarding care reported significantly more encouragement of household activities in their wards.

Sensitivity analyses in which missing values on the functional activity subscales were imputed with either 'one' or 'nine' showed similar results for the analyses with the professional characteristics and contextual factors, as well as for the analyses with the information-seeking behaviors. 
ENCOURAGEMENT OF FUNCTIONAL ACTIVITY \& ASSOCIATED FACTORS

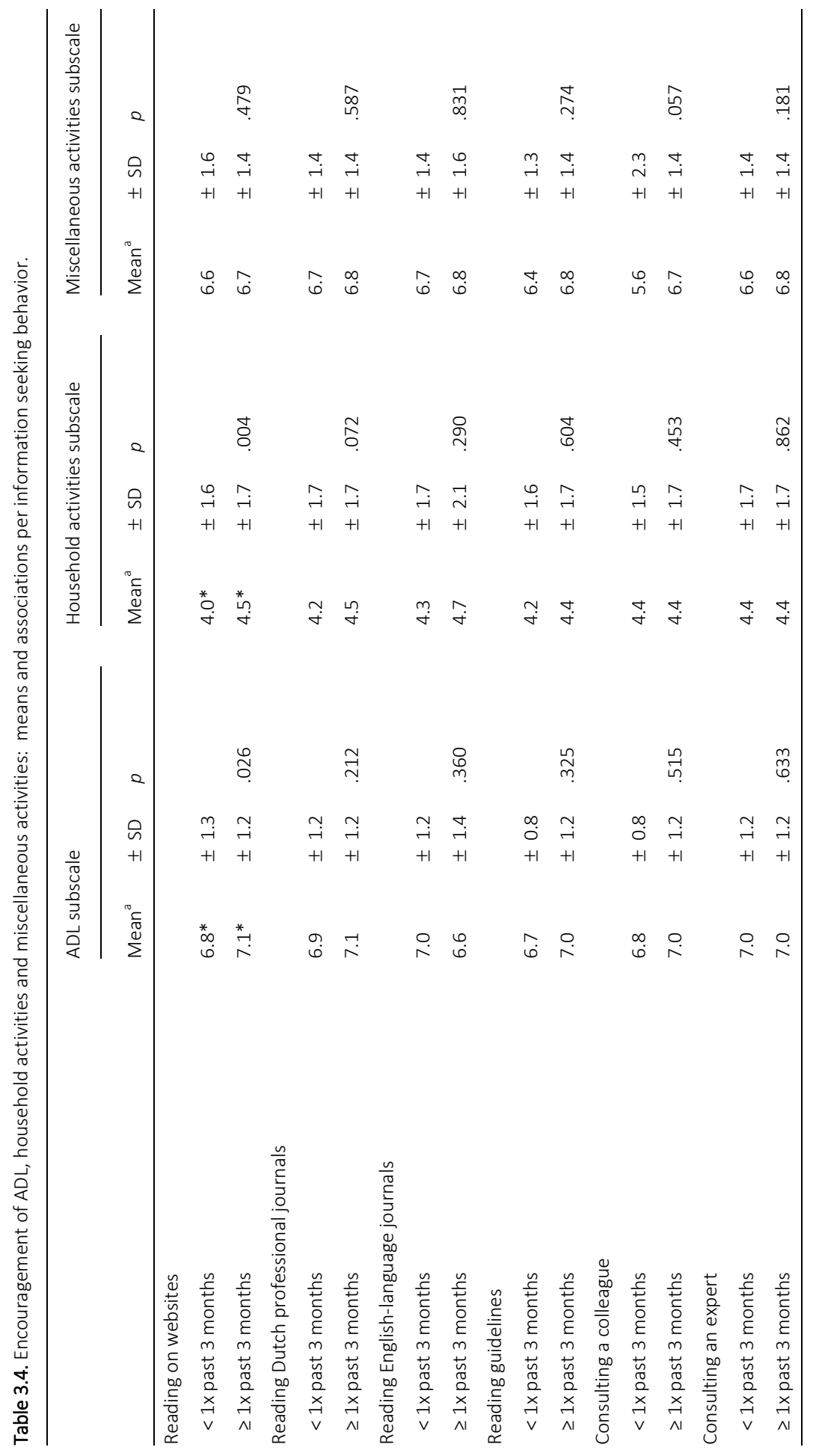




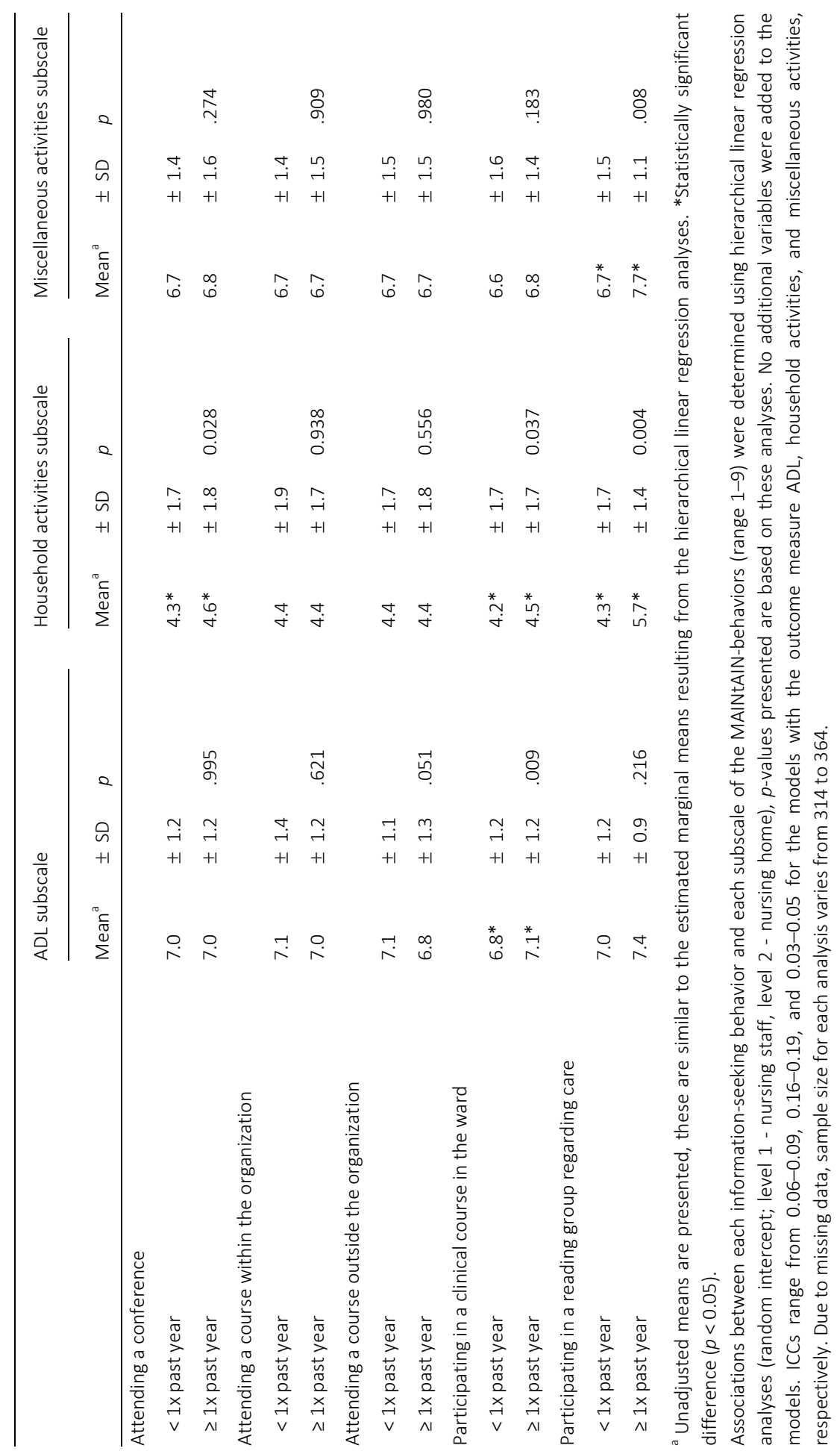




\section{Discussion}

This study showed that, according to nursing staff, household activities are not as often encouraged among residents as ADL or miscellaneous activities are. Some professional characteristics, contextual factors, and information-seeking behaviors were associated with the perceived encouragement of functional activity. However, no consistent pattern has emerged.

Although no previous research has analyzed the extent to which functional activities are encouraged by nursing staff, there are studies looking into the behavior of residents. These show that residents are largely inactive and rarely participate in household activities. ${ }^{3,10}$ For example, in an observation study among residents of seven nursing homes in the south of the Netherlands, Den Ouden et al. ${ }^{10}$ showed that residents were engaged in household activities, but only in less than $3 \%$ of their observations. This percentage is lower than one would expect, given the results of the present study, in which $39 \%$ to $86 \%$ of the nursing staff stated that certain household activities were encouraged- at least sometimes. The differences between the two studies are quite large and may be explained by the different concepts measured, i.e., perceptions of nursing staff versus behavior by residents, and by the difference in the respective samples, i.e., randomly selected nursing homes throughout the Netherlands versus a convenience sample of nursing homes in the south of the Netherlands. Another explanation may be that encouragement by nursing staff does not always result in increased functional activity among residents.

The finding that household activities were not often encouraged, compared with $A D L$, or miscellaneous activities, contrasts with the culture change ${ }^{7}$ that is currently taking place in many nursing homes across the world. Nowadays, many nursing homes strive to maintain the meaningful activities residents previously conducted, including household activities. ${ }^{18-20}$ In some nursing homes, it is expected that nursing staff prepare dinner together with residents. ${ }^{18}$ In the Netherlands, this care philosophy particularly occurs in (small-scale) psychogeriatric wards. ${ }^{18}$ Indeed, in the present study, nursing staff from psychogeriatric wards stated significantly more often that household activities were encouraged, compared with nursing staff from somatic wards.

In this study, few associations were found between professional characteristics, contextual factors, and information-seeking behaviors, and the perception whether or not functional activities were encouraged. Associations that were found were inconsistent; factors that were associated with the perceived encouragement of household activities were not associated with the perceived encouragement of ADL. Furthermore, factors that were significantly associated with this perceived encouragement reflected relatively small differences. The different kinds of measures that were used in this study may explain the inconsistent findings. Encouraging functional activities refers to specific behaviors (i.e., specific daily activities), while the information-seeking behaviors were measured on a more general level. For example, 
respondents were asked if they attended courses in general, they were not asked if they attended courses focused on the encouragement of functional activities. Searching for information in a specific area does not necessarily imply knowledgeability about the encouragement of functional activities. In addition, although we carefully selected our independent variables drawing on previous studies, ${ }^{11-15}$ it might be that the professional characteristics, contextual factors, or information-seeking behaviors used are not the most important factors for encouraging functional activity. Perhaps more closelyrelated factors, specific barriers or facilitators, such as the perceived capabilities of residents, support of colleagues, ${ }^{17,21}$ or the availability of domestic facilities in the wards determine whether or not functional activities are encouraged.

The findings of this study indicate that nursing staff prefer sources that allow interaction, such as colleagues or clinical lessons, over traditional sources of knowledge, such as journals. This is in accordance with previous research investigating the knowledge sources of nursing staff. ${ }^{22}$ Given the relatively low educational level of nursing staff in nursing homes, it is not surprising that only few nurses in this study actively searched for written information. However, to warrant the quality of care in nursing homes, it is important that evidence-based or best practices reach the nursing staff. To ensure that nursing staff encourage functional activity, nursing homes need to use strategies that meet the preferences and competences of their nursing staff. Changing nursing behavior may be best done by using interactive strategies. To achieve this, it is essential that people with the appropriate knowledge and skills are available in the nursing home.

For this study, a proportionate random sample of nursing homes was drawn from different regions within the Netherlands, resulting in a, from a national perspective, large sample representing nursing home staff throughout the country. This is one of the few studies in the Netherlands that involved so many nursing homes. Most of the nursing homes that agreed to participate in this study were situated in the south of the Netherlands and least in the central region; their distribution was largely similar to the proportionate random sample that was drawn. The results of this study can be used as a reference for other researchers or nursing homes that want to use the MAINtAINbehaviors to measure the extent to which nursing staff perceive to encourage functional activities. However, the population in the present study might not be entirely representative for nursing home staff in other countries. The majority of the nursing staff participating in this study were CNAs, who are comparable to the licensed practical nurses in the United States. ${ }^{23}$ Dutch CNAs receive a three-year secondary-vocational training. In contrast, for example, in the United States the majority of the nursing home staff are nursing assistants who receive a minimal training of $75 \mathrm{~h}^{24,25}$ 


\section{Limitations}

The present study has a cross-sectional design; therefore, no causal relationships could be assessed. In addition, the aim of this study was to assess the extent to which nursing staff perceive that they encourage functional activity; therefore it assessed nursing staff perceptions, which may not necessarily be the same as the extent to which they actually encourage functional activity. Furthermore, respondents were asked to reflect upon their ward ("in my ward, we encourage..."), which might not always completely correspond to their own personal behavior. For a more objective perspective, observations could be conducted regarding the extent to which nursing staff encourage functional activities. Moreover, other contextual factors, such as the availability of specific domestic facilities, could also have been included in this study.

\section{Implications for research and practice}

The present study examined the association between professional characteristics, contextual factors, and information-seeking behaviors, and the perceived encouragement of functional activity. Future studies could consider factors that are possibly more closely-linked to the encouragement of functional activities, for example specific barriers or facilitators nursing staff perceive towards encouraging functional activity (e.g., capabilities of residents, self-efficacy of nursing staff, support of colleagues, or time constrains ${ }^{17,26,27}$ ). Furthermore, future studies could examine how the perception of nursing staff corresponds with their actual behavior, and if increased encouragement by nursing staff leads to improved functional activity among residents.

This study showed that household activities were less often encouraged than other activities, according to the nursing staff. Performing household activities is associated with a higher quality of life among nursing home residents. ${ }^{3}$ Here lies an opportunity for nursing homes; nursing homes could focus on improving the extent to which household activities are encouraged and nursing staff should be aware of the importance of these kinds of activities.

\section{Conclusion}

The findings of this study show that, according to the nursing staff, most household activities are not often encouraged by a large proportion of the nursing home staff. ADL and miscellaneous activities are more often perceived to be encouraged. Professional characteristics, contextual factors, and information-seeking behaviors are not consistently associated with the encouragement of functional activity. Future studies aimed at improving the encouragement of functional activity could focus on the encouragement of household activities, the association between perceptions and actual 
behavior of nursing staff, and potential barriers and facilitators for encouraging residents to participate in functional activities. Furthermore, studies providing insight into whether or not encouragement of functional activity by nursing staff leads to improved functional activity among nursing home residents are necessary. 


\section{References}

1. Resnick B, Galik E, Boltz M. Function focused care approaches: Literature review of progress and future possibilities. J Am Med Dir Assoc. 2013;14(5):313-318.

2. Blair CE. Effect of self-care adls on self-esteem of intact nursing home residents. Issues Ment Health Nurs. 1997;20(6):559-570.

3. Edvardsson D, Petersson L, Sjogren K, Lindkvist M, Sandman PO. Everyday activities for people with dementia in residential aged care: Associations with person-centredness and quality of life. Int J Older People Nurs. 2014;9(4):269-276.

4. Omnibus Budget Reconciliation Act OBRA, Subtitle C. Nursing Home Reform Act. Publ. No. PL 100-203. 1987, Washington DC, US Government Printing Office.

5. Inspectie voor de Gezondheidszorg (Dutch Health Care Inspectorate). In: State of health care 2012 Prevention in curative and long-term care: The need for vulnerable groups. [In Dutch: Staat van de gezondheidszorg 2012. Preventie in de curatieve en langdurige zorg: Noodzaak voor kwetsbare groepen]. 2012. https://www.rijksoverheid.nl/documenten/rapporten/2012/11/29/staat-van-degezondheidszorg-2012 Accessed 25 April 2016.

6. White-Chu EF, Graves WJ, Godfrey SM, Bonner A, Sloane P. Beyond the medical model: The culture change revolution in long-term care. J Am Med Dir Assoc. 2009;10(6):370-378.

7. Rahman AN, Schnelle JF. The nursing home culture-change movement: Recent past, present, and future directions for research. Gerontologist. 2008;48(2):142-148.

8. MacRae PG, Schnelle JF, Simmons SF, Ouslander JG. Physical activity levels of ambulatory nursing home residents. J Aging Phys Activ. 1996;4:264-278.

9. Ice, GH. Daily life in a nursing home: Has it changed in 25 years? J Aging Stud. 2002;16(4):345-359.

10. den Ouden M, Bleijlevens MH, Meijers JM, et al. Daily (in)activities of nursing home residents in their wards: An observation study. J Am Med Dir Assoc. 2015;16(11):963-968.

11. Estabrooks CA, Squires JE, Hayduk L, et al. The influence of organizational context on best practice use by care aides in residential long-term care settings. J Am Med Dir Assoc. 2015;16(6):537 e1-10.

12. Squires JE, Estabrooks CA, Gustavsson P, Wallin L. Individual determinants of research utilization by nurses: A systematic review update. Implement Sci. 2011;6:1.

13. Eizenberg MM. Implementation of evidence-based nursing practice: Nurses' personal and professional factors? J Adv Nurs. 2011;67(1):33-42.

14. Milner M, Estabrooks CA, Myrick F. Research utilization and clinical nurse educators: A systematic review. J Eval Clin Pract. 2006;12(6):639-655.

15. Backhaus R, Verbeek H, van Rossum E, Capezuti E, Hamers JP. Nurse staffing impact on quality of care in nursing homes: A systematic review of longitudinal studies. J Am Med Dir Assoc. 2014;15(6):383-393.

16. Schols JMGA, Crebolder HFJM, van Weel C. Nursing home and nursing home physician: The Dutch experience. J Am Med Dir Assoc. 2004;5(3):207-212.

17. Kuk NO, Zijlstra GAR, Bours GJJW, Hamers JPH, Kempen GIJM. Development and usability of the MAINtAIN, an inventory assessing nursing staff behavior to optimize and maintain functional activity among nursing home residents: A mixed-methods approach. BMC Health Serv Res. 2016;16:38.

18. Verbeek H, van Rossum E, Zwakhalen SM, Kempen GI, Hamers JP. Small, homelike care environments for older people with dementia: A literature review. Int Psychogeriatr. 2009;21(2):252-264.

19. Rabig J. Home again: Small houses for individuals with cognitive impairment. J Gerontol Nurs. 2009;35(8):10-15.

20. de Boer B, Hamers JPH, Beerens HC, Zwakhalen SMG, Tan FES, Verbeek H. Living at the farm, innovative nursing home care for people with dementia - study protocol of an observational longitudinal study. BMC Geriatr. 2015;15:144.

21. Resnick B, Petzer-Aboff I, Galik E, et al. Barriers and benefits to implementing a restorative care intervention in nursing homes. J Am Med Dir Assoc. 2008;9(2):102-108.

22. Estabrooks CA, Rutakumwa W, O'Leary KA, et al. Sources of practice knowledge among nurses. Qual Health Res. 2005;15(4):460-476. 
23. Verkaik R, Francke AL, van Meijel B, Ribbe MW, Bensing JM. Comorbid depression in dementia on psychogeriatric nursing home wards: Which symptoms are prominent? Am J Geriat Psychiat. 2009;17(7):565-573.

24. Harrington $\mathrm{C}$, Choiniere J, Goldmann $\mathrm{M}$, et al. Nursing home staffing standards and staffing levels in six countries. J Nurs Scholarsh. 2012;44(1):88-98.

25. Han K, Trinkoff AM, Storr CL, Lerner N, Johantgen M, Gartrell K. Associations between state regulations, training length, perceived quality and job satisfaction among certified nursing assistants: Cross-sectional secondary data analysis. Int J Nurs Stud. 2014;51(8):1135-1141.

26. Resnick B. Restorative care nursing for older adults a guide for all care settings. New York: Springer; 2008.

27. Resnick B, Simpson M, Galik E, et al. Making a difference: Nursing assistants' perspectives of restorative care nursing. Rehabil Nurs. 2006;31(2):78-86. 


\section{CHAPTER 4}

\section{The role of nursing staff in the activities of daily living of nursing home residents}
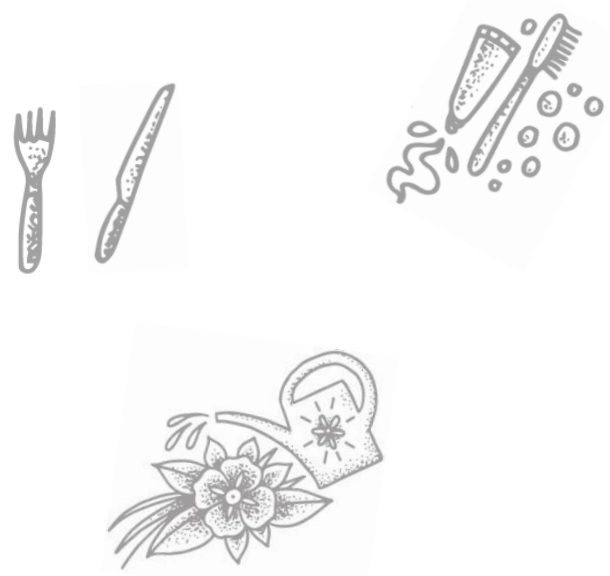

This chapter was published as:

den Ouden M, Kuk NO, Zwakhalen SMG, Bleijlevens MHC, Meijers JMM, Hamers JPH. The role of nursing staff in the activities of daily living of nursing home residents. Geriatric Nursing. 2016 (epub ahead of print). doi: 10.1016/j.gerinurse.2016.11.002. 


\section{Abstract}

The aim of this cross-sectional study was to explore the role of nursing staff in residents' activities. Nursing home residents $(n=723)$ were observed in their wards, randomly five times for one minute between 7 a.m. and 11 p.m. Resident's (in)activity and the role of nursing staff or others in this activity were recorded. Roles were defined as 'taking over the activity,' 'giving support,' or 'supervision.' Nurse observers were interviewed to obtain insight into their observation-experiences. Residents were observed in activities of daily living in $31 \%$ of all 3282 observations, and inactive in 57\%. Nursing staff provided support in $51 \%$ of the observations and took over activities in $45 \%$; supervision was rarely observed (4\%). Nurse observers who knew the residents reported that a large part of activities were taken over unnecessarily. Based on these results, nursing staff are recommended to provide more supervision and support to optimize residents' activities and independence. 


\section{Introduction}

Maintaining activities of daily living (ADL) and instrumental ADL (IADL) is of major importance in the frail nursing home population. It is well known that performing ADL and IADL, such as washing, dressing and preparing food, has a positive influence on physical functioning ${ }^{1}$ and is associated with a higher self-esteem ${ }^{2}$ and with a higher quality of life. ${ }^{3,4}$ Furthermore, residents' quality of life is positively influenced by their independence in these daily activities. ${ }^{5,6}$ Despite these positive effects, nursing home residents spend their day mainly inactive. ${ }^{7-9}$

Nursing homes are facilities that provide $24 \mathrm{~h}$ functional support and care for people who require assistance with daily activities, and have identified health needs. Nursing home care aims to provide a supportive, safe, and homelike environment in which residents are assisted to maintain their functional status as long as possible. ${ }^{10}$ In Dutch nursing homes, nursing staff are mainly certified nurse assistants (CNAs), ${ }^{11,12}$ with three years of secondary-vocational training. Besides, registered nurses (RNs), with four years of secondary-vocational training or bachelor-education, are part of the nursing staff. Henderson ${ }^{13}$ defined nursing in 1960 as: "The unique function of the nurse is to assist the individual, sick or well, in the performance of those activities contributing to health or its recovery that he would perform unaided if he had the necessary strength, will or knowledge. And to do this in such a way as to help him gain independence as rapidly as possible." This definition by Henderson ${ }^{13}$ implies that, also in the nursing home, it is the core business of nursing staff to encourage residents to perform daily activities and to encourage their independence.

Since nursing staff provide $24 / 7$ care, they play a key role in care provision and, ideally, demonstrate leadership behavior in encouraging nursing home residents in daily activities and maintaining independence. Nursing home residents' dependence is related to nursing staff behavior. ${ }^{14}$ Nursing staff can play different roles in the activities of the residents, for example, nursing staff could give instructions to complete the activity step by step. Moreover, nursing staff could take over residents' activities, which is not encouraging independence and physical activity. Previous intervention studies $^{2,15-24}$ have focused on changing the nursing behavior towards motivating and supportive behavior in the daily activities of nursing home residents. In these studies, nursing staff were taught motivational techniques to encourage residents. Most intervention studies reported on the effects on residents, for example, residents' functioning in ADL. Other studies ${ }^{22-24}$ evaluated change in behavior of nursing assistants using observations. Nursing staff were observed for 15-30 minutes in these studies, and their performance of function-focused care activities was evaluated using the Restorative Care Behavior Checklist $(\mathrm{RCBC}){ }^{25}$ Function-focused care activities performed by nursing staff could be encouraging the resident verbally to walk or walk together with the resident instead of pushing their wheelchair. Although these studies showed whether or not nursing assistants performed function focus care behaviors 
during care moments at an intervention setting, they do not provide insight into different roles of nursing staff in residents' activities during the day. Insight into the role of nursing staff in different activities of residents, especially ADL and IADL, could provide useful information for developing and evaluating nursing interventions to encourage residents in activities and their independence. Therefore, the aim of the current study was to explore the role of nursing staff in residents' ADL and IADL.

\section{Methods}

A cross-sectional mixed-method design was used in this study, consisting primarily of quantitative observations in Dutch nursing homes and additional qualitative semistructured interviews. To explore the role of nursing staff in residents' ADL and IADL during daily nursing care, the observations were conducted anonymously. Due to the anonymous observations all residents and all nursing staff in the wards could be observed without participation bias. The observations were conducted in June and July of 2014. Dutch nursing homes provide long-term care in psychogeriatric and somatic wards. Psychogeriatric wards are provided for people with dementia, while somatic wards focus on people with physical problems. ${ }^{26}$ The qualitative component of this study consisted of semi-structured interviews with the nurse observers, these interviews were conducted after the quantitative data collection.

\section{Participants}

Seven nursing homes in the southern part of the Netherlands participated in this study. The participating nursing homes are embedded in the Living Lab in Ageing and LongTerm Care. ${ }^{27}$ The nursing homes consisted of 19 psychogeriatric and 11 somatic longterm care wards and housed 723 residents (383 and 340 residents from psychogeriatric and somatic wards, respectively). The sample included the nursing home residents present in the ward during the observations, and the people who were involved in residents' activities, distinguishing between nursing staff (both RNs and CNAs) and others (such as family and volunteers). No distinction was made between CNAs and RNs, they were put together as 'nursing staff.' Furthermore, three of the five observers were RNs between 25 and 39 years of age, with up to 20 years of work experience.

\section{Measures}

The following background characteristics of the residents were extracted from the residents files: gender, age, mobility (mobile, wheelchair dependent or bedridden), functioning in $\mathrm{ADL}$ (measured by the Barthel index; $\mathrm{BI}$ ), ${ }^{28}$ and cognitive functioning (assessed by the Cognitive Performance Scale; CPS). ${ }^{29}$ The $\mathrm{BI}$ ranges from 0 to 20 , with a 
lower score indicating increased disability, ${ }^{28}$ and the CPS ranges from 0 to 6 with a higher score indicating more severe cognitive impairment. ${ }^{29}$

A self-developed observation list was used to register the daily (in)activity the resident was engaged in, and the role of nursing staff and others in the resident's activity. The development of the observation list consisted of a pilot observation study, validity check, and adjustments to the list; more details about the development can be found elsewhere. ${ }^{7}$ The daily (in)activities residents could be engaged in were categorized into 1) inactivity, 2) ADL and IADL, and 3) communication and hobbies. When residents were engaged in daily activities, it did not mean that residents were physically active themselves, since their activities could be taken over.

ADL consisted of personal care (e.g., brushing teeth, combing one's hair), going to the bathroom, eating and drinking (e.g., eating with hands or cutlery), mobility (e.g., walking, pushing a wheelchair, changing position), dressing (e.g., taking off one's clothes), and bathing (e.g., having a shower, washing at the sink). IADL that can be relevant for nursing home residents in their wards included domestic activities (e.g., setting the table) and preparing food/ pouring a drink (e.g., preparing a sandwich).

The role of nursing staff in residents' ADL and IADL was categorized as 'taking over the activity,' 'giving support,' or 'supervision.' 'Taking over the activity' was registered when nursing staff performed the activity instead of the resident (e.g., a resident in a wheelchair was pushed by the nurse, or a resident was dressed by a nurse). 'Giving support' consisted of verbal support (e.g., giving instructions), and/or physical support (e.g., taking somebody by the arm). 'Supervision' meant that the nurse observed the resident's activity and interfered when necessary (e.g., the nurse walked beside the resident and could intervene if the resident stumbled). These categories were based on a pilot observation study, in which residents' activities and positions, and the kind of support residents received (no support, some support or a lot of support) were scored.

Semi-structured interviews were conducted with each of the three nurse observers who performed the observations. The nurse observers were asked about their experiences during the observations, their perceptions of the role of nursing staff, and their ideas for positively changing the role of nursing staff in residents' daily activities.

\section{Procedure}

Permission for the anonymous observations was provided by the management of each participating nursing home by signing a research declaration. The contact person within the nursing home provided information about the number of residents in each ward. Nursing staff in the wards were informed about the observations and completed the inventory of the background characteristics of each resident living in the ward.

The observations were conducted by one out of five observers (three nurses, one research assistant, and one researcher). Two of the nurse observers conducted the observations within the nursing home they were employed in. In order to prevent 
observation bias and to reach a high interrater reliability, all observers received a three and a half hours' training program before starting, in which they received instructions for observations, practiced observations using video fragments, and discussed the definitions 'taking over', 'support,' and 'supervision' to reach consensus between the observers.

In each nursing home, the observations were performed during a $16 \mathrm{~h}$ period (between 7.00 a.m. and 11.00 p.m.), divided over two days. To provide an overview of the whole time period, the observations were divided into 5 time blocks. All wards within a nursing home were visited by an observer in a random sequence during each time block (randomization was carried out using http://www.randomizer.org). Theoretically, if all 723 residents were present in the wards during the five observation times, a total of 3615 observations could be conducted.

An observer walked around the ward and observed each resident present for one minute. The observer noted the main (in)activity the resident was engaged in during that minute. In addition, the role of nursing staff or others in the resident's activity was recorded, namely, who was involved (nursing staff or others) and, in the case of nursing staff, what their role was ('taking over the activity,' 'giving support,' or 'supervision'). If an observation did not fit within the predefined categories, the observer could describe the observation in the 'comment column.' The observer used a hand-held tablet, which was loaded with the observation list. The observation list was integrated into an Excel file and could be opened and adjusted during the observations using the e-Droid-cell Pro app. This file also provided information to the observer about the sequence of wards and observation times.

\section{Data analysis}

The data collected during the observations on the Excel files were transferred to SPSS (version 22, IBM, Armonk, NY). The residents' background characteristics were compared between the psychogeriatric and somatic wards using the chi-square test for the dichotomous variable (gender), and independent t-tests for the continuous variables (age, $\mathrm{BI}$, and CPS). Descriptive analyses of the anonymous observations were conducted for all wards and the five observation times together. To obtain insights into the role of nursing staff, percentages of the different types of roles were calculated. Additionally, a chi-square test was conducted to compare the role of nursing staff in residents' ADL and IADL between the psychogeriatric and somatic wards. The interviews were recorded and transcribed afterward. The researcher summarized each interview and sent the summary to the nurse for a member check before analyzing the data.

To test the interrater reliability of the observers regarding their score of the role of nursing staff, an intraclass correlation coefficient (ICC) was calculated. ${ }^{30}$ Reliability was tested by the extent of agreement of a small sample of 85 observations (in nine wards) between two observers during their observations in the nursing home. The role was 
scored as 1: taking over; 2: support; 3: supervision; and 4: no involvement. The ICC (two-way mixed absolute agreement) was 0.865 for the role of nursing staff, indicating good agreement between the raters. This ICC was high enough to decide to continue with the observations in the nursing home and not test the reliability any further.

\section{Ethical considerations}

The study protocol was approved by the Medical Research Ethics Committee. During all observations, the privacy of the residents was taken into account. For instance, the bathroom doors were not opened by the observer. All data, including background characteristics, were collected anonymously at ward level, which meant that residents could not be followed over time and that residents' characteristics could not be linked to the observations. Since the data were collected anonymously at ward level, the Medical Research Ethics Committee deemed exempt from individual consent of the nursing home residents. The three nurse observers signed an informed consent form for recording the interview.

\section{Results}

\section{Background characteristics of the residents}

Table 4.1 shows the background characteristics of the 723 nursing home residents living in the observed wards. In total, $68 \%$ of the residents were female. The nursing home residents living in psychogeriatric wards were, compared with the residents living in somatic wards, older, less severe dependent in ADL and more severe cognitive impaired. Furthermore, $61 \%$ of the residents in psychogeriatric ward were mobile, versus $27 \%$ of the residents in somatic wards. In total, $91 \%(n=3282)$ of the intended ( $n=3615$ ) observations were completed, the observation was not conducted if a resident was not present in the ward. In the psychogeriatric wards, $93 \%$ of the intended observations were completed and $89 \%$ in the somatic wards. The maximum number of observed residents in each ward during the different observation moments showed that at least 717 of the 723 individual residents were observed. 
Table 4.1 Background characteristics of nursing home residents living in psychogeriatric and somatic wards.

\begin{tabular}{|c|c|c|c|c|}
\hline & Total $[N=723]$ & Psychogeriatric $[n=383]$ & Somatic $[n=340]$ & $p$ \\
\hline Age: mean $\pm S D$ & $83.0 \pm 8.9$ & $85.2 \pm 6.4$ & $80.5 \pm 10.6$ & $<.001^{*}$ \\
\hline $\mathrm{BI}:$ mean $\pm \mathrm{SD}^{\mathrm{a}}$ & $7.6 \pm 5.8$ & $8.0 \pm 6.2$ & $7.1 \pm 5.3$ & $<.001^{*}$ \\
\hline $\mathrm{BI} \leq 9: n(\%)$ & $455(63)$ & $224(58)$ & $231(68)$ & $.007^{*}$ \\
\hline CPS: mean $\pm S D^{b}$ & $2.6 \pm 1.9$ & $3.5 \pm 1.7$ & $1.7 \pm 1.7$ & $<.001^{*}$ \\
\hline
\end{tabular}

*Significant difference $(p<0.05)$ between residents living in psychogeriatric and somatic wards.

${ }^{\mathrm{a}} \mathrm{BI}=$ Barthel index, range $\mathrm{BI}$ : 0-20 (a lower score indicates increased disability, where a score $\leq 9$ means severe need of help). ${ }^{28}$

${ }^{\mathrm{b}} \mathrm{CPS}=$ cognitive performance scale, range CPS: 0-6 (a higher score indicates more severe cognitive impairment). ${ }^{29}$

\section{Overall involvement in daily activities}

Nursing home residents were engaged in ADL and IADL during 31\% ( $n=1005)$ of all observations, and residents were observed as inactive during $57 \%$ of all observations. The flowchart in Figure 4.1 provides an overview of the observed (in)activities with and without involvement of nursing staff and others. The flowchart also shows the involvement of nursing staff and others in the residents' $A D L$ and $I A D L$, and the role of nursing staff. A small number of involvement observations ( $n=31,1 \%$ ) was missing, they were not recorded on the tablet by the observer.

In $11 \%$ of all observations, the involvement of nursing staff or others in the residents' daily activities was noted. Activities in which involvement was noted were mainly $A D L$ and IADL (78\%). When no involvement was recorded, residents were generally observed as inactive (65\%) (see Figure 4.1). Nursing staff $(n=235$ observations) were four times more often involved in residents' ADL and IADL than others, such as family and volunteers ( $n=52$ observations). Table 4.2 shows the observed involvement, which varied between the different ADL and IADL. Eating and drinking, and mobility, were most often observed without the involvement of nursing staff or others, respectively $76 \%(n=209)$ and $78 \%(n=374)$. Bathing, dressing, and going to the bathroom were most often observed with the involvement of nursing staff or others, respectively $88 \%(n=35), 69 \%(n=20)$, and $51 \%(n=23)$.

\section{The role of nursing staff in residents' $A D L$ and IADL}

When nursing staff were involved, they provided physical and/or verbal support in 51\% ( $n=119$ ) of the observations, took over residents' activities in $45 \%$ ( $n=106)$, and provided supervision in $4 \%(n=10)$. The nursing staff's role differed per activity (see Table 4.2); they commonly took over activities involving preparing food/pouring a drink 


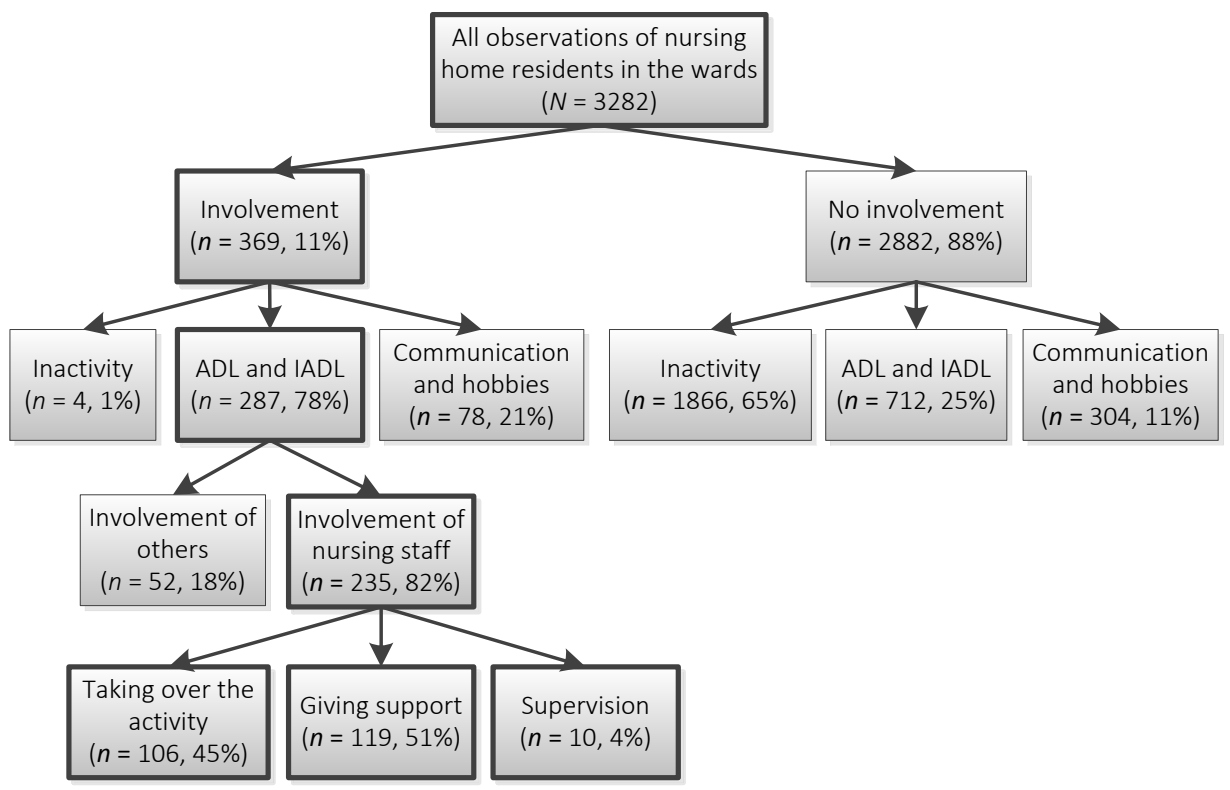

Figure 4.1. Flowchart of the observed activities and involvement, including the number of observations and percentages. $A D L=$ activities of daily living; $I A D L=$ instrumental activities of daily living.

Table 4.2 Observed involvement and the different roles of nursing staff in residents' ADL and IADL.

\begin{tabular}{|c|c|c|c|c|c|c|}
\hline & \multirow{2}{*}{$\begin{array}{l}\text { No } \\
\text { involvement } \\
{[n=712]} \\
n\end{array}$} & \multirow{2}{*}{$\begin{array}{l}\text { Involvement } \\
\text { of others } \\
{[n=52]} \\
\end{array}$} & \multicolumn{4}{|c|}{$\begin{array}{l}\text { Involvement of nursing staff }- \text { and their roles } \\
{[n=235]}\end{array}$} \\
\hline & & & $n$ & $\begin{array}{l}\text { Taking over } \\
n(\%)\end{array}$ & $\begin{array}{l}\text { Support } \\
n(\%)\end{array}$ & $\begin{array}{l}\text { Supervision } \\
n(\%)\end{array}$ \\
\hline \multicolumn{7}{|l|}{$\overline{A D L}$} \\
\hline Personal care & 51 & 4 & 28 & $17(61)$ & $11(39)$ & $0(0)$ \\
\hline Going to the bathroom & 22 & 0 & 23 & $5(22)$ & $17(74)$ & $1(4)$ \\
\hline Eating and drinking & 209 & 12 & 54 & $25(46)$ & $28(52)$ & $1(2)$ \\
\hline Mobility & 374 & 32 & 71 & $29(41)$ & $35(49)$ & $7(10)$ \\
\hline Dressing & 9 & 1 & 19 & $8(42)$ & $11(58)$ & $0(0)$ \\
\hline Bathing & 5 & 1 & 34 & $17(50)$ & $16(47)$ & $1(3)$ \\
\hline \multicolumn{7}{|l|}{$I A D L$} \\
\hline Domestic activities & 27 & 0 & 0 & - & - & - \\
\hline Preparing food & 15 & 2 & 6 & $5(83)$ & $1(17)$ & $0(0)$ \\
\hline
\end{tabular}

$A D L=$ activities of daily living; $I A D L=$ instrumental activities of daily living. 
(83\%, $n=5)$, personal care $(61 \%, n=17)$, and bathing $(50 \%, n=17)$, and provided physical and/or verbal support mostly when residents were going to the bathroom $74 \%$ ( $n=17)$. Supervision of ADL and IADL was seldom observed. There were no statistically significant differences in the role of nursing staff in residents' $A D L$ and IADL between the psychogeriatric $(n=105)$ and somatic wards $(n=130)$. 'Taking over' was scored in $51 \%$ of the observations in the somatic wards and in $40 \%$ of the observations in the psychogeriatric wards $(p=0.080)$. Nursing staff provided 'support' in $44 \%$ of the observations in the somatic wards, compared with $56 \%$ in the psychogeriatric wards ( $p$ $=0.060$ ). 'Supervision' was observed in $5 \%$ of all observations in the somatic wards and in $4 \%$ of the observations in the psychogeriatric wards $(p=0.730)$.

\section{Experience of the nurse observers}

The nurse observers $(n=3)$, acknowledged the large amount of inactivity of nursing home residents. Further, the nurse observers who knew the residents mentioned that a large part of residents' activities were unnecessarily taken over by the nursing staff: residents could have performed the activities themselves (with support or supervision). Reasons for nursing staff to take over activities included time pressure, expectations, and lack of knowledge. The nurse observers found it most remarkable that the observations made them aware of the large amount of inactivity of among the nursing home residents and the amount of activities that were taken over by nursing staff. The nurses stated that, given the findings, a change is necessary, however, it will be hard and take time to change nursing staff behavior. Their ideas for improvement were obtaining insight into residents' capacity and preferences, making appointments, pronouncing expectations, and being aware of their own behavior.

\section{Discussion}

The aim of this study was to explore the role of nursing staff in residents' ADL and IADL. When nursing staff were involved in residents' $A D L$ or IADL, they provided verbal and/or physical support in $51 \%$ of the observations; in $45 \%$ they completely took over the residents' activities. Supervision was rarely observed (4\%). The observations created awareness among the nurse observers about the large amount of inactivity of nursing home residents and a large part of ADL and IADL were unnecessarily taken over by nursing staff.

Involvement of nursing staff and others was mainly observed in residents' ADL and $I A D L$, which was to be expected, since nursing home residents show a dependency in their functioning. Eating and drinking, and mobility, were frequently performed without involvement of nursing staff or others, whereas bathing was most often observed with involvement. This is in line with the hierarchical order of ADL decline; first, older people 
lose their ability to bathe independently, thereafter, they lose their independence in mobility, and at the last, older people lose their ability to eat independently. ${ }^{31,32}$

Nursing staff have a major role in increasing the activity levels of nursing home residents; however, this might be challenging. Nursing home care is a high demanding nursing practice area and the availability of nursing staff is limited. A Dutch report about staffing and quality of care indicates that, in nursing home wards of 30 residents, on average four direct care members are available, and about 1.5 staff members to support the nursing staff. ${ }^{33}$ Geriatric nurses are trained to perform in a complex care environment so that nursing home residents remain as independent as possible in this institutionalized long-term care setting. Without any doubt this complexity requires nursing staff awareness of the possibilities and possible complications in the process of encouraging activities. Nursing staff have various tasks, such as direct and indirect care, practical nursing tasks, support, logistics, administration, and communication. ${ }^{34,35}$ They need to switch rapidly between these tasks; ${ }^{36}$ and multi-tasking is part of the job. ${ }^{34}$ Nursing staff may experience a high workload; ${ }^{21,37}$ consequently, they may feel that they do not have time to talk or listen to the residents. ${ }^{36}$ This perceived shortage of time and focus on their tasks could have led to more activities being taken over by nursing staff in the current study, instead of providing supervision or support. Nursing staff are mainly focused on the tasks they need to do (task-oriented) instead of focusing on the residents' needs and preferences (person-centered). ${ }^{38}$ Nurses should ensure that residents receive optimal care based on the person's abilities and nursing care needs. Therefore, nursing models that emphasize individualized person-centered care should be embraced. By applying such an individualized care approach; nursing staff create a stimulating living environment.

When reflecting upon the observations with the nurse observers, they pointed out that the observations made them aware of the large amount of inactivity, and that many activities that were taken over by nursing staff could have been performed by the residents themselves. This awareness seems to be essential in the process of behavioral change. $^{39}$ An observational approach to become aware of the magnitude of the problem and the explicit role of the nurses may be an important aspect to achieve a change in the nursing staff behavior that can be included in intervention and training programs.

Encouraging residents to engage in daily activities is challenging, but essential since residents may show decreased initiation of activities. ${ }^{40}$ If nursing staff do not encourage residents in daily activities but take over these activities instead, the residents will become more care dependent. ${ }^{41}$ For example, losing mobility is associated with different care problems, such as incontinence and pressure ulcers. ${ }^{42}$ In addition, encouraging residents' mobility is necessary since it gives residents a sense of freedom, choice and independence, and is therefore a key factor in their quality of life. ${ }^{43}$

Nursing staff provide care in the residents' direct environment and have the most contact with them; therefore, it is expected that they should encourage nursing home 
residents to carry out daily activities. Based on the results of this study, nursing staff are advised to change their behavior to encourage residents to become engaged in more activities, and to provide more supervision or support instead of taking over residents' activities, in order to increase activity levels and to maintain the residents' capacity and independence.

Despite the differences in cognitive and physical status between residents in psychogeriatric and somatic wards, the large amount of residents' inactivity and the role of nursing staff in these wards are comparable. Therefore, in both wards interventions should be aimed at encouraging residents' daily activities and independence. However, the differences in residents' cognitive and physical status implicates that nursing staff should use a different approach in encouraging residents. ${ }^{44}$ Residents in psychogeriatric wards commonly have cognitive problems, and therefore might need demonstration of a certain activity with step-by-step support. Residents living in somatic wards suffer from physical impairments, they often understand explanations, and therefore, might need more physical support, general instructions, and feedback during daily activities.

Nursing staff could decrease the large amount of inactivity by offering relevant activities during the day, tailored to residents' capacity and preferences. ${ }^{4}$ To encourage nursing home residents it is important to avoid highly demanding activities and build a trusting relationship. ${ }^{45}$ Nursing staff should discuss activity preferences with the resident (and family) and could collaborate with the nursing home physician and the multidisciplinary team, including physiotherapists, occupational therapists, and recreational therapists. This encouragement of activities and independence, based on residents' capacity and preference, fits into the cultural change that is ongoing from the medical model towards resident-directed care. ${ }^{46}$ Traditional nursing home wards shift to small scale wards with a homelike environment, for example in Green House homes. ${ }^{47}$ Nursing home residents living in these wards could be engaged in IADL activities, such as preparing food or setting the table.

To change nursing behavior, nursing staff need education on how to encourage residents in daily activities. ${ }^{2,15-24}$ Other important components of existing intervention studies that aim to change nursing behavior, such as function-focused care, ${ }^{19-24}$ are policy and coaching. Nursing staff should be supported by their management in the encouragement of activities and independence of nursing home residents. The management should underline the importance of activities and independence of resident and could facilitate training and coaching for nursing staff in the encouragement of residents.

\section{Limitations}

Some limitations of this study need to be addressed. Because of the anonymous observations, it is unknown which particular resident and nursing staff were observed; 
therefore, the resident's characteristics could not be linked with the role of nursing staff. It is not known if the nursing staff were more often involved and had different roles in the activities of residents with a lower functional capacity, that is, residents who needed more support by the nursing staff. Furthermore, the characteristics of the involved nursing staff (and others) were not assessed. Hence, it is not possible to examine whether the characteristics of the nursing staff, for example, educational level or years of experience, were associated with the extent to which activities were taken over. Lastly, when residents were observed without the involvement of nursing staff or others, it remains unclear if there had been involvement before the observation. The residents possibly had been encouraged to perform that activity themselves, and as a consequence, no involvement was observed.

\section{Conclusions}

This study shows that, when involved, nursing staff took over almost half of residents' ADL and IADL. Supervision of these activities, in which the nurse observed a resident and could interfere when necessary, was rarely observed. Nurses who conducted the observations reported that many activities were unnecessarily taken over; residents could have performed these themselves. It becomes imperative that nurses have to demonstrate competencies in understanding the residents' needs and how to meet these care needs. This starts at nursing home admission from initial assessment through the evaluation of care that is planned. Encouraging residents' daily activities and their independence in these activities should be a key role of nursing staff in order to decrease residents' inactivity and functional decline. Future studies should provide tools to help nursing staff to encourage residents' activities, and their independence in daily care. 


\section{References}

1. Gronstedt H, Frandin K, Bergland A, et al. Effects of individually tailored physical and daily activities in nursing home residents on activities of daily living, physical performance and physical activity level: A randomized controlled trial. Gerontology. 2013;59:220-229.

2. Blair CE. Effect of self-care ADLs on self-esteem of intact nursing home residents. Issues Ment Health Nurs. 1999;20:559-570.

3. Edvardsson D, Petersson L, Sjogren K, Lindkvist M, Sandman PO. Everyday activities for people with dementia in residential aged care: Associations with person-centredness and quality of life. Int J Older People Nurs. 2014;9:269-276.

4. Smit D, de Lange J, Willemse B, Twisk J, Pot AM. Activity involvement and quality of life of people at different stages of dementia in long term care facilities. Aging Ment Health. 2015:1-10.

5. Chan C, Slaughter S, Jones C, Wagg A. Greater independence in activities of daily living is associated with higher health-related quality of life scores in nursing home residents with dementia. Healthcare. 2015;3:503-518.

6. Andersen CK, Wittrup-Jensen KU, Lolk A, Andersen K, Kragh-Sorensen P. Ability to perform activities of daily living is the main factor affecting quality of life in patients with dementia. Health Qual Life Out. 2004;2:52.

7. den Ouden M, Bleijlevens MHC, Meijers JMM, et al. Daily (in)activities of nursing home residents in their wards: An observation study. J Am Med Dir Assoc. 2015;16:963-968.

8. MacRae PG, Schnelle JF, Simmons SF, Ouslander JG. Physical activity levels of ambulatory nursing home residents. J Aging Phys Activ. 1996;4:264-278.

9. Ice HG. Daily life in a nursing home: Has it changed in 25 years? J Aging Stud. 2002;16:345-359.

10. Sanford AM, Orrell M, Tolson D, et al. An international definition for "nursing home". J Am Med Dir Assoc. 2015;16:181-184.

11. Verkaik R, Francke AL, van Meijel B, Spreeuwenberg PMM, Ribbe MW, Bensing JM. The introduction of a nursing guideline on depression at psychogeriatric nursing home wards: Effects on certified nurse assistants. Int J Nurs Stud. 2011;48:710-719.

12. Backhaus $R$, van Rossum $E$, Verbeek $H$, et al. Quantity of staff and quality of care in Dutch nursing homes: A cross-sectional study. J Nurs Home Res. 2016;2:90-93. 13.

13. Henderson V. Basic principles of nursing care. Geneva: International Council of Nurses. 1960.

14. Barton EM, Baltes MM, Orzech MJ. Etiology of dependence in older nursing home residents during morning care: The role of staff behavior. J Pers Soc Psychol. 1980;38:423-431.

15. Morris JN, Fiatarone M, Kiely DK, et al. Nursing rehabilitation and exercise strategies in the nursing home. J Gerontol A-Biol. 1999;54:494-500.

16. Johnson CSJ, Meyers AM, Jones GR, et al. Evaluation of the restorative care education and training program for nursing homes. Can J Aging. 2005;24:115-126.

17. Blair CE. Combining behavior management and mutual goal setting to reduce physical dependency in nursing home residents. Nurs Res. 1995;44:160-165.

18. Blair CE, Glaister J, Brown A, Phillips C. Fostering activities of daily living by intact nursing home residents. Educ Gerontol. 2007;33:679-699.

19. Galik EM, Resnick B, Gruber-Baldini A, et al. Pilot testing of the restorative care intervention for the cognitively impaired. J Am Med Dir Assoc. 2008;9:516-522.

20. Resnick B, Gruber-Baldini AL, Zimmerman S, et al. Nursing home resident outcomes from the Res-Care intervention. J Am Geriatr Soc. 2009;57:1156-1165

21. Resnick B, Simpson M, Bercovitz A, et al. Pilot testing of the restorative care intervention: Impact on residents. J Gerontol Nurs. 2006;32:39-47.

22. Resnick B, Simpson M, Bercovitz A, et al. Testing of the Res-Care pilot intervention: Impact on nursing assistants. Geriatr Nurs. 2004;25:292-297. 
23. Resnick B, Gruber-Baldini AL, Galik E, et al. Changing the philosophy of care in long-term care: Testing of the restorative care intervention. Gerontologist. 2009;49:175-184.

24. Galik E, Resnick B, Hammersla M, Brightwater J. Optimizing function and physical activity among nursing home residents with dementia: Testing the impact of function-focused care. Gerontologist. 2014;54:930-943.

25. Resnick B, Rogers V, Galik E, Gruber-Baldini AL. Measuring restorative care provided by nursing assistants: Reliability and validity of the Restorative Care Behavior Checklist. Nurs Res. 2007;56:387-398.

26. Schols JM, Crebolder HF, van Weel C. Nursing home and nursing home physician: The Dutch experience. J Am Med Dir Assoc. 2004;5:207-212.

27. Verbeek H, Zwakhalen SMG, Schols JMGA, Hamers JPH. Keys to successfully embedding scientific research in nursing homes: A win-win perspective. J Am Med Dir Assoc. 2013;14:855-857.

28. de Haan R, Limburg M, Schuling J, Broeshart J, Jonkers L, van Zuylen P. Clinimetric evaluation of the Barthel index, a measure of limitations in dailly activities [in Dutch]. Ned Tijdschr Geneeskd. 1993;137:917-921.

29. Morris JN, Fries BE, Mehr DR, et al. MDS cognitive performance scale. J Gerontol. 1994;49:M174-M182.

30. Shrout PE, Fleiss JL. Intraclass correlations: Uses in assessing rater reliability. Psychol bull. 1979;86:420428.

31. Katz S, Ford A, Moskowitz R, Jackson B, Jaffe M. Studies of illness in the aged. The index of ADL: A standardized measure of biological and psychosocial function. JAMA. 1963;185:914-919.

32. Walk D, Fleishman R, Mandelson J. Functional improvement of elderly residents of institutions. Gerontologist. 1999;39:720-728.

33. Hingstman TL, Langelaan M, Wagner C. De dagelijkse bezetting en kwaliteit van zorg in instellingen voor langdurige zorg. Available from: http://www.nivel.nl/sites/default/files/bestanden/Rapport-dagelijksebezetting-zorg-in-instellingen.pdf; 2012:73-79. Accessed 21 June 16.

34. Munyisia EN, Yu P, Hailey D. How nursing staff spend their time on activities in a nursing home: An observational study. J Adv Nurs. 2011;67:1908-1917.

35. Paquay L, De Lepeleire J, Milisen K, Ylieff M, Fontaine O, Buntinx F. Tasks performance by registered nurses and care assistants in nursing homes: A quantitative comparison of survey data. Int J Nurs Stud. 2007;44:1459-1467.

36. Mallidou AA, Cummings GG, Schalm C, Estabrooks CA. Health care aides use of time in a residential longterm care unit: A time and motion study. Int J Nurs Stud. 2013;50:1229-1239.

37. Kieft RA, de Brouwer BB, Francke AL, Delnoij DM. How nurses and their work environment affect patient experiences of the quality of care: A qualitative study. BMC Health Serv Res. 2014;14:249.

38. Tuinman A, de Greef MH, Krijnen WP, Nieweg RM, Roodbol PF. Examining time use of Dutch nursing staff in long-term institutional care: A time-motion study. J Am Med Dir Assoc. 2016;17:148-154.

39. Elwyn G, Marrin K, Frosch D, White J. Sustainable change sequence: A framework for developing behavior change interventions for patients with long-term conditions. Eur J Pers Cent Healthc. 2014;2:212-216.

40. Cook C, Fay S, Rockwood K. Decreased initiation of usual activities in people with mild-to-moderate Alzheimer's disease: A descriptive analysis from the VISTA clinical trial. Int Psychogeriatr. 2008;20:952963.

41. Schüssler S, Dassen T, Lohrmann C. Care dependency and nursing care problems in nursing home residents with and without dementia: A cross-sectional study. Aging Clin Exp Res. 2014;28(5):973-982.

42. Lahmann NA, Tannen A, Kuntz S, et al. Mobility is the key! Trends and associations of common care problems in German long-term care facilities from 2008 to 2012. Int J Nurs Stud. 2015;52:167-174.

43. Bourret EM, Bernick LG, Cott CA, Kontos PC. The meaning of mobility for residents and staff in long-term care facilities. J Adv Nurs. 2002;37:338-345.

44. Braun SM, Kleynen M, Bleijlevens MHC, et al. "Interactive surfaces" technology as a potential tool to stimulate physical activity in psychogeriatric nursing home residents. Disabil Rehabil Assist Technol. 2015;10:486-492. 
45. van Alphen HJ, Hortobagyi T, van Heuvelen MJ. Barriers, motivators, and facilitators of physical activity in dementia patients: A systematic review. Arch Gerontol Geriat. 2016;66:109-118.

46. White-Chu EF, Graves WJ, Godfrey SM, Bonner A, Sloane P. Beyond the medical model: The culture change revolution in long-term care. J Am Med Dir Assoc. 2009;10:370-378.

47. Sloane PD, Zimmerman S, D'Souza MF. What will long-term care be like in 2040? NC Med J. 2014;75:326-330. 


\section{CHAPTER 5}

Promoting functional activity among nursing home residents: A cross-sectional study on barriers experienced by nursing staff

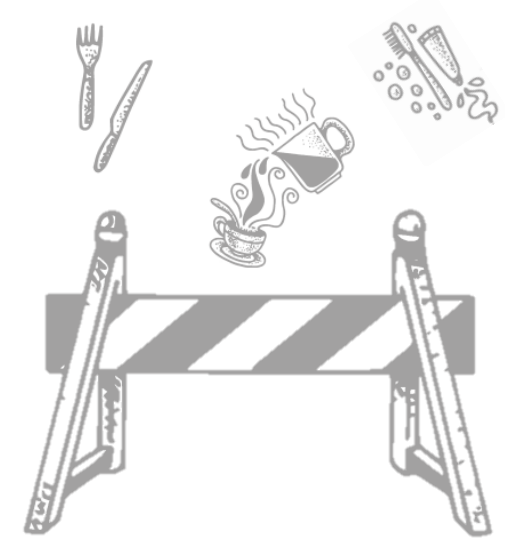

This chapter was published as:

Kuk NO, Zijlstra GAR, Bours GJJW, Hamers JPH, Tan FES, Kempen GIJM. Promoting functional activity among nursing home residents: A cross-sectional study on barriers experienced by nursing staff. J Aging Health. 2017 (epub ahead of print). doi: 10.1177/0898264316687407 


\section{Abstract}

Objective: To obtain insight into (a) the prevalence of nursing staff-experienced barriers regarding the promotion of functional activity among nursing home residents, and (b) the association between these barriers and nursing staff-perceived promotion of functional activity.

Method: Barriers experienced by 368 nurses from 41 nursing homes in the Netherlands were measured with the MAastrlcht Nurses Activities INventory (MAINtAIN)-barriers; perceived promotion of functional activities was measured with the MAINtAINbehaviors. Descriptive statistics and hierarchical linear regression analyses were performed.

Results: Most often experienced barriers were staffing levels, capabilities of residents, and availability of resources. Barriers that were most strongly associated with the promotion of functional activity were communication within the team, (a lack of) referral to responsibilities, and care routines.

Discussion: Barriers that are most often experienced among nursing staff are not necessarily the barriers that are most strongly associated with nursing staff-perceived promotion of functional activity. 


\section{Introduction}

Being functionally active is important for all people, including nursing home residents who are under supervision $24 \mathrm{~h}$ a day. In nursing home residents, being active and performing functional activities is associated with less disruptive behavior, ${ }^{1}$ less anxiety, ${ }^{1}$ higher self-esteem, ${ }^{2}$ and a higher quality of life. ${ }^{3}$ Initiatives to maintain or improve functional activity among nursing homes residents have been proposed worldwide. ${ }^{1,4,5}$ Nonetheless, several studies have shown that inactivity is common in nursing home residents. ${ }^{6-8}$ A recent observation study in the Netherlands showed that nursing home residents, including mobile residents, were sitting or lying for about $90 \%$ of the observed moments during the day. ${ }^{6}$ To improve functional activity among nursing home residents, nursing staff can play an important role. They can encourage residents to be active and to act as independently as possible during daily care activities, ${ }^{1}$ strengthen residents' self-efficacy, ${ }^{9}$ for example, by probing residents to perform activities, or complimenting residents when they have performed certain activities. A recent study among nursing staff found that some functional activities, such as household activities (e.g., setting and clearing the table), are perceived to be less often promoted by the nursing staff than other functional activities, such as activities of daily living $(A D L) .{ }^{10}$ Evidence suggests that nursing staff may be inclined to take over the activities of nursing home residents. ${ }^{11-13}$ Den Ouden and colleagues ${ }^{14}$ showed that in $45 \%$ of the observations when nursing staff were involved in residents' activities, the staff performed the activity for the resident instead of allowing the residents to do the activity themselves. The observers in this study indicated that this behavior by the nursing staff was often unnecessary.

On a more general level, previous studies have shown that certain barriers may influence the behavior of nursing staff, for example, when adopting evidence-based practices or using guidelines. ${ }^{15-17}$ Less evidence is available on the barriers nursing staff experience with regard to promoting functional activity among older people. Previous studies showed that nursing staff may not encourage residents to perform functional activities because they think residents are not capable of performing them ${ }^{18,19}$ or nursing staff may think that family expects them to perform certain activities for residents. ${ }^{18-20}$ Other barriers that may prevent nursing staff from promoting functional activity are a high workload or a lack of social support. ${ }^{18,21}$ These barriers can act on different levels. They may be related to the residents (e.g., fear of falling), the nursing staff (e.g., lack of self-efficacy), the social context (e.g., lack of social support), or the organizational and economic context (e.g., lack of resources). ${ }^{15,18}$ Although previous studies revealed some of the barriers nursing staff experience, they do not show how frequently these barriers are experienced and how these barriers are related with the promoting behavior of nursing staff. It is unknown whether the barriers that are most often experienced are also the barriers that are most strongly associated with the behavior of nursing staff. Insight into the prevalence and relative importance of the 
barriers is important to develop strategies to improve the promotion of functional activity by nursing staff.

The purpose of this study was to obtain an insight into the prevalence of the barriers that nursing staff experience regarding promoting functional activity among nursing home residents, and the association between these barriers and nursing staff-perceived behavior regarding the promotion of functional activity. In this study, a distinction is made between barriers related to the residents, the professionals, the social context, and the organizational and economic context.

\section{Material and method}

\section{Design}

In January and February 2014, a nationwide cross-sectional study was conducted to collect data from nursing staff employed at nursing homes in the Netherlands. The Medical Ethical Review Committee of Maastricht University (14-5-002) approved the study.

\section{Setting, participants, and procedures}

In the Netherlands, nursing home care is provided in somatic and psychogeriatric wards. Residents with psychogeriatric problems, such as dementia, primarily live in psychogeriatric wards, while somatic wards provide care to residents with physical problems. ${ }^{22}$ The large majority of the nursing staff in Dutch nursing homes are certified nurse assistants (CNAs), who have followed a secondary vocational training of 3 years. In addition, care is provided by registered nurses (RNs) with 4 years of vocational training and bachelor-educated RNs.

Nursing homes in the Netherlands were stratified according to five regions (north, east, south, west, and central). From each region, a random sample was drawn, proportionate to the total number of nursing homes in that region. In total, 100 nursing homes were invited to participate. To exclude care homes that have a single small nursing home ward but mainly provide care that is less intensive than regular nursing home care, the first author verified by telephone whether the nursing homes provided care to at least 25 somatic and/or 25 psychogeriatric residents. This led to the exclusion of 25 facilities; furthermore, one nursing home was excluded because it had closed its doors at the time of recruitment. Of the remaining 74 nursing homes, 46 agreed to participate.

Based on practical considerations, nursing homes with both psychogeriatric and somatic wards were invited to participate with 16 RNs or CNAs, eight from each ward type. Nursing homes with only somatic or only psychogeriatric wards were asked to 
participate with a total of 10 RNs or CNAs. In this way, a total of 622 RNs and CNAs could potentially participate. In addition to being an RN or CNA, participating nursing staff had to work at least $12 \mathrm{~h}$ per week, to ensure that they had enough insight into daily practice. Nursing staff working exclusively night shifts were excluded from participation because of the fairly limited opportunities to promote functional activities during this time of day. In each participating nursing home, a local contact person randomly administered a questionnaire among eligible nursing staff and returned the anonymously completed questionnaires within 2 weeks.

\section{Measures}

The barriers nursing staff experience regarding promoting functional activity were assessed with the MAastrlcht Nurses Activities INventory (MAINtAIN)-barriers. ${ }^{18}$ This inventory comprises 33 nine-point scaled items ranging from never to always, or completely disagree to completely agree. A distinction is made between the different levels barriers relate to, namely, (a) the residents, (b) the professionals, (c) the social context, and (d) the organizational and economic context. Data on the extent to which nursing staff perceive that they promote functional activities were collected with the MAINtAIN-behaviors ${ }^{18}$ inventory. In this article, the phrase 'behavior of the nursing staff' is applied to indicate their perceived behavior regarding the promotion of functional activities. The 19-itemed MAINtAIN-behaviors inventory comprises three subscales assessing the extent to which nursing staff promote independence during ADL, such as bathing or dressing (eight items); household activities, such as setting and clearing the table or preparing a sandwich (six items); and miscellaneous activities, such as encouraging informal caregivers not to take over activities or encouraging residents to participate in organized activities (five items). Respondents rate the items on a ninepoint scale ranging from never to always. The internal consistency for each of the three subscales ranged from .77 to $.83 .{ }^{10}$ The MAINtAIN-barriers and MAINtAIN-behaviors are the two parts of the MAINtAIN inventory (available via open access ${ }^{18}$ ). A previous study showed MAINtAIN's usability and content validity. ${ }^{18}$

Background characteristics of the nursing staff (age, sex, profession [CNA or RN], the ward type the nursing staff worked in [psychogeriatric or somatic], number of work hours per week, and years of professional experience) were assessed using single-item questions.

\section{Data analyses}

Means and proportions were used to describe the background characteristics. Regarding the MAINtAIN-barriers, the scores of the positively formulated items were reversed so that higher scores always indicate stronger experienced barriers. For each barrier, the mean score and standard deviation were calculated. In addition, to 
determine the proportion of respondents who experienced a barrier to a lower or higher extent, the answer options of the MAINtAIN-barrier items were categorized into three categories: low (score = 1-3), medium (score = 4-6), and high (score = 7-9). Missing values (0-2.2\%) on the items of the MAINtAIN-barriers were not imputed (i.e., not replaced by other values). Regarding the MAINtAIN-behaviors, mean scores and standard deviations were calculated for the ADL subscale, household activities subscale, and miscellaneous activities subscale. Missing values on the items of a subscale were imputed with the respondent's average score for the other items of that subscale, if at least $75 \%$ of the items of the subscale had been completed. Missing data for the ADL, household, and miscellaneous subscales were imputed for a total of $4.9 \%, 2.4 \%$, and $1.9 \%$ of the respondents, respectively. After imputation, $0.8 \%$ remained missing for the ADL and miscellaneous activities subscales, and $0.5 \%$ for the household activities subscale, due to respondents who did not complete at least $75 \%$ of the items. Given the few remaining missing values on the MAINtAIN-barriers and MAINtAIN-behaviors, these missing values were not imputed as they are unlikely to impact the outcomes.

To determine the association between each nine-point-scaled barrier and each subscale of the MAINtAIN-behaviors, hierarchical linear regression analyses (random intercept; Level 1, nursing staff; Level 2, nursing home) were performed. In each analysis, one barrier and one subscale of the MAINtAIN-behaviors were used. The variables ward type and profession were added to each analysis to control for potential confounding. For each model, unstandardized $B$ coefficients $(B s)$, standard errors, $p$ values, and intraclass correlation coefficients (ICCS) were determined. To account for multiple comparisons, a Bonferroni-Holm correction was used, with the global significance level of .05. Sensitivity analyses were conducted by imputing the missing scores on the MAINtAIN-behaviors subscales (for respondents who completed at least $75 \%$ of the items on that scale) with either one or nine and comparing the results of these analyses. To rank the barriers according to the strength of the associations, the mean strength of the association between each barrier and the three functional activity subscales was determined (the mean of the three Bs). Mean scores for each barrier were used to rank them; barriers were also ranked based on the Bs following the adjusted hierarchical linear regressions analyses. In addition, simple and hierarchical linear regression analyses were conducted without the potential confounders to determine the $B$ coefficients and allow comparison of the ranked mean of the three $B \mathrm{~s}$ with the ranked barriers' mean scores. All statistical analyses were performed using SPSS Statistics (version 22, IBM, Armonk, New York, USA). 


\section{Results}

\section{Sample characteristics}

Of the 448 respondents from 43 nursing homes (response rate $=72 \%$, range $=50-100 \%$ per nursing home) who completed the MAINtAIN, 80 were excluded because they did not meet the inclusion criteria (i.e., working exclusively night shifts $[n=18]$, not working in a somatic or psychogeriatric ward [ $n=35]$, not certified as an RN or CNA [ $n=24]$, or a combination of these reasons $[n=3]$ ). The 368 eligible respondents represented 41 nursing homes. The mean age of the included respondents was 41.8 years (SD 11.6 years), and 231 (63\%) of them worked in a psychogeriatric ward. Other sample characteristics are displayed in Table 5.1.

The extent to which the nursing staff promoted functional activities varied; the mean scores for the ADL, household activities, and miscellaneous activities were 6.9 (SD 1.2), 4.1 (SD 1.9), and 6.7 (SD 1.5), respectively, out of a theoretical range from 1 to 9 (data not tabulated).

Table 5.1. Sample characteristics $\left(N=368^{\mathrm{a}}\right)$.

\begin{tabular}{lll}
\hline & $n(\%)$ & Mean \pm SD \\
\hline Gender & $346(95)$ & \\
Female & $20(5)$ & \\
Male & $231(63)$ & \\
Ward type & $137(37)$ & \\
$\quad$ Psychogeriatric ward & & \\
$\quad$ Somatic ward & $275(75)$ & $17.3 \pm 11.6$ \\
Profession & $93(25)$ & $28.7 \pm 5.4$ \\
$\quad$ CNA & & \\
RN & & \\
Age (years) & & \\
Professional experience (years) & \\
Work hours per week &
\end{tabular}

CNA = certified nurse assistant; RN = registered nurse (vocationally-trained or bachelor-educated).

${ }^{a} \mathrm{~N}$ does not always add up to 368 due to missing data. 


\section{CHAPTER 5}

Table 5.2. Mean scores, standard deviations, and prevalence of nursing staff-experienced barriers for promoting functional activities $(N=368)$.

\begin{tabular}{|c|c|c|c|c|}
\hline Barriers & Mean \pm SD & $\operatorname{Low}^{\mathrm{a}}(\%)$ & Medium $^{\mathrm{a}}(\%)$ & $\operatorname{High}^{a}(\%)$ \\
\hline \multicolumn{5}{|l|}{ Residents } \\
\hline Capabilities residents & $5.37 \pm 2.52$ & 29 & 32 & 39 \\
\hline Residents' fear & $4.61 \pm 1.22$ & 19 & 76 & 5 \\
\hline Attitude residents & $4.54 \pm 1.74$ & 28 & 58 & 13 \\
\hline Attention-seeking behavior & $4.37 \pm 1.88$ & 34 & 54 & 12 \\
\hline $\begin{array}{l}\text { Residents' and families' expectations } \\
\text { regarding care }\end{array}$ & $4.34 \pm 2.02$ & 36 & 49 & 15 \\
\hline Learned dependency & $4.25 \pm 2.10$ & 42 & 41 & 17 \\
\hline Relevance for residents & $3.32 \pm 2.55$ & 64 & 19 & 17 \\
\hline Visibility of results & $2.73 \pm 2.00$ & 76 & 17 & 7 \\
\hline \multicolumn{5}{|l|}{ Professionals } \\
\hline Conflict: time consuming & $5.10 \pm 2.45$ & 28 & 40 & 31 \\
\hline Self-efficacy & $3.33 \pm 2.37$ & 63 & 24 & 13 \\
\hline Prioritizing time over care & $3.31 \pm 2.09$ & 62 & 26 & 12 \\
\hline Availability of expertise & $3.10 \pm 1.92$ & 70 & 21 & 9 \\
\hline Sense of difficulty & $2.57 \pm 1.91$ & 79 & 16 & 5 \\
\hline Task perception: taking responsibility & $2.54 \pm 1.72$ & 79 & 17 & 4 \\
\hline Outcome expectations & $2.50 \pm 2.07$ & 78 & 14 & 8 \\
\hline Task perception: task of physiotherapist & $2.49 \pm 1.89$ & 79 & 17 & 5 \\
\hline Risks for residents & $2.45 \pm 1.61$ & 79 & 19 & 2 \\
\hline Sense of importance & $2.39 \pm 1.63$ & 81 & 16 & 4 \\
\hline \multicolumn{5}{|l|}{ Social context } \\
\hline Expectations of colleagues & $4.69 \pm 2.61$ & 42 & 29 & 29 \\
\hline Care routines & $4.36 \pm 2.22$ & 39 & 38 & 22 \\
\hline Communication within team & $3.58 \pm 2.05$ & 58 & 31 & 11 \\
\hline Support of manager & $3.20 \pm 2.21$ & 66 & 24 & 10 \\
\hline Social support of colleagues & $3.18 \pm 2.04$ & 69 & 20 & 11 \\
\hline Referral to responsibility & $3.10 \pm 1.76$ & 65 & 31 & 4 \\
\hline Collaboration with experts & $2.94 \pm 2.35$ & 70 & 17 & 13 \\
\hline \multicolumn{5}{|l|}{ Organizational and economic context } \\
\hline Staffing level & $5.47 \pm 2.48$ & 26 & 34 & 39 \\
\hline Availability of resources & $5.12 \pm 2.16$ & 24 & 48 & 28 \\
\hline Time & $5.02 \pm 2.46$ & 35 & 32 & 33 \\
\hline Educational opportunities & $4.99 \pm 2.55$ & 33 & 33 & 34 \\
\hline Organizational readiness & $4.93 \pm 2.84$ & 37 & 27 & 36 \\
\hline Priority within organization & $4.47 \pm 2.25$ & 37 & 41 & 22 \\
\hline Rules and regulations & $4.17 \pm 2.35$ & 45 & 36 & 19 \\
\hline Presence of experts & $3.31 \pm 2.08$ & 65 & 24 & 11 \\
\hline
\end{tabular}

Barriers presented per level and ranked within that level based on mean scores. A higher mean score indicates a stronger experienced barrier.

${ }^{a}$ Barriers scored on the nine-point scales were categorized into low (score $=1-3$ ), medium (score $=4-6$ ), and high (score $=7-9$ ). Percentages may not add up to $100 \%$ because of rounding. 


\section{Prevalence of nursing staff-experienced barriers}

Table 5.2 provides an overview of the barriers nursing staff experienced with regard to promoting functional activity, arranged according to the level to which they relate: the residents, the professionals, the social context, or the organizational and economic context. As the table shows, the mean scores on the barriers ranged from 2.39 (item on sense of importance on the professional level) to 5.47 (item on staffing level on the organizational and economic context level), out of a theoretical range from 1 to 9. Generally, barriers related to the organizational and economic context were rated most often as a barrier, with the top three ranging from a mean score of 5.47 (SD 2.48, 39\% 'high') for staffing level to 5.02 (SD 2.46, 33\% 'high') for time. Prevalent experienced barriers within the other three levels were the capabilities of the residents (mean 5.37, SD 2.52, 39\% 'high'), conflict: time consuming (mean 5.10, SD 2.45, 31\% 'high'), and the expectations of colleagues (mean 4.69, SD 2.61, 29\% 'high'). The three lowest rated barriers were related to the level of the professionals, with sense of importance having the lowest mean score of all barriers (mean 2.39, SD 1.63, 4\% 'high').

\section{Associations between experienced barriers and promotion of functional activity}

The associations between the extent to which barriers were experienced and the extent to which nursing staff promoted $A D L$, household activities, and miscellaneous activities are presented in Table 5.3. For most barriers, a stronger experience of a barrier is associated with less promotion of $\mathrm{ADL}$, household activities, and miscellaneous activities. For example, less social support from colleagues is associated with less promotion of all the kinds of activities. There are some exceptions, in particular for the barriers related to the residents; none of these barriers are significantly associated with the promotion of all three kinds of activities.

The strength of the associations varies per barrier. While the barriers related to the residents are not, or weakly, associated with the extent to which ADL, household activities, and miscellaneous activities are promoted, most barriers related to professionals and to the organizational and economic context are moderately associated. Compared with the barriers related to the residents, professionals, and the organizational and economic context, some barriers related to the social context are slightly more strongly associated with the three outcome measures, in particular (a lack of) communication within the team about the promotion of activities ( $B=-0.34$ to $-0.36, p<0.001$ ) and (a lack of) referring colleagues to their responsibility in not taking over activities $(B=-0.28$ to $-0.30, p<0.001)$. The sensitivity analyses, in which missing data on the functional activity subscales were imputed with either 1 or 9 , showed similar results (data not shown; available upon request). 


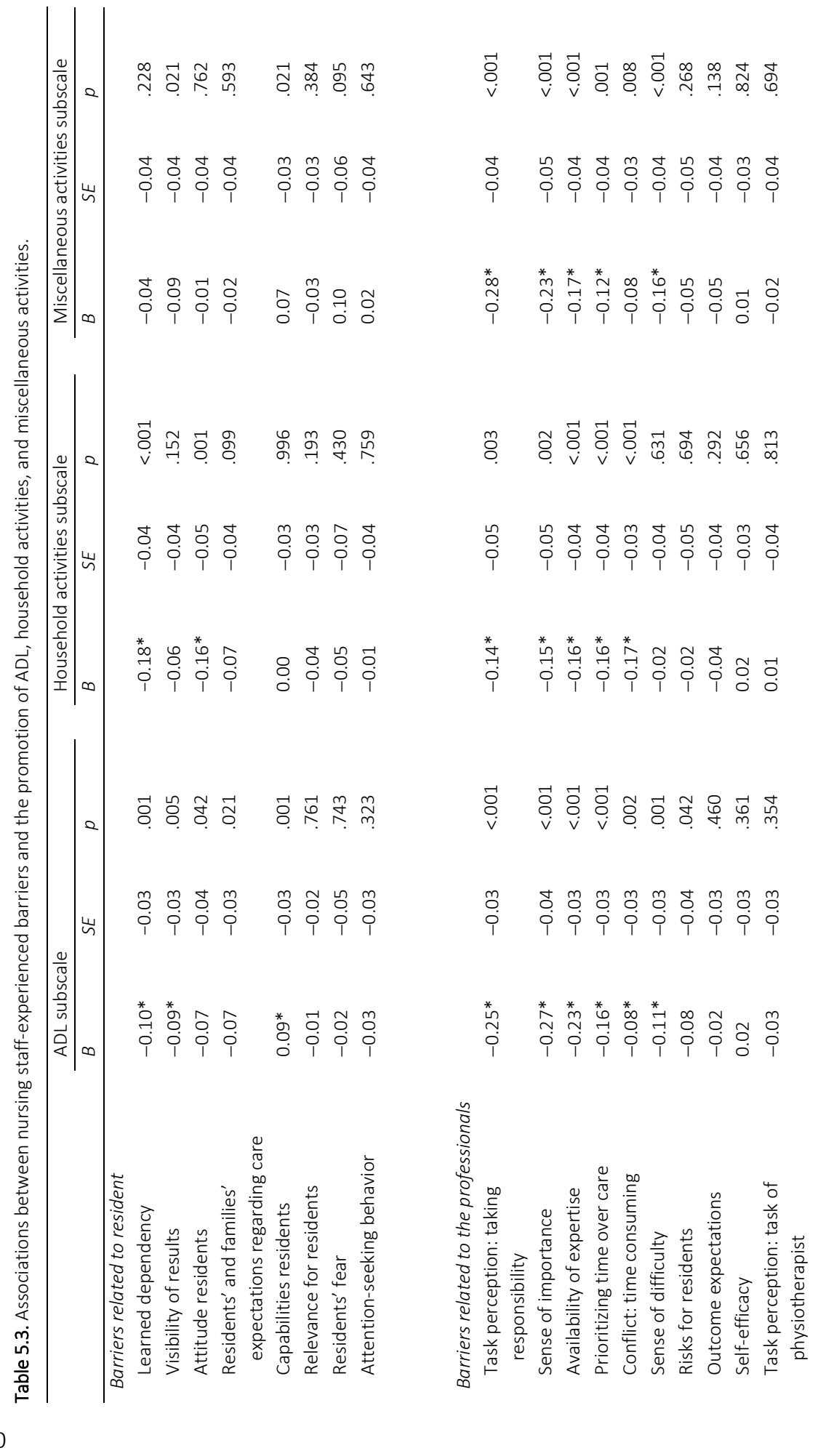




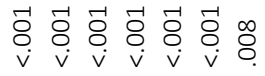

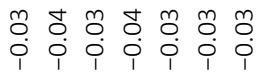

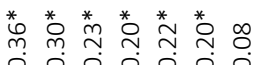

i i i i i i

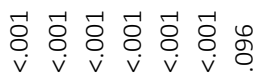

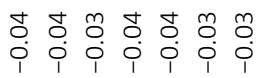

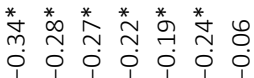

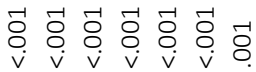

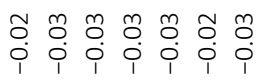

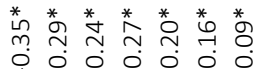

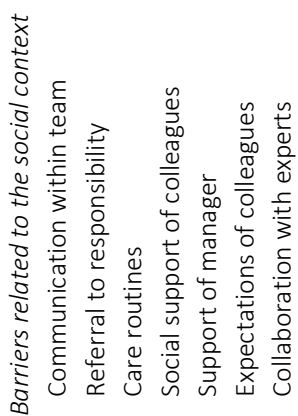

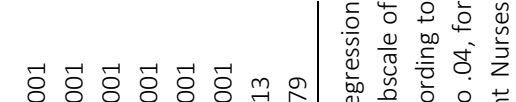

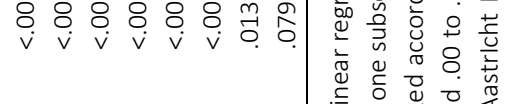

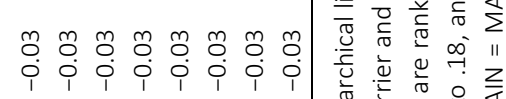

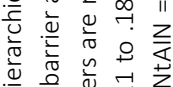

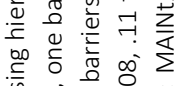

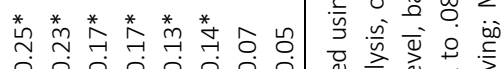
î 势 क्ष

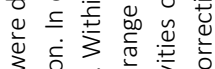

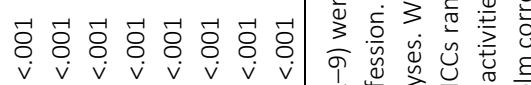

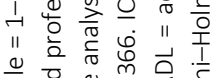

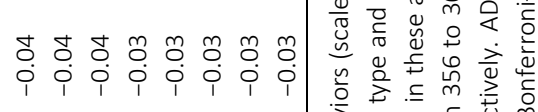

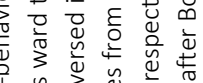

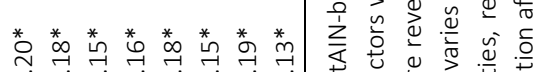

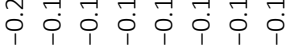

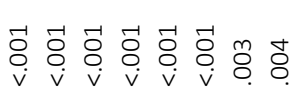

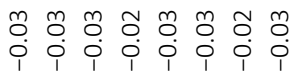

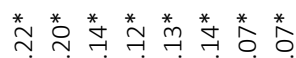

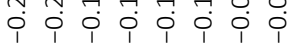

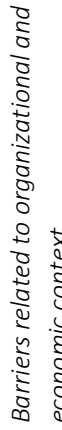


Relative importance of the experienced barriers

Table 5.4 provides an overview of the relative importance of the barriers, based upon (a) how often they are experienced (i.e., the mean score on the nine-point scale) and (b) the mean strength of the association between a barrier and the promotion of ADL, household activities, and miscellaneous activities (data on mean strength of associations can be derived from the Bs in Table 5.3). The most often experienced barriers are staffing levels, capabilities of residents, and availability of resources. In contrast, the barriers that are most strongly associated with the behavior of nursing staff are communication within the team, referral to responsibility, and care routines. The fact that these rankings do not correspond implies that the barriers that are most often experienced among the nursing staff are not the barriers that are most strongly associated with the promotion of functional activity. For instance, although staffing level is the number one barrier according to the nursing staff, based upon the strength of the associations, it is ranked 21st of the 33 barriers. The rankings based on the different kinds of regression (simple linear, unadjusted hierarchical linear, and adjusted hierarchical linear) to determine the relationship between the barriers and the extent to which functional activity was promoted, provided similar results; the top six barriers remained the same and, on average, other barriers mainly traded places (data not shown). 
Table 5.4. Comparison of the barriers based on ranking.

\begin{tabular}{|c|c|}
\hline $\begin{array}{l}\text { Barriers ranked according to the height of the mean } \\
\text { scores on the nine-point scales per item of the } \\
\text { MAINtAIN-barriers }\end{array}$ & $\begin{array}{l}\text { Barriers ranked according to the mean strength } \\
\text { (mean B) of the associations }{ }^{a}\end{array}$ \\
\hline 1. Staffing level $(\mathrm{O})$ & 1. Communication within team (S) \\
\hline 2. Capabilities residents (R) & 2. Referral to responsibility (S) \\
\hline 3. Availability of resources $(\mathrm{O})$ & 3. Care routines $(\mathrm{S})$ \\
\hline 4. Conflict: time consuming (P) & 4. Social support of colleagues (S) \\
\hline 5. Time $(\mathrm{O})$ & 5. Priority within organization $(\mathrm{O})$ \\
\hline 6. Educational opportunities (O) & 6. Task perception: taking responsibility (P) \\
\hline 7. Organizational readiness $(\mathrm{O})$ & 7. Sense of importance $(P)$ \\
\hline 8. Expectations of colleagues (S) & 8. Support of manager (S) \\
\hline 9. Residents' fear (R) & 9. Presence of experts (O) \\
\hline 10. Attitude residents ( $R$ ) & 10. Expectations of colleagues (S) \\
\hline 11. Priority within organization $(\mathrm{O})$ & 11. Availability of expertise (P) \\
\hline 12. Attention-seeking behavior (R) & 12. Availability of resources (O) \\
\hline 13. Care routines $(\mathrm{S})$ & 13. Educational opportunities (O) \\
\hline $\begin{array}{l}\text { 14. Residents' and families' expectations regarding } \\
\text { care (R) }\end{array}$ & 14. Prioritizing time over care $(P)$ \\
\hline 15. Learned dependency (R) & 15. Time (O) \\
\hline 16. Rules and regulations (O) & 16. Rules and regulations $(\mathrm{O})$ \\
\hline 17. Communication within team (S) & 17. Conflict: time consuming (P) \\
\hline 18. Self-efficacy (P) & 18. Organizational readiness $(\mathrm{O})$ \\
\hline 19. Relevance for residents (R) & 19. Learned dependency (R) \\
\hline 20. Prioritizing time over care $(P)$ & 20. Sense of difficulty (P) \\
\hline 21. Presence of experts $(0)$ & 21. Staffing level $(\mathrm{O})$ \\
\hline 22. Support of manager (S) & 22. Visibility of results (R) \\
\hline 23. Social support of colleagues (S) & 23. Attitude residents (R) \\
\hline 24. Referral to responsibility (S) & 24. Collaboration with experts (S) \\
\hline 25. Availability of expertise (P) & $\begin{array}{l}\text { 25. Residents' and families' expectations regarding } \\
\text { care }(R)\end{array}$ \\
\hline 26. Collaboration with experts (S) & 26. Capabilities residents $(R)$ \\
\hline 27. Visibility of results (R) & 27. Risks for residents (P) \\
\hline 28. Sense of difficulty (P) & 28. Outcome expectations (P) \\
\hline 29. Task perception: taking responsibility (P) & 29. Relevance for residents (R) \\
\hline 30. Outcome expectations (P) & 30. Self-efficacy (P) \\
\hline 31. Task perception: task of physiotherapist (P) & 31. Task perception: task of physiotherapist (P) \\
\hline 32. Risks for residents $(P)$ & 32. Residents' fear (R) \\
\hline 33. Sense of importance $(P)$ & 33. Attention-seeking behavior (R) \\
\hline
\end{tabular}

Barriers related to the residents $(R)$, the professionals $(P)$, the social context $(S)$, and the organizational and economic context (O).

${ }^{a}$ Ranking based on the mean strength of the associations between a barrier and the ADL, household activities, and miscellaneous activities subscales (i.e., the mean of the three Bs for each barrier of the adjusted hierarchical linear regression analyses; see Table 5.3). ADL = activities of daily living; MAINtAIN = MAastrlcht Nurses Activities INventory. 


\section{Discussion}

This study showed that the barriers that are most often experienced among nursing staff are not necessarily the barriers that are most strongly associated with their promotion of functional activity among nursing home residents. Barriers toward promoting functional activity are experienced on all levels, that is, the level of residents, the professionals, the social context, and the organizational and economic context. The most prevalent experienced barriers are on the organizational and economic level, for example, staffing levels and the availability of resources. The barriers related to the social context are generally most strongly associated with the perceived promotion of functional activity by nursing staff, particularly (a lack of) communication within the team and (a lack of) referral to responsibilities.

The findings of this study correspond with a review by Benjamin, Edwards, Ploeg, and Legault ${ }^{23}$ who found that the organizational barriers funding and staffing constraints were among the most mentioned barriers across studies, while fear (of falling) and health-related problems (i.e., 'capabilities of residents' in our study) were the most mentioned barriers at resident level. Barriers related to the professionals, for example, the perceived difficulty of promoting functional activity, seem to be less important according to nursing staff. In contrast, studies on evidence-based practice or research utilization often find factors related to the professionals to be major barriers, for instance, a lack of knowledge or skills. ${ }^{17,24,25}$ These differences between barriers on different topics reaffirm that barriers are problem specific ${ }^{26,27}$ and underline the importance of studies that systematically map problem-specific barriers.

Although many studies have mapped nursing staff-experienced barriers, to our knowledge, only a few studies have examined the association between barriers and nursing behavior (e.g., ${ }^{24,28}$ ), of which none focused on the promotion of functional activity by nursing staff. In line with our study, Ebben et al. ${ }^{28}$ found that social factors, for a large part, explain nursing staff adherence to protocol. Although the associations found in the present study may not be very strong, together the barriers related to the social context might to a great extent determine nursing behavior. The rankings of the barriers based on our regression analyses showed that generally barriers related to the social context were present in the top of the ranking. Social context barriers may, therefore, be an important target for strategies aiming to improve the promotion of functional activity, that is, behavior change in nursing staff.

Based on our cross-sectional study, it is likely that the barriers that are important according to the nursing staff are not always the barriers that have the greatest influence on their actual behavior. Due to social desirability, it may be easier for nursing staff to report barriers that are outside of their control. Staffing level, for example, is a barrier that is reported in many studies. ${ }^{16,23,29,30}$ Although nursing staff may intuitively believe that more nursing staff leads to better quality of care, ${ }^{31}$ research shows that this is not always true. ${ }^{32,33}$ This demonstrates that it is important not only to address the 
most prevalent barriers but also to consider which combination of barriers is likely to have the greatest influence on nursing behavior.

\section{Strengths and limitations}

This study has several strengths. First, our data were obtained from a nationwide sample, the variety in nursing homes making it possible to provide an overview of the barriers that matter the most to nursing staff in nursing homes in the Netherlands. Second, in this study, a wide range of barriers was taken into account, which makes it likely that the most important barriers were measured. Consequently, this study provides valuable input for the development of strategies aiming to overcome barriers and improve nursing staff promotion of functional activity. Conversely, some limitations of this study have to be taken into account. First, the cross-sectional design limits the identification of causal relationships between the experienced barriers and nursing staff-perceived behaviors. Second, this study used self-reported questionnaires assessing nursing staff-perceived behavior. Readers should keep in mind that this does not necessarily reflect their actual behavior; ${ }^{34,35}$ respondents might have overestimated the extent to which they promote functional activity. Future studies could investigate this to determine whether other data collection methods, for example, observations, are of added value to nursing staff's self-reports on promoting functional activity. Third, although a reversed facilitator is not always the same as a barrier, ${ }^{16}$ we chose to reverse the answer options of the positive formulated items, so that a higher score always indicated a stronger experienced barrier. The use of a nine-point scale allowed us to treat the barriers and facilitators as a continuum. In addition, presenting all results as barriers increased the readability of this article. However, we do acknowledge the importance of facilitators and recommend focusing not only on decreasing barriers but also on strengthening facilitators.

\section{Implications}

The present study provides implications for research and practice. Future research could include resident perspectives and examine their perceptions of the barriers toward performing functional activities. Future research with longitudinal designs, using repeated measures, could examine whether changes in nursing staff-experienced barriers are associated with changes in nursing behavior. Furthermore, to reduce the barriers nursing staff experience, strategies are needed. Although strategies are available, ${ }^{36,37}$ they are often not very specific or tailored to the nursing home setting. Therefore, further research toward the development, feasibility, and effectiveness of strategies for this setting is warranted.

In nursing practice and nursing education, raising awareness of barriers and their (negative) influence on nursing staff behavior may help to address the barriers. The 
present study showed that barriers are experienced on different levels and that those related to the social context were generally most strongly associated with promotion of functional activity. Studies in different healthcare settings $s^{38,39}$ indicate that the enablement of successful leadership is an example of a potential relevant strategy that could be used to change nursing behavior. By influencing their colleagues, providing feedback, and providing an example, a leader could positively influence the social environment in a ward, reduce barriers, and consequently change nursing behavior. For instance, in addition to rewarding nurses for having someone neat and clean and out of bed before breakfast, a nurse could also be rewarded for promoting a resident's functional activity during the ADL regarding personal care in the morning, particularly if personal care is expressed as important to the resident. Selecting which (combination of) barriers need to be addressed should not solely be based on the strength of the associations between the barriers and nursing behavior. We recommend taking into account the extent to which barriers are experienced by the nursing staff, the probability that changing these barriers is possible, and the likelihood that changes will actually lead to a change in behavior among nursing staff.

\section{Conclusion}

This cross-sectional nationwide study in Dutch nursing homes showed that the barriers that are most often experienced among nursing staff are not the barriers that are most strongly associated with their promotion of functional activity. Nursing staff experience barriers on the level of the residents, the professionals, the social context, and the organizational and economic context. Their most prevalent experienced barriers are related to the organizational and economic context, for example, staffing levels and the availability of resources. However, the barriers that are most strongly associated with the promotion of functional activity act on the level of social context, in particular (a lack of) communication within the team and (a lack of) referral to responsibilities. Based on the results of our study, we recommend that future studies aiming to improve the extent to which nursing staff promote functional activity among nursing home residents address a combination of barriers, including barriers of social context, taking into account both the extent to which barriers are experienced by the nursing staff and the likelihood that a change will actually lead to a change in behavior among nursing staff. 


\section{References}

1. Resnick B, Galik E, Boltz M. Function focused care approaches: Literature review of progress and future possibilities. J Am Med Dir Assoc. 2013;14(5):313-318.

2. Blair CE. Effect of self-care adls on self-esteem of intact nursing home residents. Issues Ment Health Nurs. 1997;20(6):559-570.

3. Edvardsson D, Petersson L, Sjogren K, Lindkvist M, Sandman PO. Everyday activities for people with dementia in residential aged care: Associations with person-centredness and quality of life. Int J Older People Nurs. 2014;9(4):269-276.

4. Peri K, Kerse N, Robinson E, Parsons M, Parsons J, Latham N. Does functionally based activity make a difference to health status and mobility? A randomised controlled trial in residential care facilities (The Promoting Independent Living Study; PILS). Age Ageing. 2008;37(1):57-63.

5. Slaughter SE, Wagg AS, Jones CA, et al. Mobility of Vulnerable Elders Study: Effect of the sit-to-stand activity on mobility, function, and quality of life. J Am Med Dir Assoc. 2015;16(2):138-143.

6. den Ouden M, Bleijlevens MH, Meijers JM, et al. Daily (in)activities of nursing home residents in their wards: An observation study. J Am Med Dir Assoc. 2015;16(11):963-968.

7. Ice HG. Daily life in a nursing home: Has it changed in 25 years? J Aging Stud. 2002;16(4):345-59.

8. MacRae PG, Schnelle JF, Simmons SF, Ouslander JG. Physical activity levels of ambulatory nursing home residents. J Aging Phys Activ. 1996;4:264-278.

9. Sabol VK, Resnick B, Galik E, Gruber-Baldini AL, Morton PG, Hicks GE. Exploring the factors that influence functional performance among nursing home residents. J Aging Health. 2011;23(1):112-134.

10. Kuk NO, Bours, GJJW, Zijlstra GAR, Hamers JPH, Kempen GIJM. Nurses' behaviors and perceived barriers to optimize function among nursing home residents. Paper presented at the The Gerontological Society of America, 68th Annual Scientific Meeting, Orlando, Florida, USA. Gerontologist. 2015;55(Suppl 2):702.

11. Brown D, McWilliam C, Ward-Griffin C. Client-centred empowering partnering in nursing. J Adv Nurs. 2006;53(2):160-168.

12. Davies S, Ellis L, Laker S. Promoting autonomy and independence for older people within nursing practice: An observational study. J Clin Nurs. 2000;9(1):127-136.

13. Resnick B, Gruber-Baldini AL, Zimmerman S, et al. Nursing home resident outcomes from the res-care intervention. J Am Geriatr Soc. 2009;57(7):1156-1165.

14. den Ouden M, Kuk NO, Zwakhalen SMG, Bleijlevens MHC, Meijers JMM, Hamers, JPH. The role of nursing staff in the activities of daily living of nursing home residents. Geriatr Nurs. 2016, Advance online publication.

15. Grol RP, Wensing M. What drives change? Barriers to and incentives for achieving evidence-based practice. Med J Aust. 2004;180(6 Suppl):S57-60.

16. Jun J, Kovner CT, Stimpfel AW. Barriers and facilitators of nurses' use of clinical practice guidelines: An integrative review. Int J Nurs Stud. 2016;60:54-68.

17. Solomons NM, Spross JA. Evidence-based practice barriers and facilitators from a continuous quality improvement perspective: An integrative review. J Nurs Manag. 2011;19(1):109-120.

18. Kuk NO, Zijlstra GAR, Bours GJJW, Hamers JPH, Kempen GIJM. Development and usability of the MAINtAIN, an inventory assessing nursing staff behavior to optimize and maintain functional activity among nursing home residents: A mixed-methods approach. BMC Health Serv Res. 2016;16:38.

19. Resnick B, Petzer-Aboff I, Galik E, et al. Barriers and benefits to implementing a restorative care intervention in nursing homes. J Am Med Dir Assoc. 2008;9(2):102-108.

20. Galik EM, Resnick B, Pretzer-Aboff I. 'Knowing what makes them tick': Motivating cognitively impaired older adults to participate in restorative care. Int J Nurs Pract. 2009;15(1):48-55.

21. Resnick B, Simpson M, Galik E, et al. Making a difference: Nursing assistants' perspectives of restorative care nursing. Rehabil Nurs. 2006;31(2):78-86.

22. Schols JMGA, Crebolder HFJM, van Weel C. Nursing home and nursing home physician: The Dutch experience. J Am Med Dir Assoc. 2004;5(3):207-212. 
23. Benjamin K, Edwards N, Ploeg J, Legault F. Barriers to physical activity and restorative care for residents in long-term care: A review of the literature. J Aging Phys Activ. 2014;22(1):154-165.

24. Boström AM, Kajermo KN, Nordstrom G, Wallin L. Barriers to research utilization and research use among registered nurses working in the care of older people: Does the BARRIERS scale discriminate between research users and non-research users on perceptions of barriers? Implement Sci. 2008;3:24.

25. Sitzia J. Barriers to research utilization: The clinical setting and nurses themselves. Eur J Oncol Nurs. 2001;5(3):154-164.

26. Boström AM, Slaughter SE, Chojecki D, Estabrooks CA. What do we know about knowledge translation in the care of older adults? A scoping review. J Am Med Dir Assoc. 2012;13(3):210-219.

27. Kajermo KN, Boström AM, Thompson DS, Hutchinson AM, Estabrooks CA, Wallin L. The BARRIERS scale the barriers to research utilization scale: A systematic review. Implement Sci. 2010;5:32.

28. Ebben RH, Vloet LC, van Grunsven PM, et al. Factors influencing ambulance nurses' adherence to a national protocol ambulance care: An implementation study in the Netherlands. Eur J Emerg Med. 2015;22(3):199.

29. Abrahamson KA, Fox RL, Doebbeling BN. Original research: Facilitators and barriers to clinical practice guideline use among nurses. Am J Nurs. 2012;112(7):26-35.

30. Strand T, Lindgren M. Knowledge, attitudes and barriers towards prevention of pressure ulcers in intensive care units: A descriptive cross-sectional study. Intensive Crit Care Nurs. 2010;26(6):335-342.

31. Arling G, Mueller C. Nurse staffing and quality: The unanswered question. J Am Med Dir Assoc. 2014;15(6):376-378.

32. Backhaus R, Verbeek H, van Rossum E, Capezuti E, Hamers, JPH. Future distinguishing competencies of baccalaureate-educated registered nurses in nursing homes. Geriatr Nurs. 2015;36(6):438-444.

33. Spilsbury K, Hewitt C, Stirk L, Bowman C. The relationship between nurse staffing and quality of care in nursing homes: A systematic review. Int J Nurs Stud. 2011;48(6):732-750.

34. Dorresteijn TA, Zijlstra GAR, Van Haastregt JC, Vlaeyen JW, Kempen GIJM. Feasibility of a nurse-led inhome cognitive behavioral program to manage concerns about falls in frail older people: A process evaluation. Res Nurs Health. 2013;36(3):257-270.

35. Van de Mortel TF. Faking it: Social desirability response bias in self-report research. Aust J Adv Nurs. 2008;25(4):40-48

36. Cochrane Effective Practice and Organisation of Care Group. Data Collection Checklist. 2002; Retrieved from: http://epoc.cochrane.org/sites/epoc.cochrane.org/files/uploads/datacollectionchecklist.pdf

37. Powell BJ, Waltz TJ, Chinman MJ, et al. A refined compilation of implementation strategies: Results from the Expert Recommendations for Implementing Change (ERIC) project. Implement Sci. 2015;10:21.

38. Gifford WA, Davies BL, Graham ID, Tourangeau A, Woodend AK, Lefebre N. Developing leadership capacity for guideline use: A pilot cluster randomized control trial. Worldviews Evid Based Nurs. 2013;10(1):51-65.

39. Holleman G, van Tol M, Schoonhoven L, Mintjes-de Groot J, van Achterberg T. Empowering nurses to handle the guideline implementation process: Identification of implementation competencies. J Nurs Care Qual. 2014;29(3):E1-E6. 


\section{CHAPTER 6}

\section{Implementation Activities for nursing home staff: Results of a World Café method}

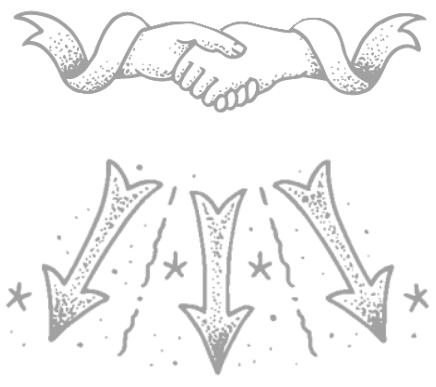

This chapter was submitted for publication as:

Kuk NO, Zijlstra GAR, Hamers JPH, Kempen GIJM, Bours GJJW. Implementation activities for nursing home staff: Results of a World Café method. 


\section{Abstract}

The objective of this study was to identify practical implementation activities aimed at improving functional activity of nursing home residents. A multidisciplinary group of twenty-one professionals from seven nursing homes in the Netherlands participated. Using the World Café method the professionals discussed in small groups during three consecutive rounds the translation of six internationally applied implementation strategies, e.g., education, and multi-disciplinary collaborations, into practical activities. Notes were taken during the discussions. Categorization of the data resulted in 40 practical implementation activities, 23 preconditions in order for the activities to be successful, and 24 content-related remarks. For instance, multidisciplinary collaborations could include that physiotherapists observe preventively at a ward, but this requires a trusting environment in which nursing staff feel acknowledged. Outcomes of this study may support nursing home staff to implement innovations in their daily practice which are aimed at improving functional activity among nursing home residents. 


\section{Introduction}

The importance of encouraging functional activity among nursing home residents has been widely recognized. ${ }^{1-3}$ Performing functional activities is associated with less disruptive behavior and anxiety, ${ }^{3}$ and a higher quality of life of nursing home residents. ${ }^{4}$ Nursing staff can encourage residents to perform their activities of daily living as independently as possible. Nonetheless, certain barriers, such as time constrains, family expectations or the assumption that residents are not able to perform activities, inhibit nursing staff from adopting this behavior, ${ }^{2,5-8}$ making it difficult to implement related innovations. 6,8 To ensure that nursing home staff encourage functional activity, strategies to sustainably change nursing practice are needed.

Overviews of implementation strategies are available, for example, from the Effective Practice and Organization of Care (EPOC) group, ${ }^{9}$ or from the Expert Recommendations for Implementing Change project. ${ }^{10}$ Both include strategies such as 'local opinion leaders' or 'audit and feedback.' The advantages of these overviews are that they are comprehensive and compile strategies which address different levels within healthcare organizations, from nursing staff to management. However, the compiled strategies are generally not very specific or detailed, they often lack practical guidance, and do not match the target group or the context in which they will be used. For example, the audit and feedback strategy can be operationalized in many different ways; ${ }^{11,12}$ it can be provided by email or face to face, by a peer or a manager, etc. To reinforce the successful use of strategies in daily practice, it is important that strategies are described in detail ${ }^{13}$ and tailored to the end-users and the barriers experienced. ${ }^{14}$

Previous studies have argued that it is critical to involve healthcare practitioners early in the implementation process during the development of strategies. ${ }^{15-17}$ In cocreation, strategies can be adjusted to the needs of the end-users, making it more likely that they will be used in practice. ${ }^{18}$ Consequently, to improve nursing home care and operationalize strategies into feasible and practical activities that are tailored to the target group and the context in which they will be used, it seems inevitable to involve nursing home staff. To gather their ideas and specific opinions, qualitative methods, such as individual face-to-face or focus group interviews, could be used. The disadvantages of individual interviews are the lack of interaction and the time it takes to involve multiple professionals. Although focus groups do allow the interaction that may trigger new ideas, the dynamics within the group may foster groupthink and certain people may dominate the discussion. ${ }^{19}$ An efficient and feasible alternative that allows the participation of a large group of different stakeholders in a short amount of time is the World Café method. ${ }^{20}$ Using this method, participants can be persuaded to discuss multiple strategies in small groups of changing compositions. It allows for the crosspollination of ideas, leading to richer data. ${ }^{21,22}$

The objective of this study was to identify practical implementation activities aimed at improving functional activity of nursing home residents using a multidisciplinary 
group of nursing home staff. One condition was set; the implementation activities had to be based on internationally applied implementation strategies. ${ }^{9}$

\section{Methods}

\section{Design}

A cross-sectional study, based on the World Café method, ${ }^{20}$ was conducted among professionals working in nursing homes in the south of the Netherlands in June 2015. Because participants in this study were neither subjected to an intervention nor required to follow rules of behavior, approval from a medical ethics review committee was not required, according to Dutch law. All participants provided written informed consent.

\section{Setting and participants}

Purposive sampling was used to recruit a multidisciplinary group of professionals working in seven nursing homes in the south of the Netherlands. The participating nursing homes were embedded in the Living Lab in Ageing and Long-term Care, a collaboration between these nursing homes and Maastricht University. ${ }^{23}$ In a letter sent to each nursing home, nursing staff, allied health professionals, managers, policy officers, and training officers were invited to participate, in view of involving the broad spectrum of nursing home staff.

\section{Procedures}

In preparation for the current study, six implementation strategies were selected, based on the recommendations of nine international experts (seven researchers with implementation expertise, of whom five were registered nurses, and two registered nurses working in nursing homes and involved in implementation projects). The experts received an overview of implementation strategies from the EPOC taxonomy ${ }^{9}$ (financial strategies excluded), and an overview of those barriers experienced most often by nursing staff when encouraging functional activity among nursing home residents. ${ }^{24}$ Keeping in mind these barriers, the nine experts ranked the strategies according to expected effectiveness and feasibility in nursing homes, and six strategies were selected for the current study: education (a combination of educational meetings and educational outreach visits); audit and feedback; local opinion leaders; local consensus processes; multidisciplinary collaborations (based on the strategy 'clinical multidisciplinary teams'); and disseminating the policy of the organization (not an 
explicit strategy within the EPOC taxonomy, but important, according to the experts). Table 6.1 provides a short description of each strategy.

\section{Data collection}

Data were collected during the World Café conducted at Maastricht University, the Netherlands. The recruited multidisciplinary group of professionals was first introduced to the six strategies and the barriers experienced by nursing staff when encouraging functional activity. Second, the professionals were allocated to six groups of three to five people each, with professionals of different backgrounds. In three consecutive rounds of 30 minutes each, the groups discussed the translation of an implementation strategy into practical activities at a table, with each table covering a different strategy. Participants were instructed to take the barriers experienced by nursing staff and the feasibility of the activities into account during their discussions. During the consecutive rounds, participants registered their findings on a sheet covering their table. After each round the groups were mixed up and the newly formed groups continued discussing the strategies, including the findings of the previous groups. They added their comments using the same sheet and pen. At each table, a moderator, working as a researcher at Maastricht University, was available. All moderators were experienced chairs and received a one-hour training on welcoming participants, taking notes during the rounds, and encouraging participants to be as specific and practical as possible, e.g., probing them to specify what, who, where, and when. During the discussions, the moderators

Table 6.1. Description of the selected strategies.

\begin{tabular}{|c|c|}
\hline Strategy & Description \\
\hline Education & $\begin{array}{l}\text { Use of a trained person who meets with the professionals } \\
\text { and gives information with the intent of changing the } \\
\text { professional's practice. Participation of professionals in } \\
\text { conferences, lectures, workshops or traineeships. }\end{array}$ \\
\hline Audit and feedback & $\begin{array}{l}\text { Any summary of the performance of the professionals over a } \\
\text { specified period of time. }\end{array}$ \\
\hline Local opinion leaders & $\begin{array}{l}\text { Use of professionals nominated by their colleagues as } \\
\text { 'educationally influential.' }\end{array}$ \\
\hline Local consensus processes & $\begin{array}{l}\text { Inclusion of professionals in discussion to ensure that they } \\
\text { agree that the chosen clinical problem (encouraging } \\
\text { activity) is important and that the approach to managing } \\
\text { the problem is appropriate. }\end{array}$ \\
\hline Multidisciplinary collaborations & Collaborations between professionals of different disciplines. \\
\hline Disseminating the policy of the organization & $\begin{array}{l}\text { The ways in which the organization expresses that } \\
\text { encouraging activity is part of the policy of the organization. }\end{array}$ \\
\hline
\end{tabular}

The strategies and descriptions are based on the EPOC taxonomy ${ }^{9}$ except for the strategy 'disseminating the policy of the organization' which was not an explicit strategy within the EPOC taxonomy, but important, according to the experts. 
noted down comments of the participants in case the notes on the table sheets were not clear enough. Lastly, the findings for each strategy were summarized and discussed in a plenary session (30 minutes) at the end of the meeting. During this final discussion, notes were taken by the first author. The full World Café session took about 2.5 hours.

\section{Data analysis}

The data from the table sheets, the notes from the moderators, and the notes from the plenary discussion were analyzed independently by two researchers (trained in qualitative data analysis) using qualitative content analysis. ${ }^{25}$ Any discrepancies in coding were resolved by a third researcher. Relevant text fragments were highlighted. 'Practical activities' were selected from these text fragments. Text fragments that were not categorized as practical activity were given new codes that emerged from the data.

\section{Results}

At total of 21 nursing home professionals participated in the World Cafe; the multidisciplinary group included certified nurse assistants $(n=4)$, registered nurses $(n=$ 9), a physiotherapist $(n=1)$, an occupational therapist $(n=1)$, a manager $(n=1)$, a policy officer $(n=1)$, and training officers $(n=4)$.

Categorization of the data obtained from the World Café resulted in: (a) practical activities related to each strategy, (b) preconditions in order for the activity to be successful, and (c) remarks related to the content of the activities (Table 6.2). Participants proposed a total of 40 practical activities that nursing staff can apply to implement innovations to improve functional activity in nursing home residents. Most activities, 10 in total, were suggested for the strategy 'local opinion leaders.' 'Multidisciplinary collaborations' and 'disseminating the policy of the organization' were each translated into 7 distinct activities. 'Local consensus processes' was translated into 6 activities, and 'audit and feedback' and 'education' were each translated into 5 activities. Table 6.2 provides a detailed overview of the activities per strategy, the proposed preconditions, and the content-related remarks. For example, participants stressed that, when education is provided, it is important to use examples and to compliment staff when they perform the desired behavior. With regard to local consensus processes, participants stated that these could take place in the form of monthly meetings between staff and, if desired, allied health professionals; during these meetings, propositions can be discussed and, when consensus is reached, goals can be set. However, a precondition for success for these meetings was that there should be a safe and trusting environment. Furthermore, participants suggested that the policy of the organization could be disseminated by means of a newsletter; within such newsletters clear and understandable language should be used. 


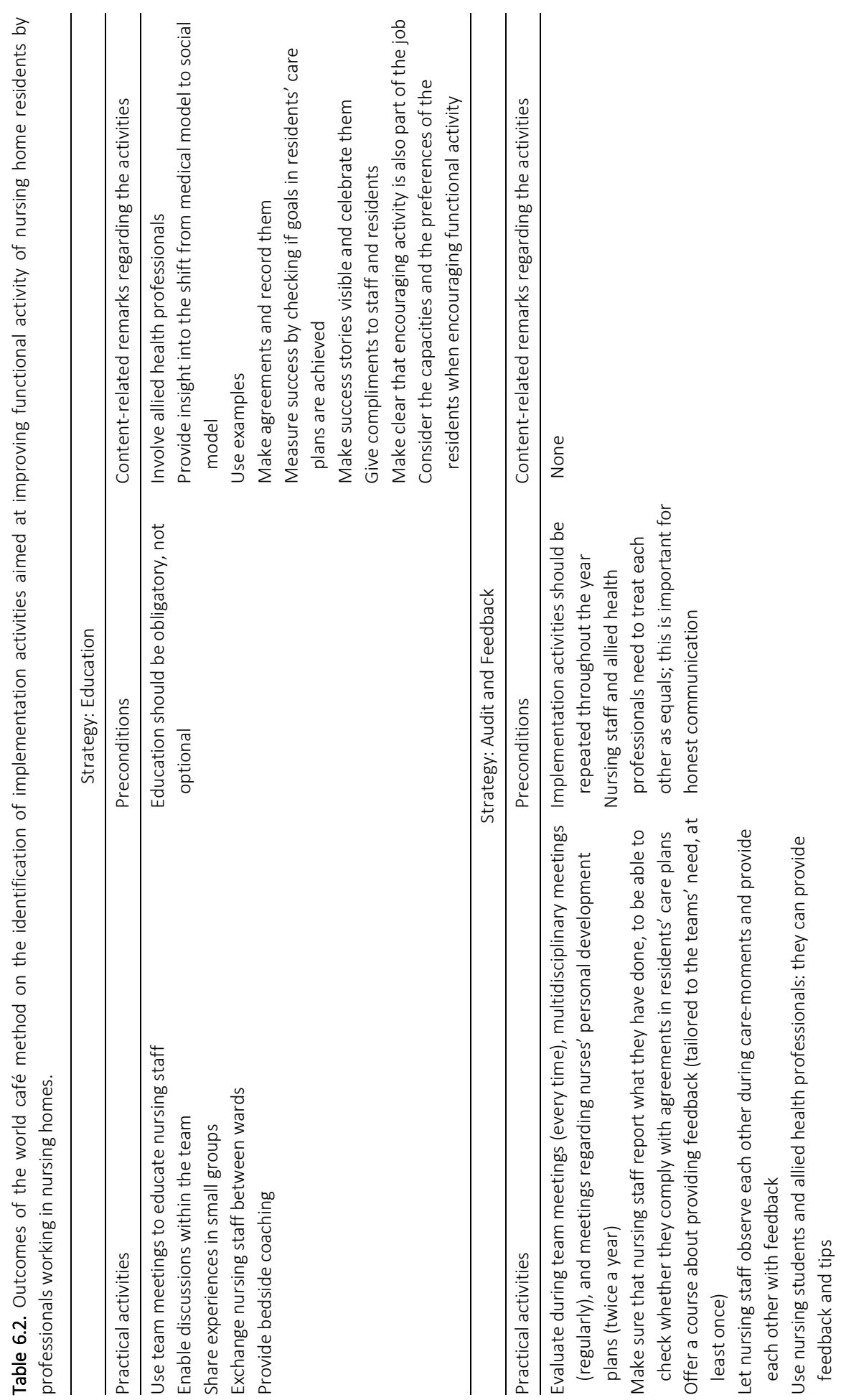




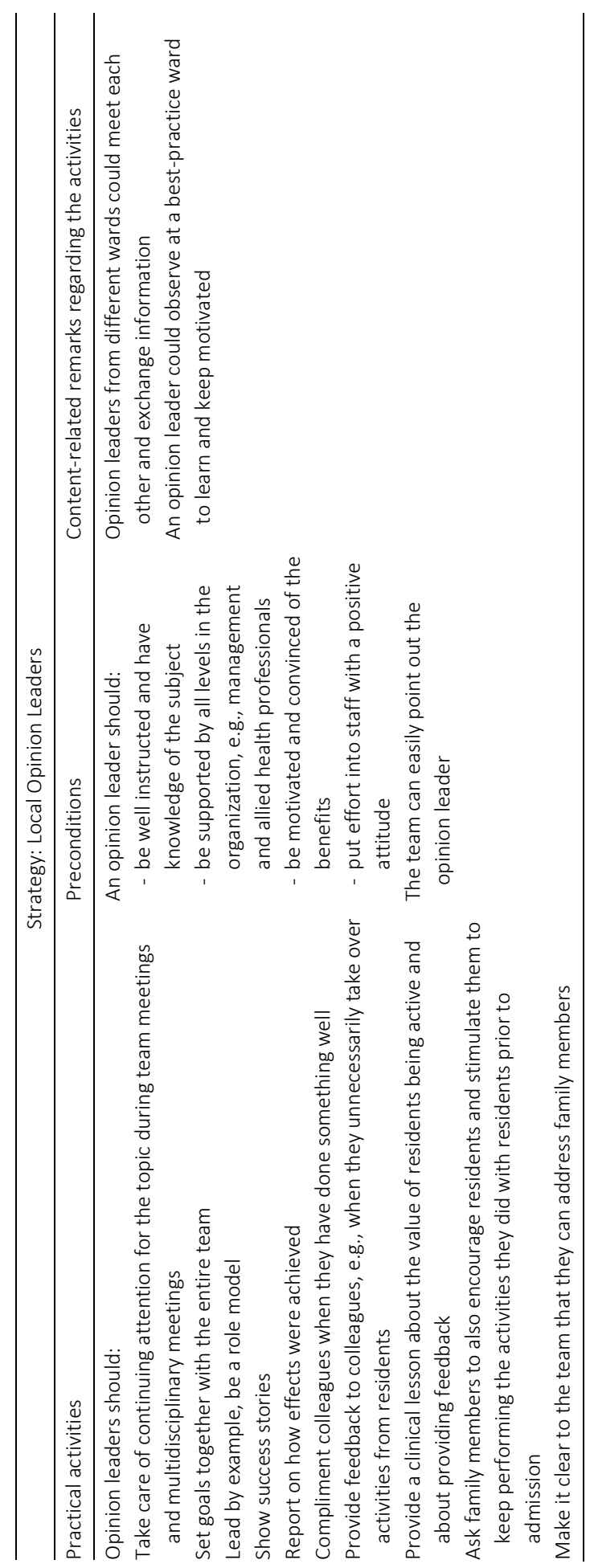




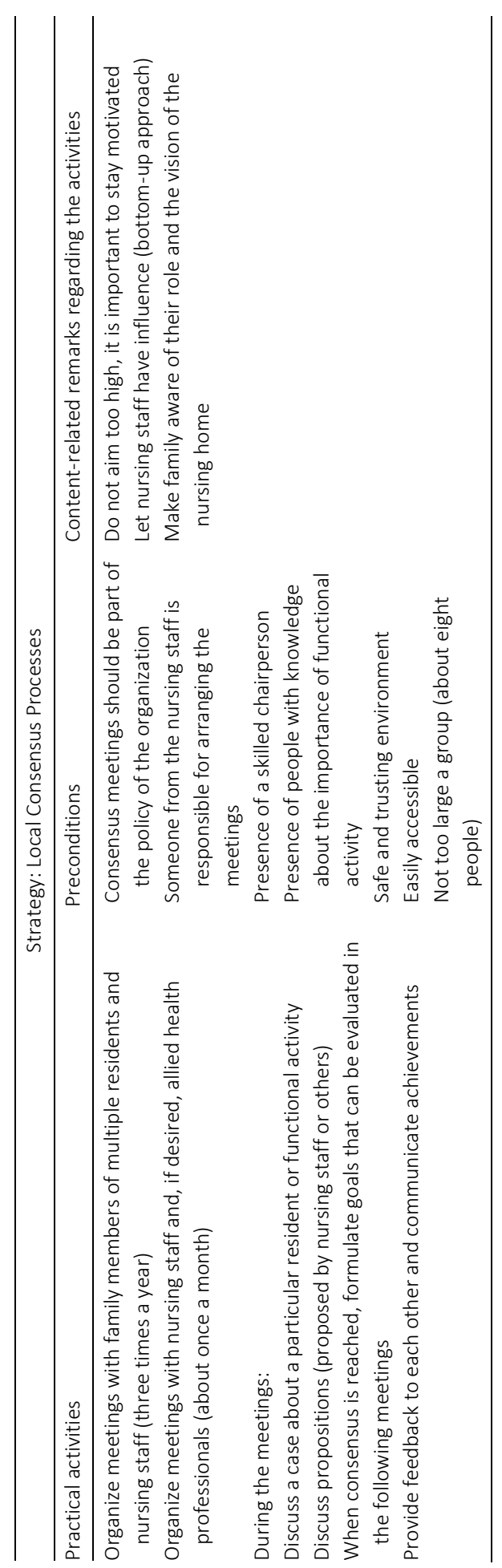




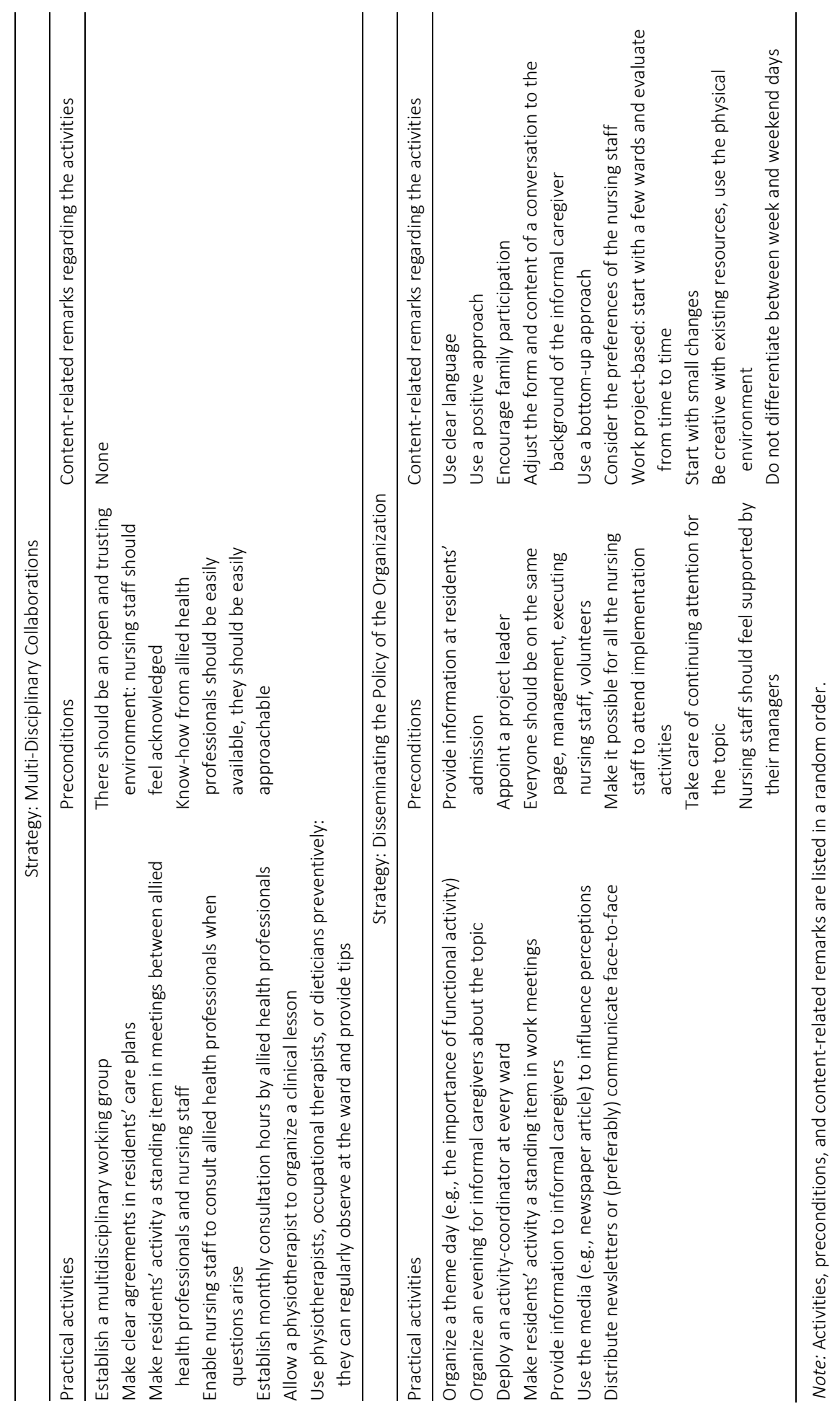




\section{Discussion}

In this study 40 practical implementation activities were identified using the World Café method. These implementation activities can be used by nursing staff to implement innovations aimed at improving functional activity among nursing home residents. In specifying the activities, participants mentioned pre-conditions and content-related remarks. Activities ranged from organizing a theme day for the strategy 'expressing the policy of the organization' to exchanging staff between wards for the strategy 'education.'

The multidisciplinary group of nursing home staff proposed a wide range of implementation activities. Some activities were more well defined than others. For example, respondents were not specific about how often the educational activities should take place or who should take the lead in these activity. Yet, these are aspects that can help to operationalize, measure, and evaluate strategies when they are used in research or practice. ${ }^{13}$ Some of the moderators considered it quite challenging to prompt participants to think about the details of an activity. Nonetheless, to be able to replicate and evaluate strategies, previous studies have argued that it is essential to clearly describe them. ${ }^{13}$ To achieve this, Proctor et al. ${ }^{13}$ recommended naming, defining and specifying strategies.

In the present study, the nursing home professionals co-created the content of the strategies. Previous studies have emphasized the importance of involving professionals in the development and implementation of strategies. ${ }^{15-18}$ One advantage of the involvement of nursing home professionals is that it increases the chance that strategies are feasible in the nursing home setting and are adjusted to their local context. $^{17}$ This makes it more likely that an innovation is successfully implemented. ${ }^{26}$ Another advantage of involving nursing home staff in the process of identifying implementation activities is the support that it creates among the participants; it may enhance a feeling of ownership. The participants in the World Café could be the advocates for the innovation in their nursing homes and ensure that the strategies are maintained. ${ }^{18}$ As such, the World Café method by itself can be a strategy to catalyze the implementation process.

Due to the varying backgrounds of the participants (i.e., a multidisciplinary group of professionals from different nursing homes, mainly nurses but also other staff), it is likely that the activities resulting from this study are applicable to a broad context. This increases the external validity of the results. Consequently, the results from this study can provide valuable input for nursing homes aiming to change their practice. Participants were instructed to take into account the barriers to encouraging functional activity among nursing home residents that are most commonly experienced by nursing staff in the Netherlands. ${ }^{24}$ However, nursing homes differ within and across countries, ${ }^{27}$ therefore activities should always be further adjusted to local settings and local barriers, ${ }^{26}$ involving local professionals. ${ }^{28}$ Nonetheless, to be able to replicate and 
compare activities it is important that adjustments to the activities are reported in detail. $^{11,13,29}$

In this study we aimed to identify implementation activities that nursing staff can apply to change practice on their wards. The input from a heterogeneous group of staff from multiple nursing homes led to a broad range of practical activities. These practical activities originate from promising strategies. Yet, further research is needed to examine whether these activities are effective and feasible in practice. When nursing staff apply the activities in practice, we recommend using a structured approach. Such an approach could comprise, for example, formulating clear aims, mapping current nursing behavior and local barriers, and evaluating changes in nursing practice.

\section{Limitations}

Despite the advantages of the co-creation method used in this study, there are several methodological limitations. We cannot eliminate the possibility that some remarks made by the participants of the World Café might have been missed due to data being recorded by notes from the respondents and the moderators, instead of audio recordings. What might also have decreased the trustworthiness of the data and affect the extent to which remarks of participants were taken into account is the lack of a

member check. ${ }^{30,31}$ Although participants had the opportunity to comment on the findings during the plenary discussion and summary at the end of the World Café session, data were not send to the participants afterwards. Furthermore, several moderators were involved in this study, of which some were more experienced than others. Although the moderators received a short training, their performance may have influenced the data collection process. As a consequence, some strategies may be more thoroughly defined than others.

\section{Conclusions}

This study involving a multidisciplinary group of nursing home staff resulted in an overview of specific practical tailored implementation activities. These activities can be used by nursing home staff, in particular, nurses, to implement innovations into daily nursing practice aimed at improving functional activity among nursing home residents. Although this overview is not exhaustive, it offers nursing home staff valuable ideas on activities that may increase the chance of successful implementation. Future users are recommended to select a well-considered combination of strategies or activities that fit their interests. If needed, small adjustments can be made to make the activities fit their local context and barriers, however, any adjustments made should be clearly reported. Further research could examine the effectiveness and feasibility of the activities in practice. 


\section{References}

1. den Ouden M, Bleijlevens MH, Meijers JM, et al. Daily (in)activities of nursing home residents in their wards: An observation study. J Am Med Dir Assoc. 2015;16(11):963-968.

2. Galik EM, Resnick B, Pretzer-Aboff I. 'Knowing what makes them tick': Motivating cognitively impaired older adults to participate in restorative care. Int J Nurs Pract. 2009;15(1):48-55.

3. Resnick B, Galik E, Boltz M. Function focused care approaches: Literature review of progress and future possibilities. J Am Med Dir Assoc. 2013;14(5):313-318.

4. Edvardsson D, Petersson L, Sjogren K, Lindkvist M, Sandman PO. Everyday activities for people with dementia in residential aged care: Associations with person-centredness and quality of life. Int J Older People Nurs. 2014;9(4):269-276.

5. Benjamin K, Edwards N, Ploeg J, Legault F. Barriers to physical activity and restorative care for residents in long-term care: A review of the literature. J Aging Phys Act. 2014;22(1):154-165.

6. Hummer DB, Silva SG, Yap TL, Toles M, Anderson RA. Implementation of an exercise program in an assisted living facility. J Nurs Care Qual. 2015;30(4):373-379.

7. Kuk NO, Zijlstra GAR, Bours GJJW, Hamers JPH, Kempen GIJM. Development and usability of the MAINtAIN, an inventory assessing nursing staff behavior to optimize and maintain functional activity among nursing home residents: A mixed-methods approach. BMC Health Serv Res. 2016;16:38.

8. Resnick B, Galik E, Gruber-Baldini A, Zimmerman S. Understanding dissemination and implementation of a new intervention in assisted living settings: The case of function-focused care. J Appl Gerontol. 2013;32(3):280-301.

9. Cochrane Effective Practice and Organisation of Care Group. Data Collection Checklist. 2002; Retrieved from: http://epoc.cochrane.org/sites/epoc.cochrane.org/files/uploads/datacollectionchecklist.pdf.

10. Powell BJ, Waltz TJ, Chinman MJ, et al. A refined compilation of implementation strategies: Results from the Expert Recommendations for Implementing Change (ERIC) project. Implement Sci. 2015;10:21.

11. Improved Clinical Effectiveness through Behavioural Research Group (ICEBeRG). Designing theoreticallyinformed implementation interventions. Implement Sci. 2006;1:4.

12. Wuchner SS. Integrative review of implementation strategies for translation of research-based evidence by nurses. Clin Nurse Spec. 2014;28(4):214-223.

13. Proctor EK, Powell BJ, McMillen JC. Implementation strategies: Recommendations for specifying and reporting. Implement Sci. 2013;8(1):1.

14. van Achterberg T, Schoonhoven L, Grol R. Nursing implementation science: How evidence-based nursing requires evidence-based implementation. J Nurs Scholarsh. 2008;40(4):302-310.

15. de Veer AJ, Fleuren MA, Bekkema N, Francke AL. Successful implementation of new technologies in nursing care: A questionnaire survey of nurse-users. BMC Med Inform Decis Mak. 2011;11:67.

16. Greenhalgh T, Robert G, Macfarlane F, Bate $P$, Kyriakidou O. Diffusion of innovations in service organizations: Systematic review and recommendations. Milbank Q. 2004;82(4):581-629.

17. Powell BJ, Beidas RS, Lewis CC, et al. Methods to improve the selection and tailoring of implementation strategies. J Behav Health Serv Res. 2015:1-18.

18. Rahman AN, Applebaum RA, Schnelle JF, Simmons SF. Translating research into practice in nursing homes: Can we close the gap? Gerontologist. 2012;52(5):597-606.

19. Polit DF. Nursing research : generating and assessing evidence for nursing practice Philadelphia: Wolters Kluwer Health; 2017.

20. Brown J. The World Cafe: Shaping our futures through conversations that matter. 1st ed. San Fransisco, CA: Berrett-Koehler Publishers; 2005.

21. Fouche C, Light G. An Invitation to Dialogue: 'The World Cafe' in social work research. Qual Soc Work. 2010;10(1):28-48.

22. Hüttinger L, Schiele $H$, Schröer D. Exploring the antecedents of preferential customer treatment by suppliers: A mixed methods approach. Supply Chain Manag. 2014;19(5/6):697-721. 


\section{CHAPTER 6}

23. Verbeek H, Zwakhalen SM, Schols JM, Hamers JP. Keys to successfully embedding scientific research in nursing homes: A win-win perspective. J Am Med Dir Assoc. 2013;14(12):855-857.

24. Kuk NO, Zijlstra GAR, Bours GJJW, Hamers JPH, Tan FES, Kempen GIJM. Promoting functional activity among nursing home residents: A cross-sectional study on barriers experienced by nursing staff. J Aging Health. 2017, Advance online publication.

25. Hsieh HF, Shannon SE. Three approaches to qualitative content analysis. Qual Health Res. 2005;15(9):1277-1288

26. Baker R, Camosso-Stefinovic J, Gillies C, et al. Tailored interventions to address determinants of practice. Cochrane Database Syst Rev. 2015;4:CD005470.

27. Sanford AM, Orrell M, Tolson D, et al. An international definition for "nursing home". J Am Med Dir Assoc. 2015;16(3):181-184.

28. Chambers DA, Azrin ST. Research and services partnerships: Partnership: A fundamental component of dissemination and implementation research. Psychiatr Serv. 2013.

29. Gold R, Bunce AE, Cohen DJ, et al. Reporting on the strategies needed to implement proven interventions: An example from a "real-world" cross-setting implementation study. Mayo Clinic proceedings. 2016;91(8):1074-1083.

30. Malterud K. Qualitative research: Standards, challenges, and guidelines. Lancet. 2001;358(9280):483488.

31. O'Brien BC, Harris IB, Beckman TJ, Reed DA, Cook DA. Standards for reporting qualitative research: A synthesis of recommendations. Acad Med. 2014;89(9):1245-1251. 


\section{CHAPTER 7}

\section{Feasibility of the Translating Innovations into}

Practice-toolbox (TIP-toolbox): A mixedmethods study for implementing activity innovations in nursing homes

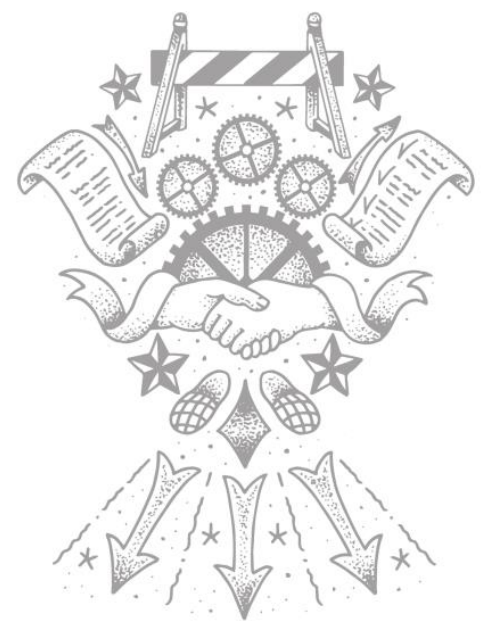

This chapter was accepted for publication as:

Kuk NO, Bours GJJW, Hamers JPH, Kempen GIJM, Zijlstra GAR. Feasibility of the Translating Innovations into Practice-toolbox (TIP-toolbox): A mixed-methods study for implementing activity innovations in nursing homes. Geriatric Nursing. 2017 (epub ahead of print). doi: 10.1016/j.gerinurse.2017.03.011. 


\section{Abstract}

This mixed-methods study evaluated the feasibility of the Translating Innovations into Practice (TIP)-toolbox. This toolbox guided nursing staff in six practical steps in developing a structured and tailored implementation plan to sustainably implement an innovation. For 9 weeks, twelve registered nurses (RNs) at three nursing homes in the Netherlands used the TIP-toolbox to develop an implementation plan related to promoting functional activity among nursing home residents. Data were collected by questionnaires, telephone interviews, participant observations, and focus group interviews. The RNs conducted most steps according to the plan. The main hampering and facilitating factors were a lack of support and collaboration. Most RNs were satisfied with the TIP-toolbox, but some considered it somewhat complex. To increase satisfaction and reduce the toolbox's complexity, the participants made suggestions for improvements. The findings of this study indicate that the TIP-toolbox was feasible and supported nursing staff in developing an implementation plan, although minor adaptations are needed. 


\section{Introduction}

Nursing staff are expected to provide high-quality care. They need to provide care according to the latest evidence. Nonetheless, studies show that a gap exists between the available evidence and nursing practice. ${ }^{1-5}$ For example, research shows a lack in the use of best practices regarding mouth care, ${ }^{1}$ urinary catheter care, ${ }^{2}$ prevention of pressure ulcers, ${ }^{3}$ and promotion of activity. ${ }^{5}$ To bridge the gap between evidence and practice, it is important to implement evidence-based innovations. ${ }^{6}$ In this study, we particularly focused on implementing innovations related to the promotion of functional activity.

Successful implementation requires the use of a structured approach in which local barriers are considered and strategies are used to overcome these barriers. ${ }^{7}$ In nursing practice, registered nurses (RNs) can be the driving force behind the implementation. Involvement of such frontline staff in the implementation process increases the commitment toward the innovation. ${ }^{8}$ The interpersonal contact between these RNs and other nursing staff improves the likelihood that nursing practice can be changed. ${ }^{9,10}$ To facilitate RNs in implementing innovations in a structured manner and to bridge the gap between evidence and practice, the Translating Innovations into Practice (TIP)-toolbox was developed.

The TIP-toolbox was based on the Implementation of Change Model of Grol and colleagues, a model integrating several theories and models for change. ${ }^{11}$ In the six practical steps of the toolbox, users are guided toward developing a structured and tailored implementation plan to sustainably implement an innovation. Each step supports the user to critically appraise what is essential to implement an intended change in a specific context. The TIP-toolbox comprised several tools to facilitate the development of an implementation plan. Nursing home staffers were actively involved in the development of the different parts of the TIP-toolbox. In the toolbox's current form, the innovation to be implemented entailed nursing staff-promotion of functional activity among nursing home residents. This included encouraging residents' independence during the activities of daily living (for example, bathing) as well as encouraging them to perform household activities (for example, setting and clearing the table). Focusing on nursing homes is relevant given the scarcity of evidence regarding the implementation of change, particularly in this setting. ${ }^{12}$ Promoting functional activity is a highly relevant topic in nursing homes. In the last decade, several studies have investigated how nursing staff can encourage nursing home residents to be more active during the day ${ }^{13-16}$; however, residents are still highly inactive. ${ }^{17,18} \mathrm{~A}$ recent observation study in the Netherlands showed that when nursing staff were involved in residents' activities, they took over $45 \%$ of these activities. ${ }^{5}$ To implement change and improve nursing care, an instrument like the TIP-toolbox can be used.

The aim of this study was to evaluate the feasibility of the TIP-toolbox, an instrument developed to support nursing staff step-by-step in implementing an 
innovation in nursing homes in order to further improve the toolbox for the needs of its end-users. Feasibility was studied by assessing the dose (the extent to which all steps of the TIP-toolbox were conducted), the fidelity (application of the TIP-toolbox as planned), the context (facilitating or hampering factors), the satisfaction (participants' satisfaction with the TIP-toolbox), complexity (the perceived complexity of the TIPtoolbox), and adaptations (suggested adaptations to achieve better outcomes).

\section{Methods}

\section{Design}

This feasibility study used a mixed-methods design, including qualitative and quantitative measures. Across-method triangulation ${ }^{19}$ was conducted to obtain rich data. Data were collected by questionnaires, telephone interviews, participant observations, and focus group interviews. The study was conducted from March 2016 to May 2016. The Medical Ethical Review Committee of Zuyderland-Zuyd approved the study protocol (\#16-N-31). All participants provided informed consent. The CONSORT checklist for feasibility trials ${ }^{20}$ and the CASP guidelines for qualitative research ${ }^{21}$ were considered in reporting this study.

\section{Setting and sample}

The study was conducted in three nursing homes in the south of the Netherlands. These nursing homes are embedded in the Living Lab in Ageing and Long-Term Care, ${ }^{22}$ a structural collaboration between seven organizations providing long-term care (home care and nursing home care), Maastricht University, and Zuyd University of Applied Sciences. The three participating nursing homes acknowledged the importance of promoting functional activity and had a task-force on improving activity in general. Two of the nursing homes provided psychogeriatric care for people with dementia and one nursing home provided somatic care for people with chronic physical problems. The three involved nursing homes comprised seven, one, and four wards, respectively. From each ward, one RN participated in this study (12 RNs in total). A purposive sampling method was used to recruit the RNs; each ward was asked to recruit one RN with a bachelor's degree or, if not available, an RN with 4 years of secondary-vocational training. This RN was, preferably, familiar with the ins and outs of the organization, competent in communicating and collaborating, and regarded as a role model. For the participant observations, three of the 12 RNs were randomly selected by the research team: one bachelor-educated RN and two vocationally-trained RNs. 
Table 7.1. Content of the TIP-toolbox and timeline.

\begin{tabular}{|c|c|c|}
\hline Steps of the TIP-toolbox & Components & Timeline \\
\hline $\begin{array}{l}\text { Step 1: Formulating a proposal for } \\
\text { change in practice with clear targets }\end{array}$ & $\begin{array}{l}\text { Formulation of a proposal for change } \\
\text { Formulation of SMART goals }\end{array}$ & Week 1 \\
\hline $\begin{array}{l}\text { Step 2: Assessing the performance of } \\
\text { nursing staff and existing barriers and } \\
\text { formulating specific targets for } \\
\text { change }\end{array}$ & $\begin{array}{l}\text { Administering the MAINtAIN-behaviors and MAINtAIN- } \\
\text { barriers among at least five nurses in the ward and } \\
\text { verifying completion } \\
\text { Entry of the data into a data-analysis tool } \\
\text { Creating an overview of the functional activities that } \\
\text { are the least encouraged } \\
\text { Creating an overview of the most mentioned barriers } \\
\text { Formulation of specific SMART targets for change } \\
\text { based on the behaviors of the nursing staff }\end{array}$ & Weeks 2 \& 3 \\
\hline $\begin{array}{l}\text { Step 3: Selecting and tailoring a set of } \\
\text { strategies }\end{array}$ & $\begin{array}{l}\text { Selection of strategy related to nursing professionals } \\
\text { and/or the social context and/or the organizational } \\
\text { context } \\
\text { Tailoring selected strategies to the most important } \\
\text { barriers }\end{array}$ & Weeks 4 \& 5 \\
\hline $\begin{array}{l}\text { Step 4: Planning the implementation } \\
\text { process }\end{array}$ & $\begin{array}{l}\text { Developing a realistic action plan } \\
\text { Contacting persons who could conduct the } \\
\text { implementation strategies }\end{array}$ & $6 \& 7$ \\
\hline $\begin{array}{l}\text { Step 5: Integrating improvement } \\
\text { within the normal practice routines }\end{array}$ & $\begin{array}{l}\text { Deciding which activities have to be undertaken to } \\
\text { make the innovation lasting }\end{array}$ & Weeks $8 \& 9$ \\
\hline $\begin{array}{l}\text { Step 6: Evaluating (and revising) the } \\
\text { plan }\end{array}$ & $\begin{array}{l}\text { Deciding on how the implementation process should } \\
\text { be evaluated }\end{array}$ & Weeks 8 \& 9 \\
\hline
\end{tabular}

TIP-toolbox = Translating Innovations into Practice-toolbox; SMART = Specific, Measurable, Attainable, Realistic, Time-sensitive; MAINtAIN = MAastrlcht Nurses Activities INventory.

\section{The TIP-toolbox}

The aim of the TIP-toolbox was to support nursing staff in developing a structured and tailored implementation plan to sustainably implement an innovation in a specific setting. To guide nursing staff during this process, the toolbox comprised six steps that were derived from the Implementation of Change Model of Grol and colleagues. ${ }^{11}$ Table 7.1 provides an overview of the six steps. The TIP-toolbox took the form of a paper booklet that could also be viewed digitally (in PDF) and was supplemented with electronic tools. It started with an introduction about the importance of promoting functional activity among nursing home residents, the preconditions for an implementation project, and a thorough description of the six steps. To assist the nursing staff in the steps, the TIP-toolbox contained several tools (Figure 7.1). 


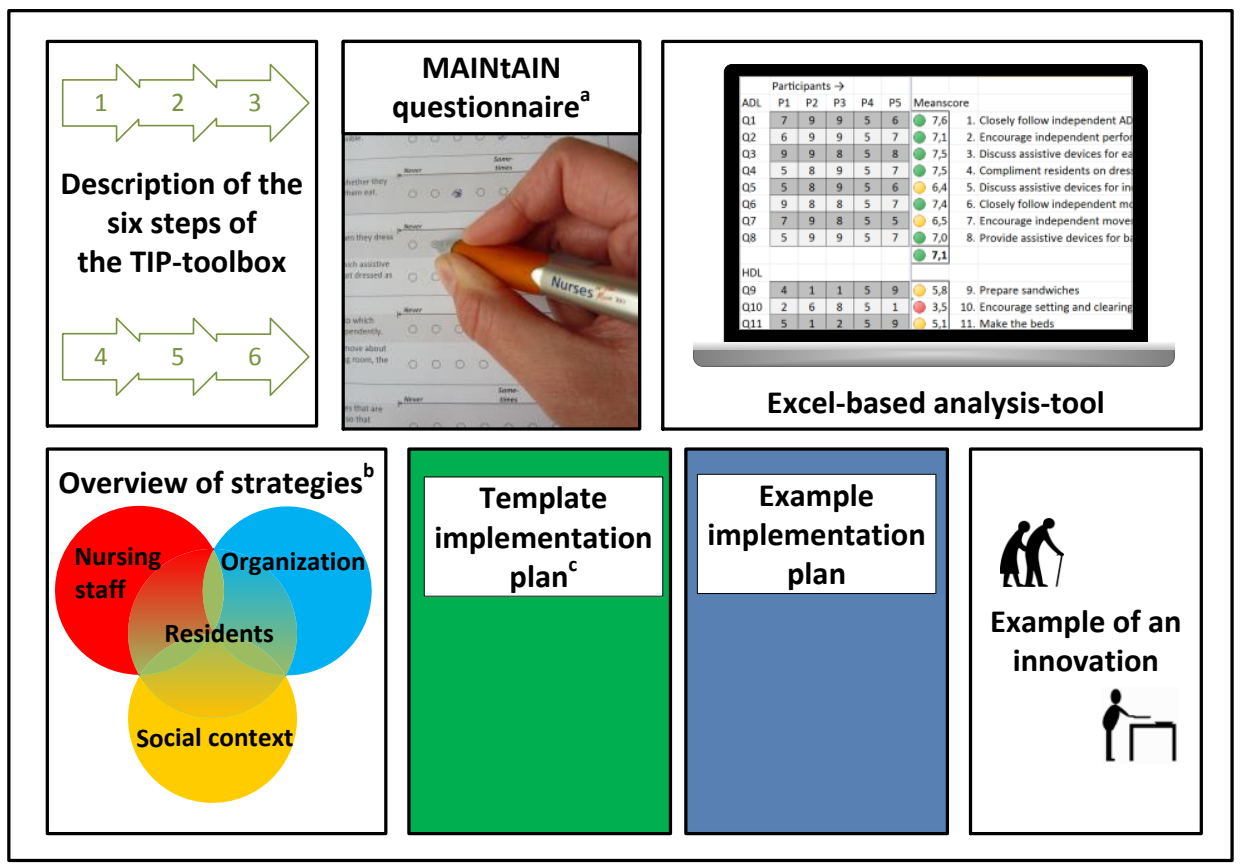

Figure 7.1. Content of the TIP-toolbox.

MAINtAIN = MAastrlcht Nurses Activities INventory; TIP-toolbox = Translating Innovations into Practicetoolbox.

${ }^{a}$ The MAINTAIN questionnaire included the MAINTAIN behaviors and MAINtAIN barriers ${ }^{23}$ for assessing the extent to which nursing staff promote functional activity among residents and the perceived barriers and facilitators that staff may encounter, respectively. ${ }^{b}$ The implementation strategies (aimed at nursing professionals, the social context, and the organization) were developed in co-creation with nursing home staff from different long-term care organizations in the Netherlands. ${ }^{24}$ Strategies included, among others, providing a clinical lesson, exchanging nursing staff between wards, and organizing a theme day. 'The step-by-step template for an implementation plan was available on paper as well as in electronic format, in Microsoft Word and PDF.

The TIP-toolbox was introduced to the participating RNs during a 1-hour educational meeting at the start of the study. In this meeting, guided by the first author, a researcher trained in implementation in healthcare, the RNs were briefly introduced to the steps of the TIP-toolbox, informed about the importance of implementing innovations in a structured manner, and asked to observe to what extent functional activities are promoted in their ward during daily care. For the current study, a timeline was set (Table 7.1). Within a period of 9 weeks, the RNs needed to develop an implementation plan for an activity-related innovation using Steps 1 through 6 of the TIP-toolbox. This implied that the RNs were not expected to actually implement the innovation within the given 9 weeks. 


\section{Data collection}

Feasibility was evaluated based on the relevant key elements of a process evaluation. ${ }^{25,26}$ Elements assessed were fidelity, dose, context, satisfaction, complexity, and adaptations. Table 7.2 provides an overview of the operationalization of these elements and the corresponding data collection methods.

Fidelity and dose were assessed on the basis of parts of the implementation plan that participants emailed to the research team every 1 or 2 weeks after the completion of each step. The elements context, satisfaction, complexity, and adaptations were assessed using web-based questionnaires, telephone interviews, participant observations, and focus group interviews. After each step, the participants completed a web-based questionnaire that was created with Qualtrics survey software (Qualtrics, Provo, UT, USA). These questionnaires included open-ended questions on the elements operationalized as depicted in Table 7.2. Satisfaction and complexity (including the capability to complete the steps and the difficulty experienced) were also rated on a scale from 1 to 10, ranging from very dissatisfied to very satisfied, not at all capable to very capable, and very easy to very difficult, respectively. To ensure that all necessary data were gathered, the questionnaire was followed by a short telephone interview. In addition, the first author, who was trained in qualitative research, conducted participant observations each time the three selected RNs executed a step of the TIPtoolbox. During these observations, field notes were taken and difficulties were discussed. Finally, at the end of the study, two focus group interviews were conducted; the participants were divided into two groups to allow active participation. The first author moderated the focus group interviews using a topic list that was based on the previously mentioned key elements of process evaluation as summarized in Table 7.2 (for example, participants' satisfaction with the toolbox and the complexity of the toolbox). Notes were taken by a second researcher and audio-recordings were made. A summary of the outcomes of the focus group was sent to each participant for a member check.

Additionally, the background characteristics of the participants (gender, ward type where they worked, profession, age, years of professional experience, and number of work hours per week) were assessed with a web-based questionnaire. 
Table 7.2. Outcome measures of the process evaluation and how they were measured.

\begin{tabular}{|c|c|c|c|c|c|c|}
\hline \multirow[t]{2}{*}{ Element } & \multirow[t]{2}{*}{ Operationalization } & \multicolumn{5}{|c|}{ Measurements } \\
\hline & & IP & Q & 1 & FG & $\mathrm{O}$ \\
\hline Fidelity & $\begin{array}{l}\text { Extent to which each step of the TIP-toolbox } \\
\text { was conducted as planned }\end{array}$ & + & & & & \\
\hline Dose & $\begin{array}{l}\text { The extent to which all steps of the TIP- } \\
\text { toolbox were conducted by each } \\
\text { participant }\end{array}$ & + & & & & \\
\hline Context & $\begin{array}{l}\text { The extent to which contextual factors } \\
\text { facilitated or hampered conducting the } \\
\text { steps of the TIP-toolbox }\end{array}$ & & + & + & + & + \\
\hline Satisfaction & $\begin{array}{l}\text { The extent to which the participants were } \\
\text { satisfied with each step of the TIP-toolbox }\end{array}$ & & + & + & + & + \\
\hline Complexity & $\begin{array}{l}\text { The perceived complexity of each step of } \\
\text { the TIP-toolbox, that is, the extent to } \\
\text { which participants found themselves } \\
\text { capable of completing the step and the } \\
\text { difficulty of the step }\end{array}$ & & + & + & + & + \\
\hline Adaptations & $\begin{array}{l}\text { Alterations that should be made to the TIP- } \\
\text { toolbox to achieve better outcomes }\end{array}$ & & + & + & + & + \\
\hline
\end{tabular}

$\mathbb{I P}=$ parts of the implementation plan that are uploaded by the participants every 2 weeks; $Q=$ digital questionnaire participants had to complete every 2 weeks once a part of the TIP-toolbox was completed; $I=$ short telephone interview after each completed step; FG = focus group interview at the end of the study in which the entire TIP-toolbox was evaluated; $\mathrm{O}=$ observations of three participants during the execution of each step; TIP-toolbox = Translating Innovations into Practice-toolbox.

\section{Data analyses}

Quantitative data were analyzed using descriptive statistics in SPSS Statistics (version 22, IBM, Armonk, NY, USA). Qualitative data (answers to open-ended questions and data from the telephone interviews, the participant observations, and the focus group interviews) were analyzed independently by two researchers (including the first author and a researcher not involved in the data collection) using directed content analysis. ${ }^{27}$ This entailed that the main coding categories were predetermined; they were based on the relevant key elements of the process evaluation (context, satisfaction, complexity, and adaptations). Within these categories, subcategories were established. Differences in coding were discussed until a consensus was reached. The individual data collected for each step by questionnaires and telephone interviews formed the basis for the analyses; this was supplemented by the data from the observations and the focus group interviews. With regard to the fidelity, two researchers, both uninvolved in the data collection, used a checklist to independently score if the implementation plans adhered to the steps of the TIP-toolbox and their underlying components (that is, if participants completely, partly, or not at all performed each step as intended; Table 7.1 shows the 
steps and their components). Any discrepancies in scoring were resolved with the first author.

\section{Results}

\section{Background characteristics}

Table 7.3 provides an overview of the background characteristics of the participating RNs. Three of the 12 RNs had a bachelor degree in nursing; the others received 4 years of secondary-vocational training. The three randomly selected RNs who were observed during the study worked at psychogeriatric wards. The professional experience of these three RNs varied from working in the nursing home for 1 year $(n=2)$ to 32 years $(n=1)$.

Table 7.3. Characteristics of the participating RNs $(N=12)$.

\begin{tabular}{|c|c|c|c|c|}
\hline & $N$ & Mean & $\pm S D$ & (Range) \\
\hline \multicolumn{5}{|l|}{ Gender } \\
\hline Female & 10 & & & \\
\hline Male & 2 & & & \\
\hline \multicolumn{5}{|l|}{ Ward type } \\
\hline Psychogeriatric ward & 8 & & & \\
\hline Somatic ward & 4 & & & \\
\hline \multicolumn{5}{|l|}{ Educational level } \\
\hline Vocationally-trained RN & 9 & & & \\
\hline Bachelor-educated RN & 3 & & & \\
\hline Age (years) & & 40 & \pm 13 & $(21-54)$ \\
\hline Professional experience (years) & & 16 & \pm 13 & $(1-38)$ \\
\hline Work hours per week & & 31 & \pm 4 & $(24-36)$ \\
\hline
\end{tabular}

$\mathrm{RN}=$ registered nurse.

Dose

Of the 12 participants, 10 completed all six steps of the implementation plan. Two participants withdrew during the study. The first withdrew after Step 2 due to health problems and the second withdrew after Step 4 due to annual leave.

\section{Fidelity}

Table 7.4 provides an overview of the extent to which the participants completed the steps of the TIP-toolbox according to plan (fidelity) and the time that it took them to 
complete each step. Step 1, formulating a proposal for change in practice with clear targets, was least often performed according to plan. Participants had difficulties with formulating SMART goals (Specific, Measurable, Attainable, Realistic, Time-sensitive); for example, they were not always specific in what they would like to change or within what timeframe. Step 2 was the most time-consuming step according to the participants. This step was more often performed according to plan than Step 1, but two of the twelve participants did not succeed in recruiting five of their colleagues in the ward to fill out the MAastrlcht Nurses Activities INventory (MAINtAIN)questionnaire. Furthermore, their formulated targets for change were not always completely based on the results of the MAINtAIN-questionnaire or were not specific. Overall, Steps 3 to 6 were conducted in line with the toolbox-instructions. However, applying consistency and precision throughout the steps was challenging (the implementation strategies selected in Step 3 did not always match all the barriers that were exposed in Step 2). In general, the implementation plans of the four participants working on the somatic wards were most consistent and most clearly formulated; these plans adhered to all the steps of the TIP-toolbox.

Table 7.4. Participants' fidelity to the steps of the TIP-toolbox and their time-investment.

\begin{tabular}{|c|c|c|c|c|c|c|}
\hline \multirow[t]{2}{*}{ Steps of the TIP-toolbox } & \multicolumn{3}{|c|}{ Fidelity $^{a}$} & \multicolumn{3}{|c|}{$\begin{array}{l}\text { Time-investment } \\
\text { (minutes) }\end{array}$} \\
\hline & $\begin{array}{c}\text { Fully } \\
\text { (n/total) }\end{array}$ & $\begin{array}{l}\text { Partly } \\
\text { (n/total) }\end{array}$ & $\begin{array}{c}\text { Not } \\
\text { (n/total) }\end{array}$ & Mean & $\pm \mathrm{SD}$ & (range) \\
\hline $\begin{array}{l}\text { Step 1: Formulating a proposal for } \\
\text { change in practice with clear targets }\end{array}$ & $6 / 12$ & $6 / 12$ & - & 37 & \pm 29 & $(15-120)$ \\
\hline $\begin{array}{l}\text { Step 2: Assessing performance of } \\
\text { nursing staff and existing barriers and } \\
\text { formulating specific targets for change }\end{array}$ & $9 / 12$ & $3 / 12$ & - & 95 & \pm 77 & $(15-240)$ \\
\hline $\begin{array}{l}\text { Step 3: Selecting and tailoring a set of } \\
\text { strategies }\end{array}$ & $10 / 11$ & $1 / 11$ & - & 62 & \pm 46 & $(30-180)$ \\
\hline $\begin{array}{l}\text { Step 4: Planning the implementation } \\
\text { process }\end{array}$ & $11 / 11$ & - & - & 37 & \pm 15 & $(20-60)$ \\
\hline $\begin{array}{l}\text { Step 5: Integrating improvement within } \\
\text { the normal practice routines }\end{array}$ & $10 / 10$ & - & - & $35^{b}$ & \pm 14 & $(20-60)^{b}$ \\
\hline Step 6: Evaluating (and revising) the plan & $8 / 10$ & - & $2 / 10$ & & & \\
\hline
\end{tabular}

TIP-toolbox = Translating Innovations into Practice-toolbox.

A total of 12 registered nurses participated in this study; one of them withdrew after Step 2 and another after Step 4. ${ }^{a}$ Fidelity: The number of participants performing the steps according to the toolbox-instructions. Fidelity was assessed by two authors who independently scored whether the completed implementation plans adhered to the steps of the toolbox and their underlying components. Discrepancies in scoring were resolved with a third author. ${ }^{\text {P }}$ Participants performed Steps 5 and 6 simultaneously. 


\section{Context}

Participants indicated that several contextual factors facilitated or hampered performing the steps of the TIP-toolbox. Categorization of the data led to factors related to the professional context and factors related to the social and organizational context.

Factors related to the professional context that positively affected the implementation of the steps of the TIP-toolbox according to the RNs were prior knowledge about the Implementation of Change Model of Grol and Wensing (mentioned by a bachelor-educated RN), and being new in a ward which meant that they were not influenced by existing routines. The observations and telephone interviews showed that a lack of computer skills of two of the participants negatively affected the implementation of the toolbox steps.

Among the factors related to social and organizational context, support and the lack of support from others were most frequently mentioned as facilitating and hampering factors, respectively. This support included support from participants from other wards involved in the study, a manager, an occupational therapist, or the organization in general. Two of the participants mentioned that they missed the opportunity to confer with other participants. Another participant stated that working in shifts made it difficult to discuss with other people. In contrast, the four participants from the somatic wards collaborated during the study and perceived this collaboration as valuable; they discussed challenges and felt encouraged by working toward a shared goal. In addition, while most of the participants felt the support of their manager, one participant stated during the focus group interview that she did not discuss the project with her manager and her manager did not inquire about it. Moreover, the manager of one of the observed participants did not allow the full execution of a strategy she had selected; instead of two reinforcing educational meetings, she was allowed to organize only one.

\section{Satisfaction}

The results from the questionnaire showed that in general, the participants were satisfied with the TIP-toolbox (the mean score per step ranging from 7.2 to 8.1 on a scale from 1 [very dissatisfied] to 10 [very satisfied]; Table 7.5). With more steps completed, they seemed more satisfied. The participants considered the format of the TIP-toolbox attractive. One participant mentioned that the MAINtAIN-questionnaire revealed issues that remained unnoticed before, for example, the extent to which residents were involved in household activities. Participants valued the example of the completed implementation plan in the TIP-toolbox because it clarified in what detail the plan could be filled out.

Dissatisfaction was also expressed. Three participants stated that they found parts of the TIP-toolbox difficult to understand, particularly the first two steps in which they 
had to formulate a SMART-goal, administer the MAINtAIN, and map the experienced barriers and perceived behavior of the nursing staff. One participant indicated a preference for verbal explanation during the execution of the steps in addition to the educational meeting at the start of the study.

When asked during the focus group interviews about a preferred format for a future toolbox, all participants preferred a paper-based version over a digital version. Participants differed in their opinions regarding the 9-week timeline in this study for developing the implementation plan. Four of the twelve participants considered this too short. However, according to two of them, deadlines were needed and a 12 -week timeline would have been ideal. For one participant, the timeline could have been shorter; she finished Step 1 within a few days and immediately continued with the next steps.

Most of the participants felt that the TIP-toolbox already took effect during the study; colleagues became more aware of the importance of promoting activity. For example, one observed participant mentioned that, instead of the staff, now residents opened the door when the ward doorbell rang.

Table 7.5. Participants' satisfaction with the TIP-toolbox and its perceived complexity.

\begin{tabular}{|c|c|c|c|c|c|c|c|c|c|}
\hline & \multirow{2}{*}{\multicolumn{3}{|c|}{ Satisfaction $^{a}$}} & \multicolumn{6}{|c|}{ Complexity } \\
\hline & & & & \multicolumn{3}{|c|}{ Capability $^{\text {b }}$} & \multicolumn{3}{|c|}{ Difficulty $^{c}$} \\
\hline & Mean & $\pm S D$ & (Range) & Mean & $\pm S D$ & (Range) & Mean & $\pm S D$ & (Range) \\
\hline Step 1 & 7.9 & \pm 1.1 & $(6-10)$ & 8.0 & \pm 1.1 & $(6-10)$ & 3.5 & \pm 1.2 & $(2-6)$ \\
\hline Step 2 & 7.2 & \pm 1.8 & $(3-10)$ & 7.0 & \pm 2.3 & $(3-10)$ & 4.7 & \pm 2.1 & $(3-9)$ \\
\hline Step 3 & 7.5 & \pm 1.1 & $(6-10)$ & 7.7 & \pm 1.4 & $(5-10)$ & 4.4 & \pm 1.4 & $(1-6)$ \\
\hline Step 4 & 8.1 & \pm 1.1 & $(7-10)$ & 7.8 & \pm 1.4 & $(5-10)$ & 3.4 & \pm 1.1 & $(2-6)$ \\
\hline Step 5 & 8.1 & \pm 1.1 & $(7-10)$ & 8.3 & \pm 0.9 & $(7-10)$ & 3.2 & \pm 0.9 & $(1-4)$ \\
\hline Step 6 & 8.1 & \pm 1.1 & $(7-10)$ & 8.3 & \pm 1.1 & $(7-10)$ & 3.2 & \pm 0.9 & $(1-4)$ \\
\hline
\end{tabular}

TIP-toolbox = Translating Innovations into Practice-toolbox.

${ }^{\text {a }}$ Theoretical range: 1 to 10 (very dissatisfied to very satisfied).

${ }^{\text {b}}$ Theoretical range: 1 to 10 (not at all capable to very capable).

'Theoretical range: 1 to 10 (very easy to very difficult).

\section{Complexity}

The outcomes of the questionnaire revealed that most participants considered themselves capable of performing the steps (the mean capability ranging from 7.0 for Step 2 to 8.3 for Steps 5 and 6 on a scale from 1 [not at all capable] to 10 [very capable]) and that several participants experienced difficulty in some of the steps of the TIPtoolbox (the mean difficulty ranging from 3.2 for Steps 5 and 6 to 4.7 for Step 2 on a scale from 1 [very easy] to 10 [very difficult]; Table 7.5). The last three steps were considered easier than the first three. According to three of the twelve participants, 
Step 2 was perceived as the most complex because it was particularly difficult to get their colleagues to fill out the MAINtAIN-questionnaires within the given timeframe.

Other factors that increased the complexity of the TIP-toolbox according to some of the vocationally-trained RNs were the language used in the materials $(n=3)$ and the basic computer skills that were required to fill out the implementation plan $(n=2)$. Furthermore, the observations and telephone interviews showed that two of the participants considered it challenging to link the different parts of the TIP-toolbox; for example, they started filling out the template-implementation plan without reading the explanation for the related step. Another complicating factor was a lack of overview $(n=2)$ when one ward comprised three subunits and the participating RNs were not familiar with all the subunits. This hampered carrying out the steps and developing an implementation plan tailored to the entire ward.

\section{Adaptations}

Participants suggested several adaptations regarding the content of the toolbox. Most of these adaptations were focused on increasing collaboration with others and increasing the feeling of support. First, to increase the collaboration with and support from other colleagues in the ward, one participant suggested that the TIP-toolbox could comprise more information on the extent to which colleagues in the ward should be involved and informed during the implementation process, for example, regarding the chosen targets for change. Another suggestion was to include more educational information about the specific topic (in this study functional activity) to facilitate the process of informing and convincing colleagues in the ward. Second, two participants preferred the appointment of a second person in the ward to be a sparring partner and share responsibilities. Third, during the focus group interviews, the participants were convinced that collaboration between the RNs involved in the implementation could be very helpful and therefore should be emphasized more strongly in the TIP-toolbox. Other content-related adaptations recommended by the participants pertained to the toolbox's complexity. To make it easier to understand, participants suggested several changes related to the language used, for example, shorter sentences and avoiding difficult words.

Regarding the toolbox format, several participants recommended changing the order of its tools. In the current form, the TIP-toolbox provides a thorough description of all the steps, which is then followed by appendices for the different tools, for example the step-by-step template-implementation plan. Participants suggested combining all information and tools per step. According to the participants, this would make it easier to link the different parts of the TIP-toolbox and would decrease its complexity. 


\section{Discussion}

The findings of this in-depth mixed-methods study indicate that the TIP-toolbox was feasible and supported nursing staff in the step-by-step development of a structured and tailored implementation plan for innovations in nursing homes, although various adaptations are needed to further improve the toolbox and reduce its complexity. Although not all implementation plans were completely formulated according to plan, the participants were generally able to apply the toolbox in practice.

In this study, fidelity was affected by the participants' difficulties in formulating SMART goals. Other studies also found that setting goals can be challenging. ${ }^{28,29}$ Although the participants were able to go forward with their implementation plans, setting specific and measurable goals is necessary to be able to evaluate the effectiveness of the implementation process. ${ }^{11,29}$ A previous study shows that an interactive educational session could increase the ability to formulate SMART goals. ${ }^{29}$ Hence, the educational meeting at the start of this study could be extended with information and exercises related to goal-setting.

Several factors influenced the development of the implementation plan. Support from and collaboration with others were considered particular facilitating factors, while factors that made the development more difficult included being unable to get enough colleagues to fill out the MAINtAIN -questionnaire in Step 2 and difficulties with the language used in the toolbox. Although very few studies have examined how nurses in nursing homes can be supported in implementing innovations, our findings are in line with studies in different healthcare settings that found that critical facilitators for successful implementation include support from all levels within the organization, ${ }^{30-34}$ teamwork and collaboration, ${ }^{30,32}$ successful leadership, ${ }^{31-33}$ and the content of the innovation itself. 31,32 The challenge is how the TIP-toolbox can be improved in such a way that the facilitating factors are strengthened and hampering factors are minimized. On the one hand, adaptations to the toolbox are needed relating to the language use and more specific instructions about the support that is required and the fact that the implementation of innovations is a joint responsibility in the organization. The latter includes actively involving all layers within the organization from the start of the implementation. ${ }^{33}$ On the other hand, it is important to carefully select those who take the lead in the implementation. The results of this study indicate it is important that the people involved in the implementation of innovations in practice demonstrate leadership behavior and are competent in collaborating and in processing information, competencies previously found important in a study by Holleman, van Tol, Schoonhoven, Mintjes-de Groot, and van Achterberg. ${ }^{9}$ Besides carefully selecting those involved in the implementation, additional coaching may also contribute to the implementers' performance and competencies. ${ }^{9}$

The extent to which the results of this study are generalizable to nursing homes other than the three in which the feasibility of the toolbox was examined depends on 
several aspects. First, implementing innovations using the TIP-toolbox requires the presence of an RN to lead the implementation process, preferably in cooperation with others, but the availability of RNs could be a bottleneck for some nursing homes. The proportion of RNs in nursing homes differs per country, ${ }^{35}$ but in general, the educational level of the staff in nursing homes is relatively low compared to other health care settings. ${ }^{36}$ The availability of bachelor-educated RNs might be particularly limited, which was also the case in the present study. In the Netherlands, bacheloreducated RNs are expected to be competent in initiating and implementing innovations and providing leadership, while vocationally-trained RNs are trained in applying innovations. ${ }^{37}$ Involving only vocationally-trained RNs might result in more hampering factors and a lower fidelity. Second, the successful use of the TIP-toolbox requires the nursing home management to support the RNs in their implementation efforts. In the current study, the nursing homes already had a task-force on improving activity in general. In other words, promoting activity was on their agenda, which is according to Rogers $^{38}$ the first step toward innovation. Although the presence of a task-force does not guarantee success (some participants within this study felt a lack of support from their ward managers), support from other levels in the organization is important for the implementation process. A previous study of Stewart, Manges, and Ward ${ }^{8}$ found that implementation efforts are most likely to succeed when a combination between a bottom-up and top-down approach is taken, in which frontline staff take the lead and the management and administrators provide support.

This study has some limitations. We cannot exclude that information bias has occurred. Although the observer tried not to intervene during the observations that were conducted in this study, the observations might have influenced how the three observed participants completed their implementation plans. Nonetheless, by triangulating the data collected from different sources, efforts were made to minimize this potential bias. Involving a second researcher in the analyses of the qualitative data further increased the rigor of this study. Furthermore, recall bias or the participants' misinterpretations of what actions were part of each step might have caused inaccurate estimations of the time it took to complete each step of the toolbox. This is reflected by the estimated time to complete Step 2, which ranged from 15 to 240 minutes. The fact that the participating nursing homes already had a task-force on activity may be a limitation to the generalizability of the findings of this study. Moreover, although we tried to comply with existing definitions, our definition of dose (that is, the extent to which all of the steps of the TIP-toolbox were conducted by each participant) slightly deviates from existing definitions ${ }^{25,26}$ that state that dose entails how much intervention is delivered. Finally, we did not measure how the implementation plans were executed and whether this led to more promotion of functional activity. Hence, we cannot draw any conclusions on the effectiveness of the TIP-toolbox. 


\section{CHAPTER 7}

\section{Implications}

The findings of this feasibility study can inform nursing homes that want to implement innovations, in particular by using the TIP-toolbox. We recommend forming an implementation team, including the RNs responsible for the implementation in the wards, allied health professionals, and managers from the nursing home. Such collaboration may increase the feeling of support and facilitate the development of a structured implementation plan. Furthermore, it is important that the RNs working with the TIP-toolbox possess the necessary competencies; they should be able to collaborate, process information, and display leadership behavior.

This study has several implications for research. On the basis of the results of this feasibility study, the toolbox can be further improved. Future studies could then examine the effectiveness of the improved toolbox, that is, whether the use of the TIPtoolbox leads to the successful implementation of innovation. Further research could also examine the feasibility of the toolbox for implementing innovations not related to promoting functional activity or for implementing innovations in other health care settings than nursing homes, for instance in home care. This would require further adaptations to the TIP-toolbox, for example, regarding the tools that are used to measure current nursing behavior and barriers to innovation. 


\section{References}

1. Dharamsi S, Jivani K, Dean C, Wyatt C. Oral care for frail elders: Knowledge, attitudes, and practices of long-term care staff. J Dent Educ. 2009;73(5):581-588.

2. Mody L, Saint S, Galecki A, Chen S, Krein SL. Knowledge of evidence-based urinary catheter care practice recommendations among healthcare workers in nursing homes. J Am Geriatr Soc. 2010;58(8):15321537.

3. Meesterberends E, Wilborn D, Lohrmann C, Schols JM, Halfens RJ. Knowledge and use of pressure ulcer preventive measures in nursing homes: A comparison of Dutch and German nursing staff. J Clin Nurs. 2014;23(13-14):1948-1958.

4. Segaar D, Willemsen MC, Bolman C, De Vries H. Nurse adherence to a minimal-contact smoking cessation intervention on cardiac wards. Res Nurs Health. 2007;30(4):429-444.

5. den Ouden M, Kuk NO, Zwakhalen SMG, Bleijlevens MHC, Meijers JMM, Hamers, JPH. The role of nursing staff in the activities of daily living of nursing home residents. Geriatr Nurs. 2016, Advance online publication.

6. Rahman AN, Applebaum RA, Schnelle JF, Simmons SF. Translating research into practice in nursing homes: Can we close the gap? Gerontologist. 2012;52(5):597-606.

7. Baker R, Camosso-Stefinovic J, Gillies C, et al. Tailored interventions to address determinants of practice. Cochrane Database Syst Rev. 2015;4:CD005470.

8. Stewart GL, Manges KA, Ward MM. Empowering sustained patient safety: The benefits of combining topdown and bottom-up approaches. J Nurs Care Qual. 2015;30(3):240-246.

9. Holleman G, van Tol M, Schoonhoven L, Mintjes-de Groot J, van Achterberg T. Empowering nurses to handle the guideline implementation process: Identification of implementation competencies. J Nurs Care Qual. 2014;29(3):E1-E6.

10. Thompson GN, Estabrooks CA, Degner LF. Clarifying the concepts in knowledge transfer: A literature review. J Adv Nurs. 2006;53(6):691-701.

11. Grol R, Wensing M, Eccles M, Davis D. Improving patient care: The implementation of change in health care. Oxford: John Wiley \& Sons; 2013.

12. Boström AM, Slaughter SE, Chojecki D, Estabrooks CA. What do we know about knowledge translation in the care of older adults? A scoping review. J Am Med Dir Assoc. 2012;13(3):210-219.

13. Resnick B, Simpson M, Bercovitz A, et al. Testing of the Res-Care Pilot Intervention: Impact on nursing assistants. Geriatr Nurs. 2004;25(5):292-297.

14. Grönstedt H, Frändin K, Bergland A, et al. Effects of individually tailored physical and daily activities in nursing home residents on activities of daily living, physical performance and physical activity level: $A$ randomized controlled trial. Gerontology. 2013;59(3):220-229.

15. Resnick B, Gruber-Baldini AL, Zimmerman S, et al. Nursing home resident outcomes from the res-care intervention. J Am Geriatr Soc. 2009;57(7):1156-1165.

16. Peri K, Kerse N, Robinson E, Parsons M, Parsons J, Latham N. Does functionally based activity make a difference to health status and mobility? A randomised controlled trial in residential care facilities (The Promoting Independent Living Study; PILS). Age Ageing. 2008;37(1):57-63.

17. den Ouden M, Bleijlevens MH, Meijers JM, et al. Daily (in)activities of nursing home residents in their wards: An observation study. J Am Med Dir Assoc. 2015;16(11):963-968.

18. Palese A, Del Favero C, Antonio Zuttion R, et al. Inactive residents living in nursing homes and associated predictors: Findings from a regional-based, Italian retrospective study. I Am Med Dir Assoc. 2016;17(12):1099-1105.

19. Polit DF. Nursing research : Generating and assessing evidence for nursing practice Philadelphia: Wolters Kluwer Health; 2017.

20. Eldridge SM, Chan CL, Campbell MJ, et al. CONSORT 2010 statement: Extension to randomised pilot and feasibility trials. BMJ. 2016;355(1):i5239. 
21. Critical Appraisal Skills Programme. CASP Qualitative Research Checklist. 2013; http://media.wix.com/ugd/dded87_29c5b002d99342f788c6ac670e49f274.pdf. Accessed 24 October 2016.

22. Verbeek H, Zwakhalen SM, Schols JM, Hamers JP. Keys to successfully embedding scientific research in nursing homes: A win-win perspective. J Am Med Dir Assoc. 2013;14(12):855-857.

23. Kuk NO, Zijlstra GAR, Bours GJJW, Hamers JPH, Kempen GIJM. Development and usability of the MAINtAIN, an inventory assessing nursing staff behavior to optimize and maintain functional activity among nursing home residents: A mixed-methods approach. BMC Health Serv Res. 2016;16:38.

24. Kuk NO, Bours GJJW, Zijlstra GAR, Hamers JPH, Kempen GIJM. Translating implementation strategies into practice to enable nursing staff to implement innovations. J Adv Nurs. 2016;72(Suppl 1):87.

25. Moore GF, Audrey S, Barker M, et al. Process evaluation of complex interventions: Medical Research Council guidance. BMJ. 2015;350:h1258.

26. Saunders RP, Evans MH, Joshi P. Developing a process-evaluation plan for assessing health promotion program implementation: A how-to guide. Health Promot Pract. 2005;6(2):134-147.

27. Hsieh HF, Shannon SE. Three approaches to qualitative content analysis. Qual Health Res. 2005;15(9):1277-1288.

28. Bowman J. Challenges to measuring outcomes in occupational therapy: A qualitative focus group study. Br J Occup Ther. 2006;69(10):464-472.

29. Marsland E, Bowman J. An interactive education session and follow-up support as a strategy to improve clinicians' goal-writing skills: a randomized controlled trial. J Eval Clin Pract. 2010;16(1):3-13.

30. Ploeg J, Davies B, Edwards N, Gifford W, Miller PE. Factors influencing best-practice guideline implementation: Lessons learned from administrators, nursing staff, and project leaders. Worldviews Evid Based Nurs. 2007;4(4):210-219.

31. Jun J, Kovner CT, Stimpfel AW. Barriers and facilitators of nurses' use of clinical practice guidelines: An integrative review. Int J Nurs Stud. 2016;60:54-68.

32. Grol R, Wensing M. What drives change? Barriers to and incentives for achieving evidence-based practice. Med J Aust. 2004;180(6 Suppl):S57-60.

33. Greenhalgh $T$, Robert $G$, Macfarlane F, Bate $P$, Kyriakidou O. Diffusion of innovations in service organizations: Systematic review and recommendations. Milbank Q. 2004;82(4):581-629.

34. Bleijlevens MH, Gulpers MJ, Capezuti E, van Rossum E, Hamers JP. Process evaluation of a multicomponent intervention program (EXBELT) to reduce belt restraints in nursing homes. J Am Med Dir Assoc. 2013;14(8):599-604.

35. Harrington C, Choiniere J, Goldmann M, et al. Nursing home staffing standards and staffing levels in six countries. J Nurs Scholarsh. 2012;44(1):88-98.

36. Spilsbury K, Hewitt C, Stirk L, Bowman C. The relationship between nurse staffing and quality of care in nursing homes: A systematic review. Int J Nurs Stud. 2011;48(6):732-750.

37. Terpstra D, Van den Berg A, Van Mierlo C, et al. Toekomstbestendige beroepen in de verpleging en verzorging. 2015.

38. Rogers EM. Diffusion of Innovations. 5th ed. New York: Free Press; 2003. 


\section{CHAPTER 8}

General discussion

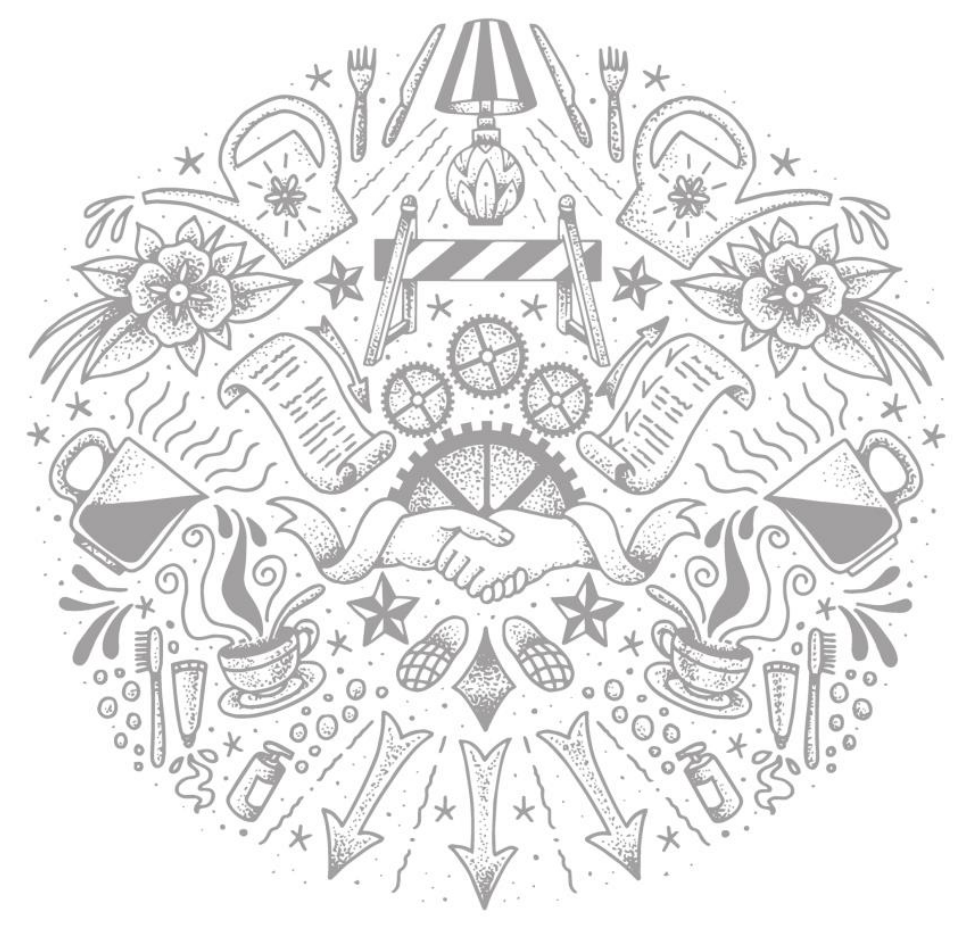


The overall objective of this dissertation was to examine how nursing staff can be supported in implementing innovations in nursing home care. Specifically, this dissertation focused on:

1. providing insight into the extent to which nursing staff in the Netherlands promote functional activity among nursing home residents;

2. providing insight into nursing staff-experienced barriers towards promoting functional activity among nursing home residents; and

3. developing an instrument that nursing staff can use to implement innovations related to the promotion of functional activity.

In this final chapter the main findings of this dissertation will be discussed, followed by a reflection on some methodical and theoretical considerations. The chapter ends with a discussion of the findings' implications for practice, education, and future research.

\section{Main findings}

First, our findings indicate that there might be a discrepancy between the extent to which nursing staff perceive that they promote functional activity and the extent to which they actually promote functional activity. Nursing staff working in nursing homes in the Netherlands perceived that they generally encourage residents to perform their own activities of daily living (ADL; e.g., bathing or dressing) and miscellaneous activities (e.g., organized group activities). Household activities (e.g., setting and clearing the table) were less often promoted according to them. However, observations revealed that residents' activities are often completely taken over by the nursing staff; the engagement of residents in household activities was almost never observed. Second, our research showed that the barriers to promoting functional activity that were most commonly experienced by the nursing staff were not the barriers that were most strongly associated with nursing staff-perceived behavior. The most commonly experienced barriers were related to organizational and economic aspects - e.g., staffing levels and availability of resources. Yet, the barriers most strongly associated with nursing staff-perceived behavior were related to the social context. For instance, a lack of communication within the team and a lack of reminding each other of their responsibilities were particularly associated with less perceived promotion of functional activity. Finally, an instrument (the Translating Innovations into Practice [TIP]-toolbox) was developed to support nursing staff in implementing innovations related to the promotion of functional activity. The TIP-toolbox includes, among other things, a questionnaire (MAINtAIN) that can be used to obtain insight into the nursing staffperceived promotion of functional activity and their experienced barriers related to this promotion, and an overview of practical implementation activities developed by nursing 
home staff. The TIP-toolbox seemed to be a feasible instrument for supporting nursing staff in developing a structured and tailored implementation plan for innovations in nursing homes, although various adaptations were needed to further improve the toolbox and decrease its complexity. Support from, and collaboration with, other nursing staff, allied health professionals, and managers were found to be of major importance during the implementation of innovations.

\section{Methodological considerations}

In this section some methodological considerations of this dissertation will be addressed. These considerations concern the measurement of (perceived) behavior and (experienced) barriers and the study samples that were used within the different studies.

\section{Measurement of (perceived) behavior and (experienced) barriers}

In this research project a questionnaire was developed and used to provide insight into nursing staff-perceived promotion of functional activity and the related barriers they experienced. This questionnaire was also incorporated within the TIP-toolbox that was developed to support nursing staff in implementing innovations (Chapter 7). Using questionnaires to collect data on nursing behavior has some limitations.

Social desirability may have influenced how people responded to the questionnaire, which might have affected the validity of our results. ${ }^{1}$ People may have exaggerated the extent to which functional activities were promoted among residents. Indeed, the extent to which nursing staff reported that they promoted functional activities (Chapter 3) was higher than one might have expected, based on the observations regarding the extent to which activities were taken over by nursing staff (Chapter 4), even though different study samples were used. Van de Mortel $^{2}$ conducted a review concerning nursing and allied health research papers that used a social desirability scale to detect social desirable responding. She found that social desirable responding influenced the results in $43 \%$ of the included studies. ${ }^{2}$ Social desirable responding was more likely to occur when participants were asked about their competence or about socially sensitive topics. ${ }^{2}$ To reduce social desirable responses, participants in this dissertation were asked what happens in their wards, instead of their own personal behavior. Still, we cannot rule out that social desirability has played a role. It may have influenced how people evaluated the promotion of functional activity, as well as their experienced barriers; literature shows that people are inclined to attribute undesirable behavior to barriers that are outside of their control instead of to barriers that are related to themselves. ${ }^{3,4}$ Furthermore, research indicates that what people think they do does not always completely correspond with what they actually do. ${ }^{5}$ Using solely the 
results of a questionnaire to pinpoint which behaviors should be addressed when implementing innovations might be suboptimal. Depending on the feasibility, nursing homes could also consider using observations to map nursing behavior (see Chapter 4).

\section{Study samples}

For the research in this dissertation, data were collected from several samples. The extent to which these samples are representative determines the external validity of the results. ${ }^{6}$ For two studies (Chapters 3 and 5), we used a two-stage sampling procedure. ${ }^{6}$ First, a random sample proportionate to the number of nursing homes per region was drawn from nursing homes throughout the Netherlands. Consequently, contact persons were asked to distribute questionnaires randomly among the nursing staff within these nursing homes. We cannot ensure that the latter was truly random, and thus sampling bias could have occurred. If the people who were selected for our study systematically differed from the people who were not selected, the generalizability of our results could be affected. ${ }^{7}$ Although we cannot test this, nursing staff from outstanding wards might have been overrepresented in our sample, which could have led to an overestimation of the extent to which functional activities were perceived to be promoted. We attempted to reduce sampling bias by drawing a random proportionate national sample ${ }^{6}$ and providing clear instructions to the local contact persons.

In the other studies in this dissertation (Chapters 2, 4, and 7), nursing staff from nursing homes in the south of the Netherlands participated. The nursing homes participating in the study regarding the feasibility of the TIP-toolbox (Chapter 7) might not be entirely representative of other nursing homes, as the availability of more highly educated nursing staff seemed relatively high here. Literature shows that the number of RNs in nursing homes is generally low. 8 , Bachelor-educated RNs are particularly rare; in a recent study, Backhaus et al. ${ }^{10}$ found that $43 \%$ of the wards included in their study were never even visited by a bachelor-educated RN. Yet, in the nursing homes involved in our study, three wards participated with a bachelor-educated RN (who regularly visited other wards within the nursing home) and in the other wards at least one vocationally-trained RN was available to participate. The possible over-representation of more highly educated nursing staff in the nursing homes included in our study might affect the generalizability of our findings. In other nursing homes, not every ward might have an RN at their disposal that can lead the implementation, or a nursing home might not employ a bachelor-educated RN that can team-up with the vocationally-trained RNs. Without the availability of educated nursing staff who possess the appropriate competencies to implement innovations, ${ }^{11}$ nursing homes might experience more difficulties when implementing innovations, and it might be that the TIP-toolbox does not meet all their needs. 


\section{Theoretical considerations}

This section addresses several theoretical considerations that help in interpreting the findings of our studies. These theoretical considerations relate to the factors that might influence implementation, the Implementation of Change model that was used throughout this dissertation, and the transferability of the TIP-toolbox that was developed in this dissertation.

\section{Factors influencing implementation}

The results of our studies add to the existing knowledge concerning the factors that influence the implementation of innovations in nursing homes in general, and the implementation of innovations related to the promotion of functional activity in particular. We found that the barriers that are most often experienced by nursing staff are not the barriers that are most strongly associated with the promotion of functional activity (Chapter 5). Ultimately, the purpose of identifying the barriers to an innovation is to be able to tailor implementation strategies and to increase the chance that an innovation is implemented successfully. ${ }^{12,13}$ However, in a systematic review, Baker et $\mathrm{al}^{14}$ found limited effectiveness of interventions tailored to pre-identified barriers, compared with interventions that were not tailored. They stated that perhaps focusing only on the number of identified barriers might not be the most appropriate, but that the importance of the barriers should also be considered. ${ }^{14}$ Our results point in the same direction and indicate that the most frequently mentioned barriers might not be the most important ones; some less frequently mentioned barriers may have a greater potential impact on nursing behavior. It is likely that not all barriers are modifiable; therefore, it is also important to focus on those barriers that are responsive for change. This reflects the complexity of implementing innovations.

Within this dissertation, we explored the association between each individual barrier and perceived nursing behavior. Using this type of reductionist approach might not fully do justice to the complex systems in which the barriers may interact. ${ }^{15}$ In reality, each barrier may be interdependent with other factors that are or are not measured. Two apparently minor barriers may influence each other in a way that greatly affects whether or not an innovation is adopted. ${ }^{16}$ This makes it impossible to simply calculate how changing one or more barriers will result in a change in nursing behavior. However, this dissertation sheds some light on which barriers might be important. Until we know more about how barriers affect nursing behavior, we propose that those deciding which barriers should be addressed should not solely consider the extent to which barriers are experienced, but also the strength of the association between a barrier and nursing behavior, and whether or not a barrier is susceptible to change. 


\section{The Implementation of Change model}

As stated in the general introduction in Chapter 1 of this dissertation, there are many models that can help explain how change can be achieved. ${ }^{13,16-21}$ We chose to use the Implementation of Change model of Grol and Wensing, ${ }^{13}$ as this model was, in contrast to other models, ${ }^{21}$ developed to guide not only researchers but also care providers during the implementation process. ${ }^{13}$ With hindsight, we can confirm that the model is usable in practice. The model provided a clear structure and it forced the nurses that participated in our study to make deliberate decisions. Although we did not examine whether this led to successful implementation, it helped them tailor their implementation plans to the needs of their wards.

The Implementation of Change model (see Figure 1.1, Chapter 1) divides the implementation process into clear steps that are substantiated by a large body of literature. However, even though the results of our study confirm the usability of the model, they also indicate that instead of a generic model, care professionals prefer easily applicable tools that are adapted to a specific problem and a specific setting. Although the extensive literature supporting the Implementation of Change model might be necessary to thoroughly understand the implementation process, for everyday practice it is important that the model is easy to use without the need to immerse oneself in a textbook with literature on implementation. Indeed, research shows that nursing staff are less likely to use written sources to inform themselves, ${ }^{22}$ which was corroborated by our findings in Chapter 3. Instead, they often prefer interactive sources. $^{22,23}$ It is therefore important to find a balance between providing too much and too little written information. The developed TIP-toolbox (Chapter 7) tries to provide this balance and translates the Implementation of Change model to an instrument with concrete tools that is usable in nursing home practice, but it is evidently also a written source of information. However, by urging the nurse implementers to form an implementation team and work together with others (Chapter 7), they can discuss issues, provide each other with feedback, and learn from each other, allowing for the interaction that most nurses prefer. ${ }^{22,23}$ Moreover, successful implementation does not only depend upon the way in which the information is provided. The support that is provided from different levels within the organization is also important (Chapter 7), just like the implementers' personal motivation and skills. ${ }^{24}$ Careful selection of those involved in the implementation is therefore required.

\section{Transferability of the TIP-toolbox}

Although the TIP-toolbox was specifically developed to help nurses in nursing homes implement innovations related to the encouragement of functional activity, this does not mean that the toolbox is not transferable to other kinds of innovations. The systematic approach that is used, the descriptions of the implementation steps, and the 
included template for an implementation plan are also applicable to other innovations, though some changes in wording might be needed. However, to be able to easily assess the performance of the nursing staff and the barriers to the innovation some adaptations to the TIP-toolbox would be required. The questionnaires included in the TIP-toolbox (i.e., the MAINtAIN-questionnaires) could be replaced by questionnaires that are applicable to the particular innovation or, if no specific questionnaires are available, a more generic questionnaire on innovation could be included - for example the Measurement Instrument for Determinants of Innovations (MIDI). ${ }^{25}$ If feasible, conducting observations and interviewing stakeholders could also be considered. Although the implementation activities that are described in the TIP-toolbox are not specifically tailored to other innovations, they might be relevant and useful as long as they match the identified barriers.

\section{Implications}

The findings of this dissertation have several implications for practice, education, and future research that will be addressed in this section.

\section{Practice}

One of the key messages of this dissertation is that it is important to use a systematic and structured approach to implementing innovations. Instead of making ad hoc decisions, nursing homes should begin with examining how the nursing staff currently works. Questionnaires can be used for this matter, but it is also important to observe what actually happens in the wards. It is, furthermore, important to gain insight into the factors that influence implementation. ${ }^{12}$ Based on these factors, strategies to overcome barriers and change nursing behavior can be selected. ${ }^{14}$ After applying these strategies, careful evaluation should take place to see if further action is warranted. ${ }^{13}$ To facilitate this process, the TIP-toolbox can be used. Once the TIP-toolbox has been proven to be effective, it can support nursing homes and nursing staff in using a structured approach to implementing innovations. It helps nursing staff to critically evaluate the decisions that should be made during the different phases of an implementation project. It supports them in linking barriers to strategies and may contribute to their analytical skills.

Our studies further indicate that RNs can take the lead during implementation projects. Involving someone who is familiar with the ward and knows the ins and outs of the ward makes it easier to create support for the implementation. ${ }^{11,26}$ This requires that nursing homes have enough more highly educated nursing staff. This includes RNs with four years of secondary-vocational training (in Dutch: MBO verpleegkundigen), as long as they are competent in processing information, demonstrate leadership 
behavior, and search for opportunities to collaborate with others. Preferably, this collaboration would also involve bachelor-educated RNs (in Dutch: HBO verpleegkundigen). It is perhaps not feasible for every ward to employ a bacheloreducated RN, but a collaboration between vocationally-trained RNs and bacheloreducated RNs could suffice. However, collaborating with bachelor-educated RNs might sometimes be challenging, as the number of bachelor-educated RNs in nursing homes is low. ${ }^{10,27}$ Hence, we argue that it is important that nursing homes employ bacheloreducated RNs.

Finally, it is important that the RNs that take the lead in the implementation do not act in isolation. Support from all layers within the organization should be sought and provided. This includes support from colleagues in the ward, support from allied health professionals, managers, and administrators. To give shape to this support, the formation of an implementation team from the start of the implementation is recommended. Such a team would preferably include an RN from each ward, one or more bachelor-educated RNs, allied health professionals, and managers.

\section{Education}

Implementing innovations or changes in healthcare requires the right skills and competencies from the nursing staff that take the lead in the implementation. As a consequence, their education should also pay attention to this. In the new Dutch education profile, Bachelor of Nursing 2020, innovating nursing practice is a topic that is addressed. ${ }^{28}$ The TIP-toolbox could be used as an instrument to help teach newly educated nurses how to approach an implementation project, and how to critically evaluate the decisions that should be made during each phase.

Leadership is another competence that is important during the implementation of innovations and it therefore ought to be given attention in the educational programs of future nurses. Providing leadership is something that is expected from bacheloreducated RNs, ${ }^{28}$ but it is less of a topic within the educational programs of RNs with four years of secondary-vocational training. ${ }^{29}$ These competencies can be acquired afterwards, but this might not suit every vocationally-trained RN. However, in many nursing home wards, no bachelor-educated RNs are available. ${ }^{10}$ The leading role, therefore, goes to the RNs with four years of vocational training. To some extent, they can also be trained in providing leadership on their wards - for example when they discuss the importance of promoting functional activity with their colleagues or by convincing their colleagues to fill out a questionnaire. This would not only be helpful in the process of implementing innovations, but also during daily nursing care. The available bachelor-educated RNs can support and coach these vocationally-trained RNs. 


\section{Future research}

In this dissertation a questionnaire (i.e., the MAINtAIN-behaviors) was developed to assess the extent to which nursing staff (perceive that they) encourage functional activity. Future research could further examine the validity and reliability of this questionnaire. Such research could, for example, combine the use of the questionnaire with observations (criterion validity) or assess whether repeated measurements provide similar results (test-retest reliability).

This research project explored the cross-sectional associations between nursing staff-perceived barriers and the encouragement of functional activity. However, it is unknown how changing these barriers will affect nursing behavior. Future longitudinal studies could examine this.

Further research on the effectiveness of the TIP-toolbox is also warranted. This dissertation provided insights into whether the TIP-toolbox is feasible in practice and how it could be improved, but future studies are needed to examine if using the improved TIP-toolbox will result in changes to nursing behavior and eventually more functional activity among nursing home residents. To do so, a controlled longitudinal study is warranted.

Lastly, we examined how nursing staff in nursing homes could be supported in implementing innovations. Since the current study started, long-term care has significantly changed in the Netherlands. Care homes that provide less extensive care than nursing homes are disappearing, ${ }^{30}$ and people entering nursing homes are in a worse condition and live there for a shorter period of time. ${ }^{31}$ Most people prefer to stay at home for as long as possible and home care has become more important. ${ }^{32,33}$ Translating the findings of this dissertation in general, and the TIP-toolbox in particular, to other healthcare settings, such as the home care setting, is desirable. Future research could examine the feasibility and effectiveness of the TIP-toolbox in these settings. 


\section{References}

1. Abernethy M. Self-reports and observer reports as data generation methods: An assessment of issues of both methods. J Psychol. 2015;3(1):22-27.

2. Van de Mortel TF. Faking it: Social desirability response bias in self-report research. Aust J Adv Nurs. 2008;25(4):40-48.

3. Patel DS, Witte K, Zuckerman C, et al. Understanding barriers to preventive health actions for occupational noise-induced hearing loss. J Health Commun. 2001;6(2):155-168.

4. Mezulis AH, Abramson LY, Hyde JS, Hankin BL. Is there a universal positivity bias in attributions? A metaanalytic review of individual, developmental, and cultural differences in the self-serving attributional bias. Psychol Bull. 2004;130(5):711-747.

5. Jenner EA, Fletcher BC, Watson P, Jones FA, Miller L, Scott GM. Discrepancy between self-reported and observed hand hygiene behaviour in healthcare professionals. J Hosp Infect. 2006;63(4):418-422.

6. Polit DF. Nursing research : Generating and assessing evidence for nursing practice. Philadelphia: Wolters Kluwer Health; 2017.

7. Levin KA. Study design II. Issues of chance, bias, confounding and contamination. Evid Based Dent. 2005;6(4):102-103.

8. McGilton KS, Bowers BJ, Heath $\mathrm{H}$, et al. Recommendations from the international consortium on professional nursing practice in long-term care homes. J Am Med Dir Assoc. 2016;17(2):99-103.

9. Backhaus $\mathrm{R}$, van Rossum $\mathrm{E}$, Verbeek $\mathrm{H}$, et al. Quantity of staff and quality of care in Dutch nursing homes: A cross-sectional study. Jour Nursing Home Res. 2016;2:90-93.

10. Backhaus $R$, van Rossum E, Verbeek $H$, et al. Relationship between the presence of baccalaureateeducated RNs and quality of care: a cross-sectional study in Dutch long-term care facilities. BMC Health Serv Res. 2017;17:53.

11. Holleman G, van Tol M, Schoonhoven L, Mintjes-de Groot J, van Achterberg T. Empowering nurses to handle the guideline implementation process: Identification of implementation competencies. J Nurs Care Qual. 2014;29(3):E1-6.

12. Grol R, Wensing M. What drives change? Barriers to and incentives for achieving evidence-based practice. Med J Aust. 2004;180(6 Suppl):S57-60.

13. Grol R, Wensing M, Eccles M, Davis D. Improving patient care: The implementation of change in health care. Oxford: John Wiley \& Sons; 2013.

14. Baker R, Camosso-Stefinovic J, Gillies C, et al. Tailored interventions to address determinants of practice. Cochrane Database Syst Rev. 2015;4:CD005470.

15. Holmes BH, Finegood DT, Riley BL, Best A. Systems thinking in dissemination and implementation research. In: Brownson RC, Colditz GA, Proctor EK, eds. Dissemination and implementation research in health: Translating science to practice. Oxford University Press; 2012:192-212.

16. Nilsen P. Making sense of implementation theories, models and frameworks. Implement Sci. 2015;10:53.

17. Rogers EM. Diffusion of Innovations. 5th ed. New York: Free Press; 2003.

18. Greenhalgh T, Robert G, Bate P, Macfarlane F, Kyriakidou O. Diffusion of innovations in health service organisations: A systematic literature review. Oxford: John Wiley \& Sons; 2008.

19. Rycroft-Malone J. The PARIHS framework-A framework for guiding the implementation of evidencebased practice. . J Nurs Care Qual. 2004;19(4):297-304.

20. Grol RP, Bosch MC, Hulscher ME, Eccles MP, Wensing M. Planning and studying improvement in patient care: The use of theoretical perspectives. Milbank Q. 2007;85(1):93-138.

21. Tabak RG, Khoong EC, Chambers DA, Brownson RC. Bridging research and practice: Models for dissemination and implementation research. Am J Prev Med. 2012;43(3):337-350.

22. Estabrooks CA, Rutakumwa W, O'Leary KA, et al. Sources of practice knowledge among nurses. Qual Health Res. 2005;15(4):460-476.

23. Skår R. How nurses experience their work as a learning environment. Vocat Learn. 2009;3(1):1-18. 
24. Greenhalgh T, Robert G, Macfarlane F, Bate $P$, Kyriakidou O. Diffusion of innovations in service organizations: Systematic review and recommendations. Milbank Q. 2004;82(4):581-629.

25. Fleuren MA, Paulussen TG, Van Dommelen P, Van Buuren S. Towards a measurement instrument for determinants of innovations. Int J Qual Health Care. 2014;26(5):501-510.

26. Thompson GN, Estabrooks CA, Degner LF. Clarifying the concepts in knowledge transfer: A literature review. J Adv Nurs. 2006;53(6):691-701.

27. ActiZ. Samen op weg. Achtergronden van de Benchmark in de Zorg. 2014.

28. Landelijk Overleg Opleidingen Verpleegkunde. Bachelor of Nursing 2020: Een toekomstbestendig opleidingsprofiel 4.0. 2016.

29. Terpstra D, Van den Berg A, Van Mierlo C, et al. Toekomstbestendige beroepen in de verpleging en verzorging. 2015.

30. Janssen D, Jongen W, Schroder-Back P. Exploring the impact of austerity-driven policy reforms on the quality of the long-term care provision for older people in Belgium and the Netherlands. J Aging Stud. 2016;38:92-104.

31. ActiZ. Feiten en cijfers over de verpleeghuiszorg. 2016.

32. Smits $\mathrm{CH}$, van den Beld HK, Aartsen MJ, Schroots JJ. Aging in the Netherlands: State of the art and science. Gerontologist. 2014;54(3):335-343.

33. Liebel DV, Friedman B, Watson NM, Powers BA. Review: Review of nurse home visiting interventions for community-dwelling older persons with existing disability. Med Care Res Rev. 2009;66(2):119-146. 

Summary

Samenvatting

Valorization addendum

Dankwoord

About the author

List of publications

Living lab in ageing and long-term care

Appendix: Translating Innovations into Practice

(TIP)-toolbox 



\section{SUMMARY}

Implementing innovations in healthcare is a challenging task. Numerous studies have shown that a gap exists between evidence and nursing practice. To bridge this gap, it is important to implement innovations. This dissertation investigates how nursing staff can be supported in implementing innovations. It specifically focuses on innovations related to the promotion of functional activity among nursing home residents. Several studies were conducted 1) to provide insight into the extent to which nursing staff in the Netherlands promote functional activity among nursing home residents; 2) to provide insight into nursing staff-experienced barriers towards promoting functional activity among nursing home residents; and 3) to develop an instrument that nursing staff can use to implement innovations related to the promotion of functional activity. This section provides an overview of all the studies described in this dissertation.

Chapter 1 provides a general introduction in which the concepts functional activity and nursing homes are introduced. Furthermore, it describes the Implementation of Change model of Grol and colleagues, a model that is used throughout this dissertation. The chapter ends with an overview of the outline of this dissertation and the main objectives.

To be able to map the extent to which nursing staff encourage functional activity and the related barriers and facilitators they perceive, a questionnaire was developed. Chapter 2 describes the stepwise approach that was used to develop and test the usability of the MAastrlcht Nurses Activities INventory (MAINtAIN)-behaviors and MAINtAIN-barriers. The MAINtAIN-behaviors targets nursing staff behavior to optimize and maintain functional activity, and includes 19 items covering activities of daily living, household activities, and miscellaneous activities such as encouraging informal caregivers not to take over activities from residents. MAINtAIN-barriers addresses the perceived barriers and facilitators related to this behavior and comprises 33 items covering barriers and facilitators related to the residents, the professionals, the social context, and the organizational and economic context. The usability study showed that the inventory was not difficult to complete, that items and response options were clear, and that the number of missing values was low.

Chapter 3 presents the results of a cross-sectional study among the 368 nurses and certified nurse assistants from 41 nursing homes throughout the Netherlands that filled out the MAINtAIN-behaviors. It provides insight into the extent to which nursing staff perceive that they encourage functional activity among nursing home residents and the associations between these nursing behaviors and professional characteristics, contextual factors, and information-seeking behaviors. The results showed that nursing staff perceived that household activities were less often encouraged among residents than ADL or miscellaneous activities. The extent to which these activities were 
encouraged differed for some of the professional characteristics, contextual factors, or information-seeking behaviors, but no consistent pattern of associations emerged.

Chapter 4 further addresses the behavior of the nursing staff during residents' daily activities. It describes an observation study conducted in seven nursing homes in the southern part of the Netherlands, housing a total of 723 nursing home residents. In this study, nursing home residents were observed for one minute, five times a day. During these observations, residents' (in)activity and the role of the nursing staff during this activity ('taking over the activity,' 'giving support,' or 'supervision') were recorded. The study revealed that when nursing staff were involved in the observations, they mainly supported (51\%) or took over residents' activities (45\%); supervision was rarely observed (4\%). The nurse observers indicated that a large part of the activities were taken over unnecessarily.

Chapter 5 focuses on the barriers that nursing staff perceive to promoting functional activity, and the association between these barriers and nursing staff-perceived promotion of functional activity. In this cross-sectional study involving, again, the 368 nurses and certified nurse assistants from Chapter 3, the MAINtAIN-barriers was used to measure the experienced barriers and the MAINtAIN-behaviors was used to assess nursing staff-perceived behavior. Barriers related to the organizational and economic context were most often experienced among nursing staff - e.g., staffing level - while barriers on a professional level were least often experienced. Barriers related to the social context showed the strongest associations with nursing staff-perceived behavior - e.g., communication within the team. More importantly, the study showed that the barriers that were most often experienced among nursing staff were not necessarily the barriers that were most strongly associated with nursing staff-perceived encouragement of functional activity. Strategies aiming to improve functional activity among nursing home residents should take into account the extent to which barriers are experienced by nursing staff and the likelihood that a change will lead to a change in nursing staff behavior.

In order to remove existing barriers and ensure that nursing home staff encourage functional activity, strategies to sustainably change nursing practice are needed. However, overviews of implementation strategies are generally not very specific or detailed, they often lack practical guidance, and do not match the target group or the context in which they will be used. Chapter 6 describes a study that used the World Café method to identify practical implementation activities aimed at improving functional activity among nursing home residents. In three consecutive rounds of 30 minutes each, 21 nursing home professionals discussed in small groups the practical translation of six implementation strategies (audit and feedback; education; local opinion leaders; local consensus processes; multidisciplinary collaborations; and disseminating the policy of the organization) into practical implementation activities. This resulted in 40 practical implementation activities, 23 preconditions in order for the activities to be successful, and 24 content-related remarks. The activities ranged from organizing a theme day for 
the strategy 'expressing the policy of the organization,' to exchanging staff between wards for the strategy 'education.' The detailed activities described by the participants of the World café may support nursing home staff, and nurses in particular, in implementing innovations that are aimed at improving functional activity among nursing home residents in their daily nursing practices.

Chapter 7 describes a mixed-methods study that aimed to evaluate the feasibility of the Translating Innovations into Practice (TIP)-toolbox. This toolbox guides nursing staff in six practical steps through the process of developing a structured and tailored implementation plan to sustainably implement an innovation. It contains several tools, including the MAINtAIN-questionnaires (Chapter 2) and an overview of the practical implementation activities that resulted from the World Café method (Chapter 6). In nine weeks, twelve registered nurses used the TIP-toolbox to develop an implementation plan for their ward. Data were collected via questionnaires, telephone interviews, participant observation, and focus group interviews. The results of this study showed that the participating registered nurses (RNs) conducted most steps of the TIPtoolbox according to plan; two RNs did not complete all steps. Both barriers to and facilitators in carrying out the steps were reported - e.g., use of difficult language in the toolbox (barrier) and support and collaboration (facilitators). Overall, the RNs were satisfied with the TIP-toolbox, but some regarded the toolbox as somewhat complex. To increase their satisfaction and reduce the complexity of the toolbox the participants made suggestions for improvements. Based on the rich data collected, we concluded that the TIP-toolbox seems a feasible instrument, although various adaptations are needed to further improve the toolbox and increase users' satisfaction.

The final chapter, Chapter 8 , provides a summary and discussion of the main findings of this dissertation. It discusses several methodological and theoretical considerations of the conducted studies and, lastly, outlines the implications of the findings for practice, education, and future research. 



\section{SAMENVATTING}

Onderzoek heeft aangetoond dat er een verschil bestaat tussen wat de wetenschap aan kennis voortbrengt en wat er in de verpleegkundige praktijk plaatsvindt. Om dit verschil te verkleinen is het belangrijk om evidence-based innovaties te implementeren. Dit is echter niet makkelijk. In dit proefschrift is daarom onderzocht hoe verpleegkundigen ondersteund kunnen worden bij het implementeren van innovaties. Het proefschrift focust zich in het bijzonder op innovaties gericht op het stimuleren van functionele activiteiten bij verpleeghuisbewoners. De onderzoeken in dit proefschrift hebben als doel om 1) inzicht te krijgen in de mate waarin verzorgenden en verpleegkundigen in Nederland functionele activiteiten stimuleren bij verpleeghuisbewoners; 2) inzicht te krijgen in de barrières die verzorgenden en verpleegkundigen ervaren bij het stimuleren van functionele activiteiten; en 3) een instrument te ontwikkelen dat verpleegkundigen kunnen gebruiken bij het implementeren van innovaties die gerelateerd zijn aan het stimuleren van functionele activiteiten. In deze paragraaf worden alle onderzoeken uit dit proefschrift beknopt beschreven.

Hoofdstuk 1 bevat een algemene introductie. In dit hoofdstuk worden modellen beschreven die kunnen helpen bij het implementeren van innovaties, waaronder het 'Implementation of Change' model dat is gebruikt in dit proefschrift. Verder worden de concepten 'verpleeghuis' en 'functionele activiteiten' toegelicht. Het hoofdstuk eindigt met een beschrijving van de opzet en de doelstellingen van dit proefschrift.

Om in kaart te kunnen brengen in welke mate functionele activiteiten volgens verzorgenden en verpleegkundigen worden gestimuleerd en welke barrières ze hierbij tegenkomen is een vragenlijst ontwikkeld. Hoofstuk 2 beschrijft de stapsgewijze aanpak die is gebruikt voor het ontwikkelen en testen van de MAastrlcht Nurses Activities INventory (MAINtAIN)-behaviors en MAINtAIN-barriers. De MAINtAIN-behaviors bevat 19 items die in kaart brengen in welke mate functionele activiteiten volgens verzorgenden en verpleegkundigen bij verpleeghuisbewoners worden gestimuleerd. Hierbij gaat het om activiteiten van het dagelijks leven ( $A D L)$, huishoudelijke activiteiten en overige activiteiten, zoals het aanmoedigen van mantelzorgers om niet onnodig activiteiten van bewoners over te nemen. De MAINtAIN-barriers bevat 33 items waarmee de barrières en bevorderende factoren voor het stimuleren van functionele activiteiten in kaart worden gebracht. Hierbij wordt onderscheid gemaakt tussen factoren die gerelateerd zijn aan de bewoners, de verzorgenden en verpleegkundigen, de sociale context en de organisatorische en economische context. De uitkomsten van dit onderzoek lieten zien dat verzorgenden en verpleegkundigen het niet moeilijk vonden om de ontwikkelde vragenlijsten in te vullen; de items en antwoordcategorieën waren duidelijk en het aantal missende antwoorden was laag. 
In Hoofdstuk 3 worden de resultaten gepresenteerd van een cross-sectioneel onderzoek onder 368 verzorgden en verpleegkundigen uit 41 verpleeghuizen in Nederland die de MAINtAIN-behaviors invulden. Het hoofdstuk geeft inzicht in de mate waarin verzorgenden en verpleegkundigen denken dat ze functionele activiteiten bij verpleeghuisbewoners stimuleren. Ook geeft het inzicht in de relaties tussen dit gerapporteerde gedrag en verschillende achtergrondkenmerken van de verzorgenden en verpleegkundigen (bijvoorbeeld leeftijd), contextuele factoren (bijvoorbeeld afdelingssoort), en de mate waarin ze gebruik maken van verschillende informatiebronnen (bijvoorbeeld vakbladen). De resultaten toonden aan dat huishoudelijke activiteiten volgens verzorgenden en verpleegkundigen minder worden gestimuleerd dan ADL of overige activiteiten. Hoewel de mate waarin deze activiteiten werden gestimuleerd verschilde voor sommige van de achtergrondkenmerken, contextuele factoren en de mate waarin verschillende informatiebronnen werden gebruikt, was er geen duidelijk patroon te zien.

Hoofdstuk 4 gaat verder in op het gedrag van verzorgenden en verpleegkundigen tijdens dagelijkse activiteiten van bewoners. Het hoofdstuk beschrijft een observatiestudie die is uitgevoerd in zeven verpleeghuizen in het zuiden van Nederland, waar in totaal 723 bewoners verbleven. In dit onderzoek werden bewoners verspreid over de dag, vijf maal gedurende één minuut geobserveerd. Tijdens deze observaties werden de activiteiten van bewoners genoteerd en de rol van de zorgmedewerkers hierbij. Daarbij werd onderscheid gemaakt tussen het overnemen van activiteiten, het ondersteunen bij activiteiten, of het houden van toezicht tijdens activiteiten. Het onderzoek toonde aan dat wanneer zorgmedewerkers betrokken waren bij activiteiten van de bewoner ze voornamelijk ondersteuning boden (51\%) of activiteiten overnamen (45\%). Het houden van toezicht werd zelden geobserveerd (4\%). De observatoren gaven aan dat een groot deel van de activiteiten onnodig leken te worden overgenomen.

Hoofdstuk 5 gaat over de barrières die verzorgenden en verpleegkundigen ervaren bij het stimuleren van functionele activiteiten. Ook gaat het in op de relatie tussen deze barrières en de mate waarin verzorgenden en verpleegkundigen aangeven dat functionele activiteiten worden gestimuleerd. Aan dit cross-sectionele onderzoek namen dezelfde 368 verzorgenden en verpleegkundigen uit 41 verpleeghuizen deel als in Hoofdstuk 3. De MAINtAIN-barriers werd gebruikt om de ervaren barrières in kaart te brengen, de MAINtAIN-behaviors om het gedrag te meten. Barrières gerelateerd aan de organisatorische en economische context (bijvoorbeeld een te lage personeelsbezetting) werden het meest ervaren en barrières gerelateerd aan de professionals (bijvoorbeeld bewegen onbelangrijk vinden) het minst. De barrières gerelateerd aan de sociale context (zoals communicatie binnen het team) waren het sterkst geassocieerd met de mate waarin functionele activiteiten werden gestimuleerd. De bevindingen uit dit onderzoek toonden aan dat de barrières die het meest werden ervaren, niet de barrières waren die het sterkst gerelateerd waren aan het gerapporteerde gedrag van de verzorgenden en verpleegkundigen. 
Hoofdstuk 6 beschrijft een onderzoek waarin de Wereldcafémethode werd gebruikt voor het identificeren van praktische implementatie-activiteiten gericht op het stimuleren van functionele activiteit bij verpleeghuisbewoners. Deze implementatieactiviteiten hebben als doel om barrières weg te nemen en het gedrag van verzorgenden en verpleegkundigen duurzaam te veranderen. In drie opeenvolgende rondes van elk 30 minuten discussieerden 21 verpleeghuisprofessionals (waaronder verzorgenden, verpleegkundigen, een manager en een beleidsmedewerker) in kleine groepjes over de praktische vertaling van zes abstracte implementatie-strategieën (audit en feedback, educatie, lokale opinieleiders, lokale consensusprocessen, multidisciplinaire samenwerking en het uitdragen van het beleid van de organisatie) naar praktische activiteiten die kunnen helpen bij het implementeren van een innovatie. Dit resulteerde in 40 praktische implementatie-activiteiten, 23 randvoorwaarden voor succes en 24 inhoudelijke opmerkingen over hoe de implementatie-activiteiten zouden kunnen worden uitgevoerd. Implementatie-activiteiten varieerden van het organiseren van een themadag binnen de strategie 'uitdragen van beleid van de organisatie' tot het uitwisselen van staf tussen afdelingen binnen de strategie 'educatie'. Een van de randvoorwaarden voor succes was volgens de deelnemers dat verzorgenden en verpleegkundigen het gevoel moeten hebben dat ze in een veilige omgeving werken.

Hoofdstuk 7 gaat in op een 'mixed methods'-onderzoek dat als doel had om de toepasbaarheid van de 'Translating Innovations into Pracice' (TIP)-toolbox te evalueren. De TIP-toolbox leidt verpleegkundigen in zes stappen door het proces van het opstellen van een gestructureerd implementatieplan voor het duurzaam implementeren van een innovatie. Dit plan wordt afgestemd op de verpleeghuisafdeling waarin de innovatie wordt ingevoerd, zo moet er bijvoorbeeld rekening worden gehouden met de plaatselijke barrières. De TIP-toolbox bevat verschillende hulpmiddelen, waaronder de MAINtAIN-vragenlijst (Hoofdstuk 2) en een overzicht van strategieën die zijn gebaseerd op de uitkomsten van het Wereldcafé-onderzoek (Hoofdstuk 6). Tijdens dit onderzoek zijn 12 verpleegkundigen gedurende 9 weken gevolgd bij het opstellen van een implementatieplan voor hun afdeling. Data werden verzameld door middel van vragenlijsten, telefonische interviews, observaties en focus groep interviews. De resultaten van dit onderzoek lieten zien dat verpleegkundigen de meeste stappen van de toolbox volgens plan uitvoerden; twee verpleegkundigen voerden niet alle stappen uit. Zowel belemmerende als bevorderende factoren bij het uitvoeren van de stappen werden door de verpleegkundigen genoemd, waaronder moeilijk taalgebruik in de toolbox (belemmerende factor) en steun en samenwerking (bevorderende factoren). In het algemeen waren de verpleegkundigen tevreden met de toolbox, sommigen ervaarden de toolbox als enigszins complex. Om de tevredenheid met de toolbox te verhogen en de toolbox minder complex te maken gaven de deelnemers aanbevelingen. Op basis van alle informatie die werd verzameld in dit onderzoek concludeerden we dat de TIP-toolbox een instrument is dat toepasbaar lijkt in de 
praktijk, maar dat er wel enkele kleine aanpassingen nodig zijn om de toolbox te verbeteren en de tevredenheid van de gebruikers te verhogen.

Tot slot worden in het laatste hoofdstuk, Hoofdstuk 8, de belangrijkste bevindingen van dit proefschrift samengevat. In het hoofdstuk worden verder enkele methodologische en theoretische overwegingen van de uitgevoerde onderzoeken bediscussieerd. Het hoofdstuk wordt afgesloten met aanbevelingen voor de praktijk, onderwijs van professionals en toekomstig onderzoek. 


\section{VALORIZATION ADDENDUM}

This section focuses on the relevance of the findings of this dissertation. It elaborates on how the findings can help to improve the quality of nursing home care and describes which activities will be performed to disseminate these findings.

\section{Relevance}

The results and conclusions of this dissertation support nursing homes and nursing staff 1 ) in implementing innovations to improve the quality of nursing home care in general, and 2) in implementing innovations related to the promotion of functional activity among nursing home residents specifically.

First, the findings of this dissertation can help nursing staff to implement innovations to improve the quality of nursing home care in general. Although implementing innovations might be difficult, such reforms would be timely. Lately, the issue of improving the quality of nursing home care has received major attention in the Netherlands. Concerns about the quality of nursing home care regularly hit the headlines, tens of thousands of people recently signed a petition to improve the quality of nursing home care, and the issue is high on the agenda of most political parties. To facilitate all Dutch nursing homes meeting basic care quality requirements, the Quality Improvement Framework for Nursing Home Care has recently been published. ${ }^{1}$ This framework comprises the legal basis for the quality of nursing home care in the Netherlands. It aims to contribute to the quality of life of nursing home residents. It elaborates on what residents may expect during daily care and describes the conditions that nursing homes should create to realize this. It states, among other things, that nursing homes should deliver person-centered care, within a safe care environment that adds to the residents' wellbeing, while using the best available evidence to provide optimal care. However, in practice, nursing homes do not always comply with these criteria and the care that is delivered is not always evidence-based. The quality improvement framework therefore states that nursing homes should learn to continuously improve their care. This requires that they are able to implement innovations. However, changing health care and implementing innovations can be challenging. This is particularly true for nursing homes, in which the educational level of the nursing staff is generally not as high as in, for example, hospitals. Barriers may prevent the implementation of innovations and eliminating these barriers is difficult. This requires nurse leaders who know how to implement innovations. The importance of innovation and leadership is also recognized in the new Dutch education profile Bachelor of Nursing 2020. ${ }^{2}$ Nonetheless, eliciting leadership behavior and making 
sustainable changes to nursing home practice can be complex. In practice, decisions during change processes are often ad hoc, resulting in no or unsustainable change. To change health care and implement innovations, it is important that nurses use a systematic approach that is tailored to the setting. This requires insight into the current situation, insight into the barriers and facilitators for change, and insight into strategies that can be used to overcome the barriers and strengthen facilitators. The results and conclusions of this dissertation can help in this.

Second, the findings of this dissertation can particularly help nurses and nursing homes to implement innovations related to the promotion of functional activity among nursing home residents. Promoting functional activity contributes to the 'positive health' of residents. According to this concept, health or 'positive health' can be defined as people's ability to adapt and self-manage. This means focusing on what people can do instead of what they cannot do; focusing on their strengths and resources instead of their weaknesses. This has implications for the care of nursing home residents. It shows that it is important for nursing staff to encourage residents to perform their own activities when possible, instead of taking them over on their behalf. This includes promoting activities of daily living, such as bathing or dressing, or promoting household activities, for example preparing a sandwich or setting the table. Performing such functional activities is associated with less anxiety, less disruptive behavior, higher selfesteem, and a higher quality of life among nursing home residents. This in turn may also lead to more job satisfaction among nursing staff. Despite the advantages of functional activity, research shows that nursing home residents are mainly inactive during the day. Hence, one way to improve the quality of nursing home care is to implement innovations related to the promotion of functional activity.

\section{How to improve the quality of care in nursing homes \& what to be aware of}

This dissertation resulted in several products and insights that can help nurses and nursing homes change their practices and improve the quality of nursing home care.

One of the first steps of a quality improvement project is to obtain insight into current nursing practice. The MAastrlcht Nurses Activities INventory (MAINtAIN)behaviors questionnaire, developed within this dissertation, can help care professionals to obtain insight into the extent to which activities are promoted in their nursing homes. Our findings indicate that nursing staff do not very often encourage residents to perform household activities, other activities are more often encouraged. However, nursing homes should be aware that what nursing staff report doing does not always correspond fully with what they actually do. An alternative to using a questionnaire would be to conduct observations. 
Another important step in a quality improvement project is to obtain insight into the barriers and facilitators for change. For nursing homes that want to obtain insight into the extent to which nursing staff experience barriers towards promoting functional activity, the MAINtAIN-barriers can be used. This dissertation showed that the barriers which are most often mentioned might not be those that are most influential. For example, staffing level was the number one mentioned barrier by nursing staff, a view in line with that of many newspapers. However, social factors, such as communication within the team or explaining to each other the nature of their responsibilities, were more strongly related to the behavior of the nursing staff. Hence, to implement innovations and improve the quality of care, nursing homes should not only look at which barriers are most often mentioned, but also consider the likelihood that changing a barrier will lead to a change in nursing behavior. This indicates that nursing homes should not omit social factors e.g., how does the team function? How do nursing staff communicate?

To overcome the barriers to change and alter nursing behavior, insight into implementation activities is needed. This dissertation therefore provides an overview of implementation activities (e.g., observing each other, providing feedback) that are appropriate for the nursing home setting. This overview was embedded in the Translating Innovations into Practice (TIP)-toolbox that was developed based on all the findings of this dissertation. The TIP-toolbox comprises several tools (including the MAINtAIN-questionnaires) and offers an overall approach that supports nursing staff in developing a structured and tailored implementation plan for innovation in nursing homes. Using this toolbox may help nurses and nursing homes to implement innovations and improve the quality of care in nursing homes.

\section{Dissemination of findings and products}

The findings of this dissertation have been or will be published in international scientific journals. However, it is also important that the findings and the products that resulted from this dissertation reach the level of practice. Therefore, a summary of this dissertation will be distributed among the nursing staff of the seven large long-term care organizations that are a member of the Living Lab in Ageing and Long-Term Care. The MAINtAIN-questionnaires and the TIP-toolbox that were developed within this dissertation will become available on the website of the Living Lab and will be included in their newsletter. A grant has been provided to translate the TIP-toolbox to the homecare setting and test its effectiveness there. Moreover, to ensure that the findings of this dissertation reach the nurses who work in nursing homes, we have applied for a grant that we can use to organize a national conference for nurses working in geriatric care. Lastly, efforts will be made to incorporate the results of this dissertation in the nursing curriculum of Zuyd University of Applied Sciences in the Netherlands. 


\section{References}

1. Zorginstituut Nederland. Kwaliteitskader Verpleeghuiszorg 2017;

https://www.zorginstituutnederland.nl/publicaties/publicatie/2017/01/13/kwaliteitskaderverpleeghuiszorg.

2. Landelijk Overleg Opleidingen Verpleegkunde. Bachelor of Nursing 2020: een toekomstbestendig opleidingsprofiel 4.0. 2016. 


\section{DANKWOORD}

Dan is het moment daar. Het proefschrift is klaar. Klaar! Dat was niet gelukt zonder de hulp en steun van heel veel mensen. Een aantal van hen wil ik hier graag in het bijzonder bedanken.

Allereerst wil ik de vele verpleeghuisprofessionals en andere experts bedanken die hebben meegewerkt aan de verschillende onderzoeken in dit proefschrift. Zonder jullie was dit proefschrift niet mogelijk geweest.

Uiteraard mijn promotieteam, Ruud Kempen, Jan Hamers, Rixt Zijlstra en Gerrie Bours. De afgelopen jaren hebben we vaak overlegd, altijd in een heel prettige sfeer. Meestal op de Dub, een enkele keer naast het zwembad in Florida. Altijd heeft jullie opbouwende feedback mij vooruit geholpen en daarvoor wil ik jullie graag bedanken.

Ruud, bedankt voor je expertise en steeds nauwkeurige en snelle feedback. Vrijwel altijd had ik binnen een dag antwoord op een mail. Dat maakte het heel erg prettig samenwerken.

Jan, jij lette er altijd op dat de vertaalslag naar de praktijk gemaakt werd. Jouw opmerkingen zorgden ervoor dat ik nooit het doel van dit proefschrift uit het oog verloor. Altijd vroeg je aan het eind van een afspraak of ik zo verder kon. En dat kon ik.

Rixt, ook al weet ik dat je het vaak druk hebt, in de afgelopen jaren heb ik altijd het gevoel gehad dat ik bij je binnen kon lopen. Ik waardeer de manier waarop je inhoudelijke feedback geeft, maar zeker ook de ruimte die er was voor het delen van de leuke en moeilijkere momenten.

Gerrie, fysiek een deel van de week iets verder weg, maar ook bij jou kon ik altijd terecht. Al was het soms maar om even twee straten verderop een boek op te halen. Bedankt voor je inhoudelijke steun en persoonlijke interesse.

Graag wil ik de leden van de beoordelingscommissie, prof. dr. Raymond Koopmans, dr. Marieke Spreeuwenberg, prof. dr. Hester Vermeulen, dr. Marjolein de Vugt en voorzitter prof. dr. Trudy van der Weijden bedanken voor het lezen en beoordelen van dit proefschrift.

Mijn dank gaat verder uit naar de leden van de klankbordgroep van Nurses on the Move: Susanne Bruijns (Actiz), Sonja Kersten (V\&VN), Corry Ketelaars (IGZ), Kina Koster (Cicero Zorggroep), Marthijn Laterveer (LOC), Herm Leenders (Zuyderland), Jan Maarten Nuijens (Envida), Roger Ruijters (MeanderGroep), Trudie Severens (Sevagram) en Brigitte Verhage (VWS). Ook Dineke Abels (ZonMw) wil ik bedanken voor haar waardevolle input tijdens de klankbordgroep-bijeenkomsten. 
Graag dank ik ook alle collega's van Health Services Research. In het bijzonder de overige leden van het Nurses on the Move project: Sandra, Judith, Michel, Hilde, Erik, Ruud Halfens, Math en Susy. Bedankt voor jullie input tijdens de periodieke overleggen en natuurlijk ook voor jullie interesse in de wandelgangen. Frans, bedankt voor de statistische ondersteuning gedurende het gehele project. Arnold, Brigitte, Joanna en Suus, ook jullie bedankt voor de ondersteuning in de afgelopen jaren.

Floor en Ruth, jullie assistentie tijdens verschillende momenten van het onderzoek was onmisbaar. Bedankt!

Tussen het werken door even ontspannen is natuurlijk ook belangrijk. Angela, Bart, Bram, Daan, Donja, Hanneke, Inge, Joan, Laura, Maike, Mariska, Martine, Sanne, Susan - en alle andere (oud)junioren, bedankt voor de vele gezellige lunches en leuke discussies in de koffiehoek, ik kijk hier met veel plezier op terug.

En natuurlijk Mirre en Ramona. Samen vormden we de 'nurses' van Nurses on the Move, zonder dat een van ons verpleegkundige is. De afgelopen jaren waren nooit het zelfde geweest zonder jullie. Van alles hebben we met elkaar besproken, of dat nu over werk ging of over een van de vele andere niet nader te noemen onderwerpen. Ik prijs me gelukkig dat ik de afgelopen jaren de kamer met jullie heb mogen delen. Ik zal jullie zeker missen. Maar ook al zitten we nu wat verder bij elkaar vandaan, we houden contact.

Ramona, als dit proefschrift gedrukt is, ben jij als het goed is net gepromoveerd. Ik twijfel er niet aan dat dat zeer goed is gegaan. Ik heb met heel veel plezier met je samengewerkt, jouw droge humor had altijd de juiste consistentie!

Mirre, jij bent iets later begonnen, maar over een jaar zal jij ook zover zijn. Ik wens je veel succes met de eindsprint, maar ook dat komt helemaal goed! Ik ben blij dat je mijn paranimf wil zijn.

Mijn vrienden wil ik graag bedanken voor hun interesse in mijn proefschrift, maar eigenlijk vooral voor de afleiding die soms heel erg fijn kan zijn.

Esther, Leandra, Jennita, ik ben blij dat we elkaar ondanks de afstand nog zo geregeld zien. Nu we allemaal langzaamaan wat dichter bij elkaar komen te wonen, wordt het afspreken wellicht weer wat makkelijker.

Jeanet en Marlène, vriendinnen vanaf onze geboorte, dat kunnen niet veel mensen zeggen. Bedankt voor de heerlijke sushi-avonden - dat er nog vele mogen volgen.

Mijn familie. Jullie hebben me de afgelopen jaren altijd gesteund. Meegevierd als een artikel werd gepubliceerd en een luisterend oor geboden op de momenten dat ik vastliep.

Papa en mama, ik voel jullie steun altijd en weet dat jullie trots zijn op jullie kinderen - hoe dan ook. Het is een jaar vol hoogtepunten en ik ben blij dat jullie erbij zijn om dat te vieren. 
Gerard, lieve broer. Helaas, je weekendjes Maastricht zijn over! Maar het is ook wel fijn dat ik weer wat dichter bij woon, toch? Ook voor jou is dit een jaar met hoogtepunten en ik ben blij dat ik daarin mag delen.

Linda, je staat altijd voor me klaar. Of het nou is door het bakken van heerlijk brood, of voor een telefoongesprek. Je hebt me enorm gesteund, zeker in mijn eerste jaar in Maastricht. Ik vind het fijn om je als paranimf naast me te hebben staan.

Remko, het laatste woord is voor jou. Jij steunt me altijd. Je bent mijn rustpunt in de drukte die promoveren soms met zich meebrengt. De afgelopen jaren hebben we vele tienduizenden treinkilometers afgelegd om bij elkaar te zijn. Met de afronding van dit proefschrift komt een eind aan al dat gereis. Het is heerlijk om vanaf nu altijd samen te kunnen zijn - en dat vieren we in september door te trouwen. Ik houd van je. 



\section{ABOUT THE AUTHOR}

Nienke Kuk was born on December 13, 1987, in Lelystad, the Netherlands. She attended secondary school (VWO) at ISG Arcus in Lelystad, and subsequently followed the bachelor program 'Health and Life Sciences' at the VU University in Amsterdam. She continued her education with the master program 'Health Sciences' and received her degree in 2010, after completing her thesis on undernutrition and the quality of life in community-dwelling older people. During her studies, Nienke worked in a nursing home. After her studies, she worked at the VU University where she participated in a project on collaborative care for people with dementia.

In 2012, Nienke started as a PhD candidate at Maastricht University (Department of Health Services Research). She was involved in the project Nurses on the Move. Within this project, she focused on supporting nursing staff in implementing innovations in nursing homes, which resulted in this dissertation. During her PhD trajectory, Nienke was involved in educational activities. She presented her work on national and international conferences, and co-organized symposia and conferences, such as the European Doctoral Conference in Nursing Sciences.

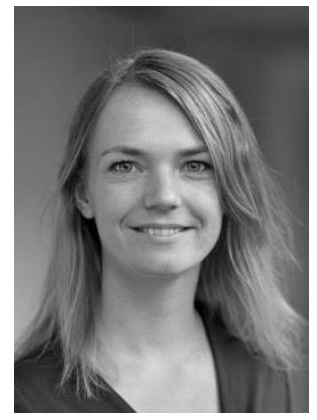

In May 2017, Nienke will start working as a policy advisor at the nursing home care organization 'Zorggroep Apeldoorn en omstreken.' 



\section{LIST OF PUBLICATIONS}

\section{Articles}

Kuk NO, Bours GJJW, Hamers JPH, Kempen GIJM, Zijlstra GAR. Feasibility of the Translating Innovations into Practice-toolbox (TIP-toolbox): A mixed-methods study for implementing activity innovations in nursing homes. Geriatric Nursing. 2017; [Epub ahead of print]. doi: 10.1016/j.gerinurse.2017.03.011

Kuk NO, Zijlstra GAR, Hamers JPH, Kempen GIJM, Bours GJJW. Implementation activities for nursing home staff: Results of a World Café method. Submitted for publication.

Kuk NO, Zijlstra GAR, Bours GJJW, Hamers JPH, Tan FES, Kempen GIJM. Promoting functional activity among nursing home residents: A cross-sectional study on barriers experienced by nursing staff. J Aging Health. 2017; [Epub ahead of print]. doi: 10.1177/0898264316687407

den Ouden M, Kuk NO, Zwakhalen SMG, Bleijlevens MHC, Meijers JMM, Hamers JPH The role of nursing staff in the activities of daily living of nursing home residents. Geriatric Nursing. 2016; [Epub ahead of print]. doi: 10.1016/j.gerinurse.2016.11.002.

Kuk NO, den Ouden M, Zijlstra GAR, Hamers JPH, Kempen GIJM, Bours GJJW. Do nursing staff encourage functional activity among nursing home residents? A cross-sectional study of nursing staff perceived behaviors and associated factors. BMC Geriatrics. 2017;17:18. doi: 10.1186/s12877-017-0412-9

Kuk NO, Zijlstra GAR, Bours GJJW, Hamers JPH, Kempen GIJM. Development and usability of the MAINtAIN, an inventory assessing nursing staff behavior to optimize and maintain functional activity among nursing home residents: a mixed-methods approach. BMC Health Serv Res. 2016;16:38. doi: 10.1186/s12913-016-1288-7

\section{Conference abstracts}

Kuk NO, Bours GJJW, Zijlstra GAR, Hamers JPH, Kempen GIJM. Translating implementation strategies into practice to enable nursing staff to implement innovations. $5^{\text {th }}$ European Nursing Congress, 4-7 October 2016, Rotterdam, the Netherlands. J Adv Nurs, 2016; 72 (Suppl 1): 87. 
Kuk NO, Bours GJJW, Zijlstra GAR, Kempen GIJM, Hamers JPH. Nurses' behaviors and perceived barriers to optimize function among nursing home residents: a crosssectional study. International Nursing Home Research Conference, 2-3 December 2015, Toulouse, France. Jour Nursing Home Res, 2015; 1: 11.

Kuk NO, Zijlstra GAR, Bours GJJW, Hamers JPH, Kempen GIJM. Developing an inventory assessing nurses' behavior to maintain function among nursing home residents (poster). 68th Annual scientific meeting of the Gerontological Society of America, 18-22 November 2015, Orlando, FL, USA. Gerontologist, 2015; 55(Suppl 2): 702.

Kuk NO, Bours GJJW, Zijlstra GAR, Hamers JPH, Kempen GIJM. Nurses' behaviors and perceived barriers to optimize function among nursing home residents. 68th Annual scientific meeting of the Gerontological Society of America, 18-22 November 2015, Orlando, FL, USA. Gerontologist, 2015; 55(Suppl 2): 142.

Kuk NO, Bours GJJW, Zijlstra GAR, Hamers JPH, Kempen GIJM. Gedrag en waargenomen barrières van verzorgenden en verpleegkundigen om het functioneren van verpleeghuisbewoners te stimuleren. 13e Nationaal Gerontologiecongres, 2 oktober 2015, Ede, the Netherlands. Tijdschrift voor Gerontologie en Geriatrie, 2015; 46(4): 2256.

Kuk NO, Zijlstra GAR, Bours GJJW, Hamers JPH, Kempen GIJM. Barriers to delivering evidence based care related to functional status of nursing home residents. 67th Annual scientific meeting of the Gerontological Society of America, 5-9 November 2014, Washington, DC. Gerontologist, 2014; 54(Suppl 2): 28.

Kuk NO, Zijlstra GAR, Bours GJJW, Hamers JPH, Kempen GIJM. Towards improved activities of daily living in nursing home residents: identifying barriers to delivering evidence based care by nurses and nurses' aides (abstract). 12e Nationaal Congres Nederlandse Vereniging voor Gerontologie "Kennisnetwerk ouder worden en samenleving", 19 september 2014, Rotterdam, the Netherlands. Tijdschrift voor Gerontologie en Geriatrie, 2014; 45(4): 252-3.

Kuk NO, Zijlstra GAR, Bours GJJW, Hamers JPH, Kempen GIJM. Nurses' perceived barriers towards evidence-based care related to stimulating functional status of nursing home residents. 14th European Doctoral Conference in Nursing Science 'Nursing science: one goal, different features', 12-13 September 2014, Maastricht, the Netherlands. Abstract book, 2014;82-83. 


\section{LIVING LAB IN AGEING AND LONG-TERM CARE}

\section{Living Lab in Ageing and Long-Term Care}

This thesis is part of the Living Lab in Ageing and Long-Term Care, a formal and structural multidisciplinary network consisting of Maastricht University, seven long-term care organizations (Cicero Zorggroep, Envida, Mosae Zorggroep, MeanderGroep ZuidLimburg, Sevagram, Vivantes and Zuyderland) and Zuyd University of Applied Sciences, all located in the southern part of the Netherlands. In the Living Lab we aim to improve the quality of care and quality of life for older people via a structural multidisciplinary collaboration between research, policy, education and practice. Practitioners (such as nurses, physicians, psychologists, physio- and occupational therapists), work together with managers, researchers, students, teachers and older people themselves to develop and test innovations in long-term care.

\section{Academische Werkplaats Ouderenzorg Zuid-Limburg}

Dit proefschrift is onderdeel van de Academische Werkplaats Ouderenzorg ZuidLimburg, een structureel, multidisciplinair samenwerkingsverband tussen de Universiteit Maastricht, zeven zorgorganisaties (Cicero Zorggroep, Envida, Mosae Zorggroep, MeanderGroep Zuid-Limburg, Sevagram, Vivantes en Zuyderland) en Zuyd Hogeschool. In de werkplaats draait het om het verbeteren van de kwaliteit van leven en zorg voor ouderen. Zorgverleners (zoals verpleegkundigen, verzorgenden, artsen, psychologen, fysio- en ergotherapeuten), beleidsmakers, onderzoekers, studenten en ouderen zelf wisselen kennis en ervaring uit. Daarnaast toetsen en evalueren we vernieuwingen in de dagelijkse zorg. Praktijk, beleid, onderzoek en onderwijs gaan hierbij hand in hand.

\section{PhD-theses Living Lab in Ageing and Long-Term Care / Proefschriften Academische Werkplaats Ouderenzorg Zuid-Limburg}

Nienke Kuk. Moving forward in nursing home practice. Supporting nursing staff in implementing innovations. 2017

Irma Everink. Geriatric rehabilitation. Development, implementation and evaluation of an integrated care pathway for older patients with complex health problems. 2017 
Ramona Backhaus. Thinking beyond numbers. Nursing staff and quality of care in nursing homes. 2017

Martin Van Leen. Prevention of pressure ulcers in nursing homes, a big challenge. 2017

Mariëlle Daamen-Van der Velden. Heart failure in nursing home residents. Prevalence, diagniosis and treatment. 2016

Armand Rondas. Prevalence and assessment of (infected) chronic wounds. 2016

Hanneke Beerens. Adding life to years. Quality of life of people with dementia receiving long-term care. 2016 (Cum Laude)

Donja Mijnarends. Sarcopenia: a rising geriatric giant. Health and economic outcomes of community-dwelling older adults with sarcopenia. 2016

Tanja Dorresteijn. A home-based program to manage concerns about falls. Feasibility, effects and costs of a cognitive behavioral approach in community-dwelling, frail older people. 2016

Basema Afram. From home towards the nursing home in dementia. Informal caregivers' perspectives on why admission happens and what they need. 2015

Noemi Van Nie-Visser. Malnutrition in nursing home residents in the Netherlands, Germany and Austria. Exploring and comparing influencing factors. 2014

Esther Meesterberends. Pressure ulcer care in the Netherlands versus Germany 01. What makes the difference? 2013

Math Gulpers. EXBELT: expelling belt restraints from psychogeriatric nursing homes. 2013

Hilde Verbeek. Redesigning dementia care. An evaluation of small-scale homelike care environments. 2011

Judith Meijers. Awareness of malnutrition in health care, the Dutch perspective. 2009

Ans Bouman. A home visiting program for older people with poor health. 2009.

Monique Du Moulin. Urinary incontinence in primary care, diagnosis and interventions. 2008

Anna Huizing. Towards restraint free care for psychogeriatric nursing home residents. 2008

Pascalle Van Bilsen. Care for the elderly, an exploration of perceived needs, demands and service use. 2008

Rixt Zijlstra. Managing concerns about falls. Fear of falling and avoidance of activity in older people. 2007

Sandra Zwakhalen. Pain assessment in nursing home residents with dementia. 2007 


\section{APPENDIX: TRANSLATING INNOVATIONS INTO PRACTICE (TIP)-TOOLBOX}

Om $u$ een beeld te geven van hoe de TIP-toolbox eruit ziet, treft $u$ op de volgende pagina's een deel van de TIP-toolbox. Weergegeven zijn de inleiding tot en met de zes toolbox-stappen. De volledige toolbox met alle tools is (in kleur) te downloaden via: www.academischewerkplaatsouderenzorg.nl/tiptoolbox. 


\section{Inleiding: waarom deze toolbox?}

De zorg staat nooit stil. Telkens worden vernieuwingen doorgevoerd om de zorg verder te verbeteren, de kwaliteit te verhogen en de zorg meer kosteneffectief te maken. Het doorvoeren, implementeren, van vernieuwingen gaat niet altijd vlekkeloos. Om ondersteuning te bieden bij het implementeren van innovaties is de 'Translating inovations into Practice' (TIP)-toolbox ontwikkeld. Deze toolbox biedt 'tips' bij het implementeren van innovaties. De TIP-toolbox is bedoeld voor iedereen die de zorg op een duurzame wijze wil aanpassen, dat wil zeggen: duurzaam wil innoveren. Voor mensen die ervaring hebben met het implementeren van zorginnovaties kan de TIP-toolbox als naslagwerk dienen, het biedt een leidraad tijdens het implementatieproces. De TIP-toolbox biedt ondersteuning bij het implementeren van zorginnovaties in het algemeen, maar is hier toegespitst op bewegen en zelfredzaamheid in verpleeghuizen.

Waarom bewegen en zelfredzaamheid? Bewegen en zelfredzaamheid zijn belangrijke onderwerpen in de langdurige ouderenzorg. Uit onderzoek blijkt dat veel verpleeghuisbewoners inactief zijn en het grootste gedeelte van de dag liggend en zittend doorbrengen. ${ }^{1}$ Dit geldt ook voor bewoners die nog mobiel zijn. De laatste jaren is hier steeds meer aandacht voor. Verschillende organisaties, zoals de Inspectie voor de Gezondheidszorg, onderschrijven het belang van het stimuleren van bewegen. Het is belangrijk dat ouderen hun dagelijkse activiteiten zo zelfstandig mogelijk uitvoeren. Verzorgenden en verpleegkundigen kunnen hen hierbij helpen. De TIP-toolbox ondersteunt verpleeghuizen bij het invoeren van een innovatie, een aanpak, die bewegen stimuleert. Wilt u meer lezen over het belang van bewegen of over de onderzoeken waarop deze toolbox is gebaseerd? Kijk dan bij de referentielijst.

Het is belangrijk dat het implementeren van een (beweeg)innovatie op een systematische manier gebeurt. $^{2}$ Daarom beschrijft de TIP-toolbox stap voor stap hoe het implementeren van een innovatie kan worden aangepakt.

\section{Voor wie is de toolbox bedoeld?}

De TIP-toolbox is met name gericht op verpleegkundigen, maar ook andere professionals die de zorg willen veranderen kunnen er gebruik van maken. Als u met de TIP-toolbox aan de slag gaat is het belangrijk dat $u$ goed kunt samenwerken, leiderschap vertoont, informatie uit teksten kunt lezen en verwerken en beschikt over basale computervaardigheden.

\section{Voordat u begint: randvoorwaarden}

Voordat een implementatieproces kan beginnen, moet er aan enkele randvoorwaarden worden voldaan. Als verpleegkundige, als kartrekker, kunt u niet in uw eentje de zorg veranderen. Zorg er daarom voor dat aan de volgende randvoorwaarden wordt voldaan:

1. Goede samenwerking. Vorm een team van mensen met wie u kunt overleggen. Bij het invoeren van een beweeginnovatie kan dit gaan om bijvoorbeeld een fysiotherapeut of ergotherapeut. Maar ook overleggen met mensen van de afdeling, een teamleider of een beleidsmedewerker is belangrijk. Door uw collega's van de afdeling gedurende het traject te betrekken, vergroot u de kans dat ze open staan voor verandering.

2. Overleg regelmatig met andere kartrekkers. Werk ook samen met andere kartrekkers die bezig zijn met het implementeren van een (beweeg)innovatie op hun afdeling. Plan overleggen met 
hen, bijvoorbeeld voor het uitvoeren van elke stap. Als u ergens tegenaan loopt kunt $u$ dit met hen bespreken, mogelijk komt u samen wel tot een oplossing.

3. Het management van de zorgorganisatie moet achter de innovatie staan. Het management moet de implementatie van de innovatie ondersteunen en dit uitdragen. Zij moeten de middelen beschikbaar stellen die nodig zijn. Het is belangrijk dat u voor de start van het project de steun van het management verkrijgt. Overleg daarom voordat $u$ begint met uw manager of teamleider.

\section{Systematisch implementeren: hoe pakt u dat aan?}

Om een implementatieproces op een systematische manier uit te voeren, moeten een aantal stappen worden doorlopen (Grol, Wensing et al. 2013). Dit hoofdstuk beschrijft deze zes stappen. Op basis van de stappen makkt $u$ een passend plan voor de implementatie van een innovatie binnen uw organisatie. $U$ begint telkens met het lezen van de stap. In de stap staat beschreven welke hulpmiddelen uit de toolbox u bij die stap kunt gebruiken en waar die te vinden zijn (bijlage $A 1, A 2, B, C$ of D). Na elke stap vult $u$ een deel van het implementatieplan in (bijlage A1). De toolbox bevat ook een uitgewerkt voorbeeld van een implementatieplan, dat laat zien hoe $u$ te werk kunt gaan (bijlage A2), bekijk dit goed wanneer u de stappen doorloopt. In deze toolbox is ook een voorbeeld opgenomen van een beweeginnovatie die kan worden ingevoerd, deze is erop gericht om bewoners meer te laten bewegen tijdens dagelijkse activiteiten (bijlage B). Dit is een voorbeeld, u kunt deze toolbox ook gebruiken om andere innovaties door te voeren.

Gemiddeld kost het maken van het totale implementatieplan ongeveer 5 uur, dit verschilt per afdeling en per persoon en is verspreid over een langere periode. Houd er wel rekening mee dat het inplannen van overleggen met collega's of het laten invullen van vragenlijsten (in Stap 2) extra (wacht)tijd kost die hierin niet is meegenomen.

\section{Stap 1: Ontwikkel een voorstel voor verandering}

Hier bepaalt $u$ wat $u$ precies wilt veranderen, wat het algehele doel is van het implementatieproces. Dit doel heeft te maken met bewegen en gaat over uw hele afdeling. $U$ zorgt ervoor dat dit doel zo SMART mogelijk is: Specifiek, Meetbaar, Acceptabel, Realistisch en Tijdgebonden.
Tools die u nodig heeft bij deze stap:

- Stap 1 invulformulier

implementatieplan (A1)

- Evt. voorbeeld

implementatieplan (A2)

- Evt. voorbeeldinnovatie (B)

- $\quad$ Specifiek: U benoemt wat er moet veranderen.

- Meetbaar: $U$ benoemt hoeveel er moet veranderen en maakt zo uw doel meetbaar.

- Acceptabel: $U$ kiest een doel waarvoor voldoende draagvlak is.

- Realistisch: $U$ kiest een doel dat realistisch is.

- $\quad$ Tijdgebonden: $U$ stelt een termijn wanneer dit doel behaald moet zijn.

Bespreek dit doel met uw collega's; vertel waar u mee bezig bent.

Vul in bijlage A1 (Stap 1) het voorstel voor verandering in en bepaal het doel van het implementatieproces.

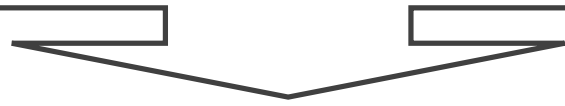




\section{Stap 2: Breng de huidige zorg en belemmeringen in kaart \& stel doelen voor verandering op}

- In kaart brengen huidige zorg \& belemmeringen:

Als $u$ de zorg op een duurzame manier wilt veranderen is het belangrijk dat $u$ in kaart brengt hoe het er op dit moment aan toe gaat. Ook is het belangrijk om te weten wat mogelijke belemmeringen zijn voor verandering. Dit kunt $u$ in kaart brengen door te observeren, met mensen te praten, of door gebruik te maken van een vragenlijst. Wanneer het gaat om het stimuleren van bewegen - zoals in deze toolbox - kunt u de MAINtAIN-behaviors en MAINtAIN-barriers afnemen (bijlage C). Laat alle verzorgenden en verpleegkundigen van afdelingen die de beweeginnovatie willen invoeren de MAINtAIN-behaviors en MAINtAIN-barriers invullen. Leg uit waarom $u$ de vragenlijst wil afnemen. Neemt $u$ de vragenlijsten anoniem af, dan vergroot dit de kans op eerlijke antwoorden.

MAINtAIN-behaviors: Met de MAINtAIN-behaviors meet $u$ het gedrag van de verzorgenden en verpleegkundigen; $u$ brengt in kaart of zij volgens henzelf ADL en $\mathrm{HDL}$ activiteiten stimuleren. Op basis hiervan kunt u kijken waar winst te behalen valt.

MAINtAIN-barriers: Met MAINtAIN-barriers meet $u$ welke belemmerende en bevorderende factoren verzorgenden en verpleegkundigen ervaren bij het stimuleren van bewegen. De factoren die gemeten worden zijn onderverdeeld in 4 niveaus: 'de bewoners', 'de verzorgenden en verpleegkundigen', 'de sociale context: het team' en 'de organisatie: het management'. Het belemmeringendiagram twee pagina's verderop geeft een overzicht van de mogelijke factoren, per niveau. Bij het doorvoeren van veranderingen moeten de belangrijkste belemmeringen worden weggenomen. Bevorderende factoren die weinig aanwezig zijn kunnen worden versterkt. 
- Invoeren \& analyseren: nadat de vragenlijsten

zijn ingevuld door de verzorgenden en verpleegkundigen, moeten ze op de PC worden ingevoerd en geanalyseerd. $U$ gebruikt hiervoor de digitale analysetool (met instructie) die bij de toolbox hoort (te downloaden via www.academischewerkplaatsouderenzorg.nl/tiptoolbox, zie ook bijlage D van de TIP-toolbox).

- $\quad$ Resultaten: Wat is het resultaat van de vragenlijsten, wat geeft de tool weer? Kijk om u heen, komt het gerapporteerde gedrag overeen met de werkelijkheid? Lijken de resultaten te kloppen of overschatten verzorgenden en verpleegkundigen hoeveel ze cliënten stimuleren om te bewegen? Bespreek de resultaten met de verpleegkundigen en verzorgenden op de afdeling. Bekijk de resultaten van de MAINtAIN-barriers en geef in het implementatieplan (bijlage A1, Stap 2) voor elk niveau ('de bewoners', 'de verzorgenden en verpleegkundigen', 'de sociale context: het team' en 'de organisatie: het management') aan wat de belangrijkste belemmerende en bevorderende factoren zijn. Welke belemmeringen wilt u verminderen? Welke bevorderende factoren wilt $u$ versterken?

- Doelen stellen:

- $\quad$ Stel vast welk specifieke gedrag verzorgenden en verpleegkundigen meer kunnen vertonen om bewoners te stimuleren te bewegen. Stel op basis daarvan specifieke doelen op. Zorg er weer voor dat ze SMART (zie Stap 1) zijn!

- Bekijk voor elk niveau (bewoner, professional, team en organisatie) wat veel voorkomende belemmeringen zijn of te weinig voorkomende bevorderende factoren. Hiermee moet rekening worden gehouden in de rest van het proces.

Bespreek de doelen en belemmeringen met uw collega's, kijk of zij het met u eens zijn.

Vul in het implementatieplan (bijlage A1, Stap 2) in a) welk gedrag meer gestimuleerd kan worden, b) welke doelen op basis hiervan gesteld worden en c) welke belemmeringen er op elk niveau worden aangepakt. 


\section{Belemmeringendiagram:}

\section{Belemmeringen die kunnen worden ervaren door verzorgenden en verpleegkundigen bij}

het stimuleren van bewegen

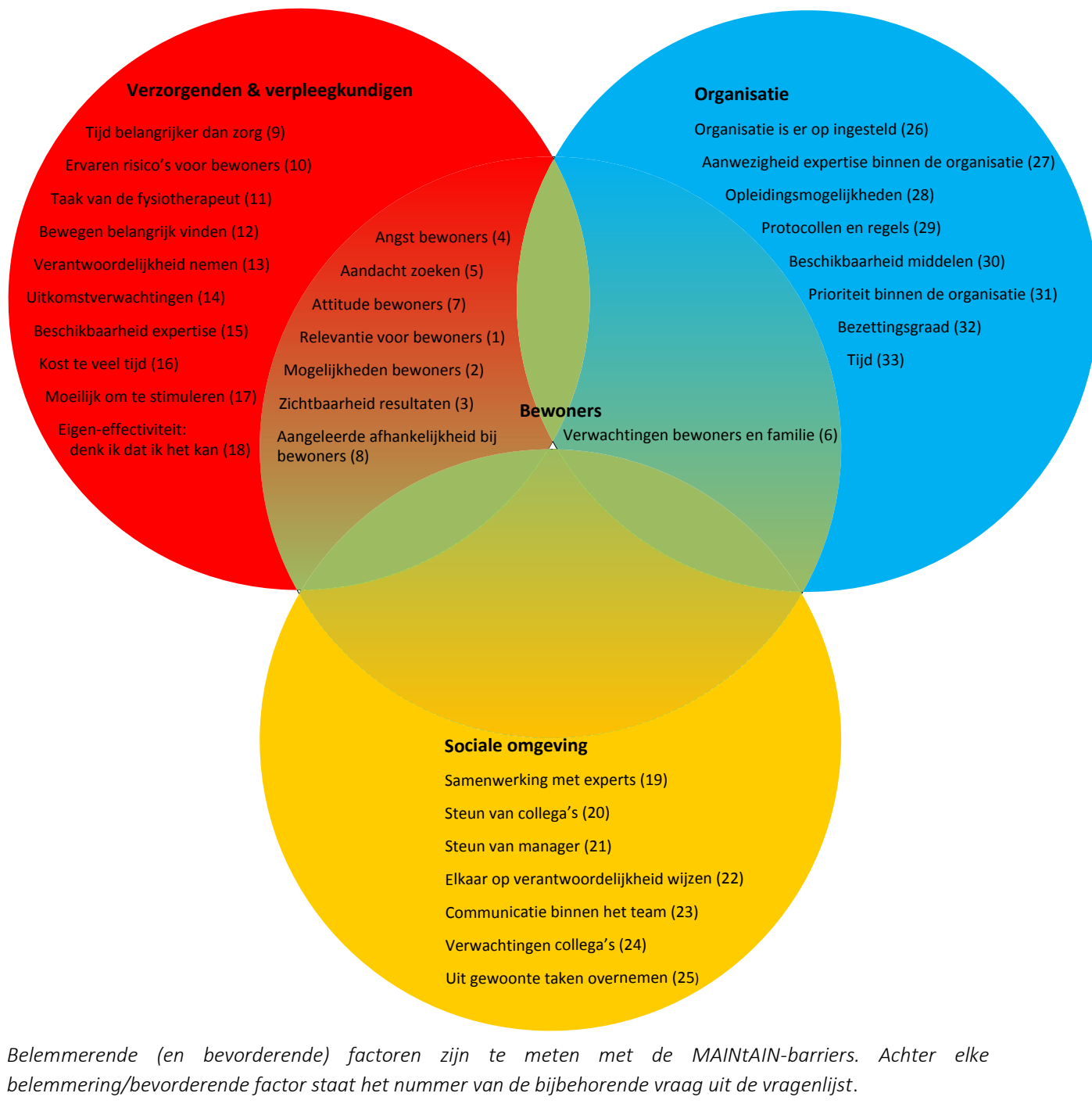




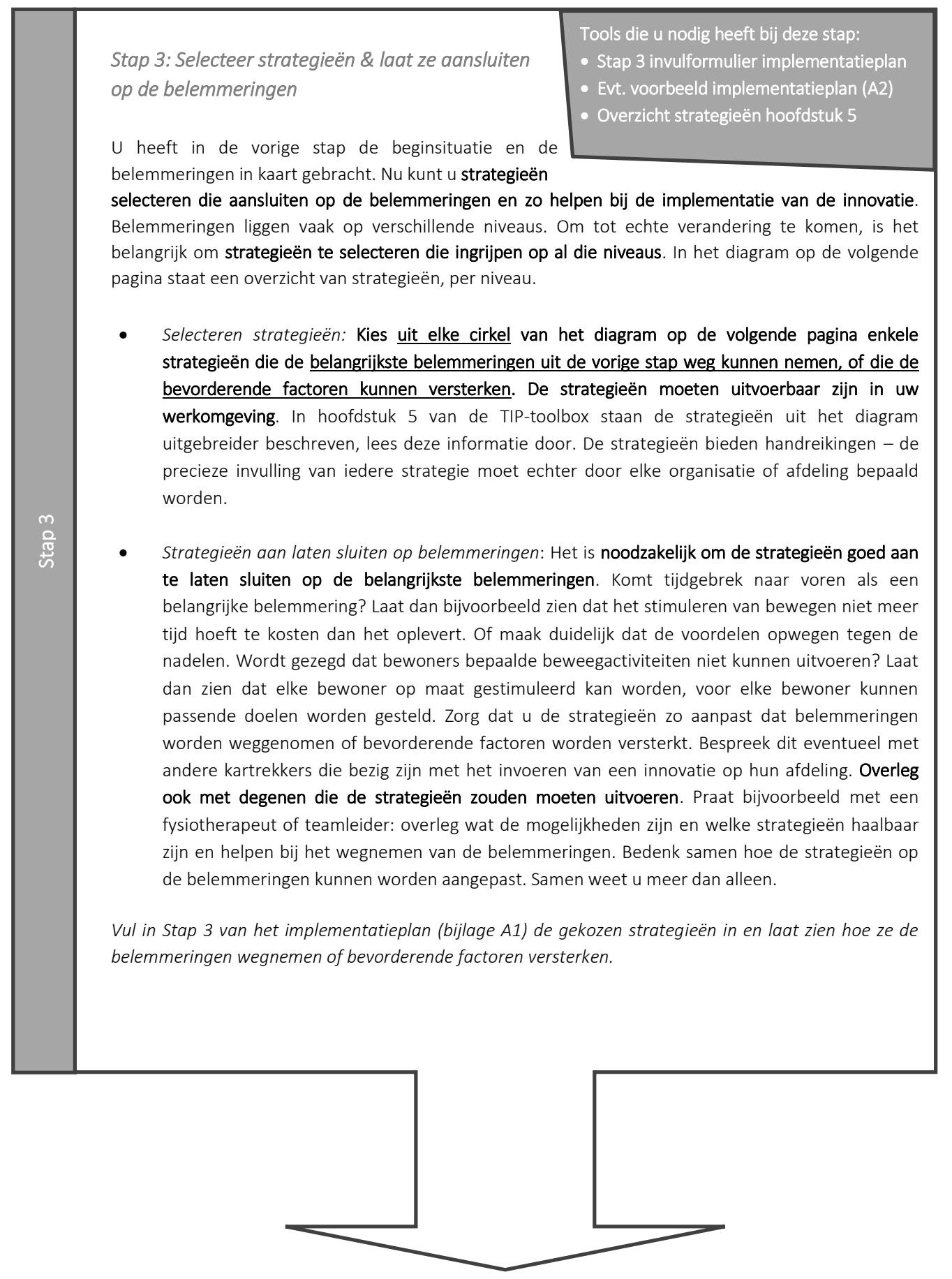




\section{Strategieëndiagram: \\ Strategieën die kunnen worden geselecteerd om een beweeginnovatie te implementeren en belemmeringen weg te nemen}

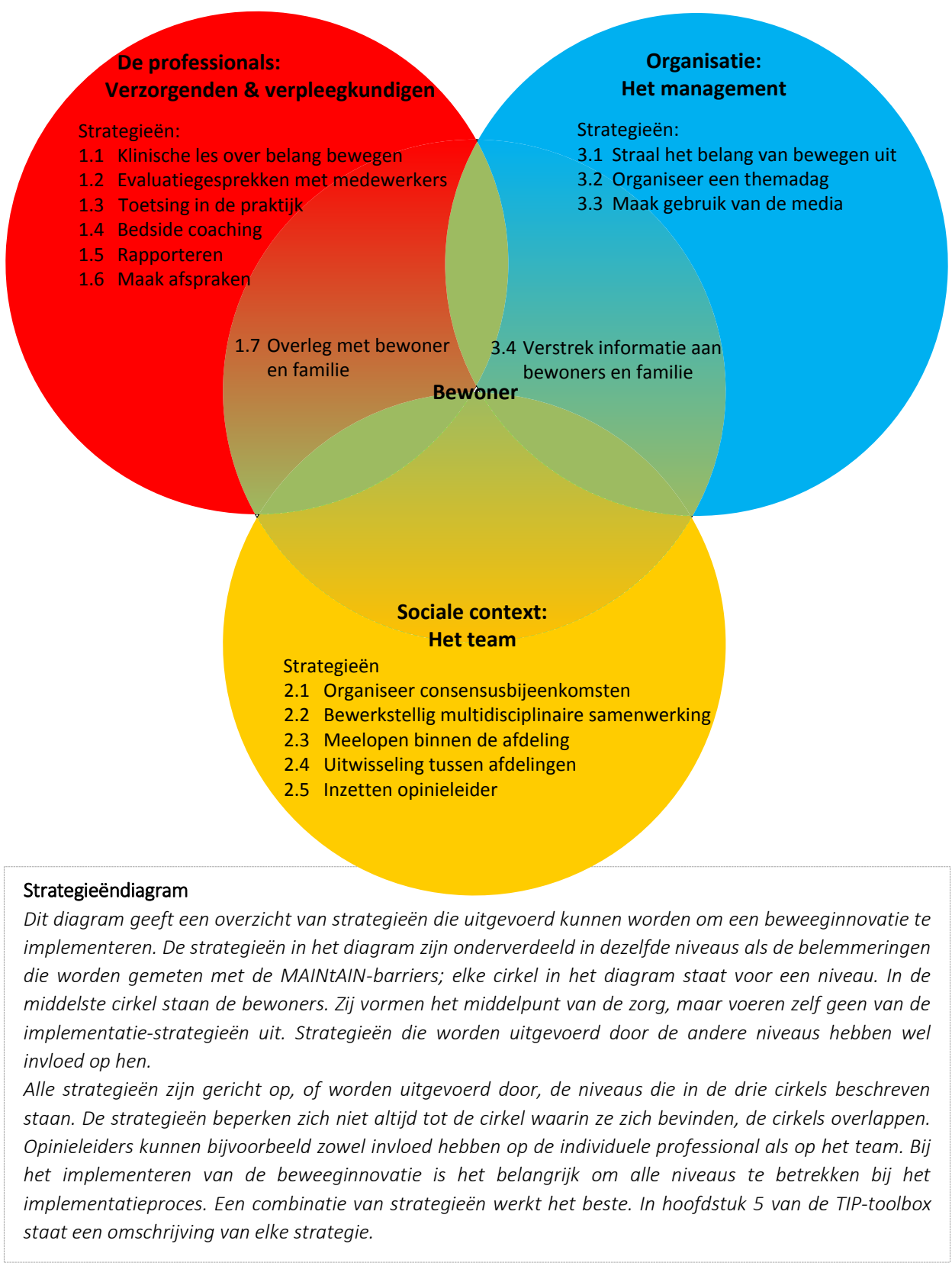



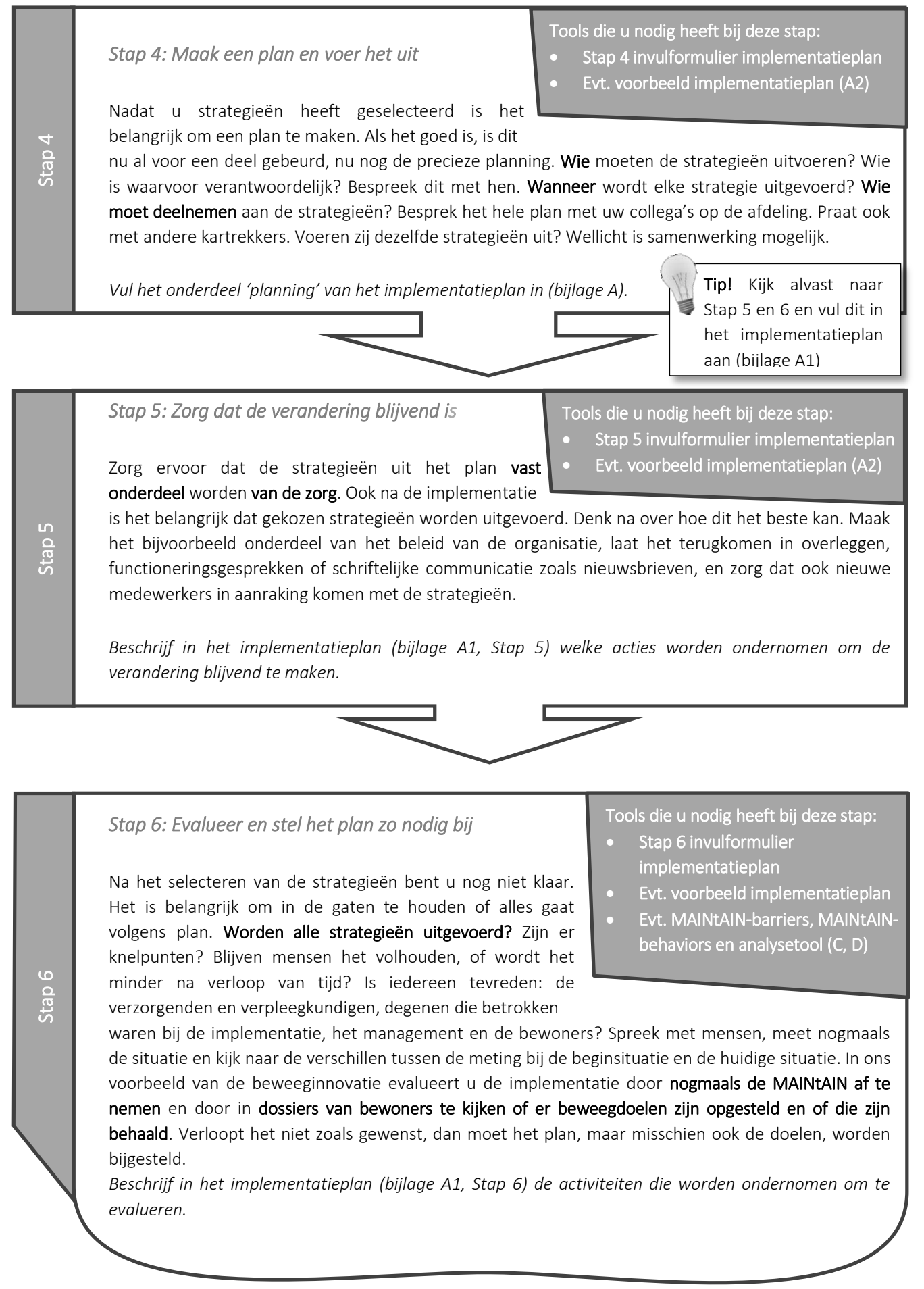
